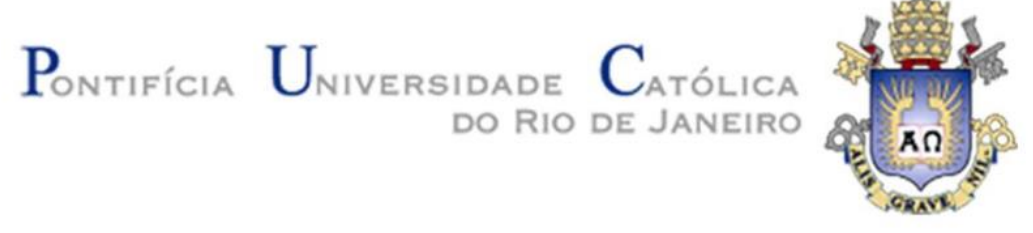

Rafael Moscardi Pedroso

\title{
Marx in the Anthropocene: Metabolism, Machinery and
} Alienation

\section{Master's Thesis}

Thesis presented as partial prerequisite for the attainment of the title of Master's in International Relations through the Graduate Program in International Relations of the Instituto de Relações Internacionais of PUC-Rio.

Advisor: Prof. Paula Orrico Sandrin

Co-Advisor: James Matthew Davies

Rio de Janeiro, 


\section{Rafael Moscardi Pedroso}

\section{Marx in the Anthropocene: Metabolism, Machinery and Alienation}

Thesis presented as partial prerequisite for the attainment of the title of Master in International Relations through the Graduate Program in International Relations of the Instituto de Relações Internacionais of PUC-Rio.

Approved by the following Evaluating Committee:

Prof. Paula Orrico Sandrin

Advisor Instituto de Relações Internacionais - PUC-Rio

Prof. James Matthew Davies

Co-Advisor Instituto de Relações Internacionais - PUC-Rio

Prof. Paulo Chamon

Instituto de Relaçooes Internacionais - PUC-Rio

Prof. Gabriel Tupinambá

Universidade Federal do Rio de Janeiro - UFRJ 
All rights reserved.

\section{Rafael Moscardi Pedroso}

B.A. in International Relations at Federal University of Uberlândia

(UFU-MG)

Pedroso, Rafael Moscardi

Marx in the anthropocene : metabolism, machinery and alienation / Rafael Moscardi Pedroso ; advisor: Paula Orrico Sandrin ; co-advisor: James Matthew Davies. - 2021.

180 f. ; $30 \mathrm{~cm}$

Dissertação (mestrado)-Pontifícia Universidade Católica do Rio de Janeiro, Instituto de Relações Internacionais, 2021. Inclui bibliografia

1. Relações Internacionais - Teses. 2. Metabolism. 3. Anthropocene. 4. Labor. 5. Marx. 6. Inhuman. I. Sandrin, Paula Orrico. II. Davies, James Matthew. III. Pontifícia Universidade Católica do Rio de Janeiro. Instituto de Relações Internacionais. IV. Título. 


\section{Acknowledgements}

It is particularly easy for the labor of producing a thesis to be misrepresented as an individual endeavor, conjured through the image of a single person, reading and typing a thesis in a room. While often my work looked a lot like that, such an impression could not be more misleading. It was only through countless connections, conversations, comradery and genuine generosity that it could happen. Writing and finishing it was less about claiming property on a chunk of written intellect and more like being a catalyst of whatever I encountered during the process.

I thank my parents, Agenor and Márcia, for their sustained support and trust. My girlfriend, Midori, for her kindness and support which always pushed me to make the best out of my own efforts while also not letting me burn out. I am also grateful to the entire departmental structure at IRI/PUC-Rio for making me feel at home.

To my advisors Paula Sandrin and Matt Davies for both giving me the needed space for thinking things but also encouraging me to focus and put an end to them. I am particularly grateful to Paula for having welcomed me into IRI from the outset, reviewing and discussing countless papers, seminars, classes and having conversations that always challenged me to organize my own, often scattered, ideas.

A crucial role was also played by parallel academia spaces: The New Centre for Research and Practice, the Associação de Pesquisas e Práticas em Humanidades (APPH), in particular the study group in History and Philosophy of technology, GTEC in which many fruitful discussions were carried.

To all my friends who endured at least one, often uncalled for, long monologue about the Anthropocene, Marx, value, machines, production, the posthuman, the inhuman and related matters. For giving some of their time for constructive criticism and reviewing pieces of this thesis, I should single out and thank Zenóbio Almeida, Luiz Valle Júnior and Gabriel Caetano.

I thank also the Rio de Janeiro Research Support Foundation (FAPERJ) for the scholarship which allowed me to fully focus on my research. 


\section{Abstract}

PEDROSO, Rafael Moscardi; SANDRIN, Paula (Advisor) Marx in the Anthropocene: Metabolism, Machinery and Alienation. Rio de Janeiro 2021. 180 p. Dissertação de Mestrado - Instituto de Relações Internacionais, Pontifícia Universidade Católica do Rio de Janeiro.

The Anthropocene, which entails the recognition of the impact of human activity on the planet, has been a crucial point of transdisciplinary debate. This thesis intervenes in the theorization about the Anthropocene in International Relations (IR) by arguing for the importance of including a criticism of production in those efforts. Casting production as a central historical determination for understanding our current predicament, and positioning labor and technology as crucial topics is an important theoretical e political move because it enables the establishment of a common ground between environmental and labor struggles. First, we clarify the connection between the Anthropocene and production, arguing how neglecting it blunts the critical edge of critical approaches within IR. This claim is made through a dialogue with the concept of metabolism as advanced in Marxist Ecology, emphasizing labor as metabolic activity, that is, a socially mediated form of relating to nature. Second, we foreground how those interactions with nature are not only always partial, but mediated by tools, machines and other apparatuses. We run against conceptions of technology that cast it as the expression of certain "ideas of matter", opting to see machinery as a conurbation of flows that condenses mutating social divisions of labor and whose materiality, since the Industrial Revolution, is particularly based on how they split and manage energy and information. Looking at that split allows a synthetic narration of the technological trajectory in which the Anthropocene emerges and casts it as a regime of information and energy. Last, we end by entertaining the hypothesis of communism as the collective management of alienation. Alienation appears not as estrangement from a creative potential we share with nature, but as the ambivalent capacity of the human and of nature to create things from which we lose control and may come to determine us, changing what both human and nature mean. While capitalism is a specific mode of alienation based on value production that generates specific determinations, communism appears as the collective experimental remaking of our social organization of production, an unfinishable task that while performed changes how the human and nature are determined by production.

\section{Keywords}

Metabolism; Anthropocene; Labor; Marx; Inhuman 


\section{Resumo}

PEDROSO, Rafael Moscardi; SANDRIN, Paula (orientadora) Marx no Antropoceno: Metabolismo, Maquinaria e Alienação. Rio de Janeiro 2021. 180 p. Dissertação de Mestrado - Instituto de Relações Internacionais, Pontifícia Universidade Católica do Rio de Janeiro.

O Antropoceno, enquanto o reconhecimento do impacto da atividade humana no planeta, tem sido um ponto crucial e transdisciplinar de debate. Esta dissertação intervém na teorização sobre o Antropoceno nas Relações Internacionais (RI), defendendo a importância de incluir uma crítica à produção nesses esforços. Entender a produção como uma determinação histórica central para compreender nossa situação atual e posicionar o trabalho e a tecnologia como tópicos cruciais é um movimento teórico e político importante porque constrói um terreno comum entre lutas ambientais e trabalhistas. Em primeiro lugar, esclarecemos a conexão entre o Antropoceno e a produção, argumentando como negligenciá-la prejudica o caráter crítico de certas abordagens em RI. Essa afirmação é feita por meio de um diálogo com o conceito de metabolismo desenvolvido na Ecologia Marxista, enfatizando o trabalho como atividade metabólica, ou seja, uma forma de relacionamento socialmente mediada com a natureza. Em segundo lugar, destacamos como essas interações com a natureza não são apenas sempre parciais, mas mediadas por ferramentas, máquinas e outros aparelhos. Opondo concepções de tecnologia como expressão de certas "ideias de matéria", optando por ver a maquinaria como uma conurbação de fluxos que condensa divisões sociais mutantes do trabalho e cuja materialidade, desde a Revolução Industrial, se baseia sobretudo em como eles dividem e gerenciam energia e informação. Olhar para essa divisão permite uma narração sintética da trajetória tecnológica em que o Antropoceno emerge e o projeta como um regime de informação e energia. Por último, analisamos a hipótese do comunismo como gestão coletiva da alienação. A alienação aparece não como alienação de um potencial criativo que compartilhamos com a natureza, mas como a capacidade ambivalente do ser humano e da natureza de criarem coisas das quais perdemos o controle e que podem vir a nos determinar, mudando o significado tanto do humano quanto da natureza. Enquanto o capitalismo é um modo específico de alienação baseado na produção de valor que gera determinações específicas, o comunismo aparece como a reconstrução experimental coletiva de nossa organização social de produção, uma tarefa inacabável que implica uma mudança na forma como o humano e a natureza são determinados pela produção.

\section{Palavras-Chave}

Metabolismo; Antropoceno; Trabalho; Marx; inumano 


\section{Table of contents}

Introduction $\quad 8$

Chapter 1 - Framing the Anthropocene through Value and Metabolism 13

$\begin{array}{ll}\text { Making the Anthropocene } & 13\end{array}$

The Anthropocene Encounters the Discipline of the Global 23

A detour: Value and Labour in Marx's critique of capitalism 30

Back to IR and the Anthropocene 36

Value between History and the Planetary 38

Capital, Abstraction and Nature: Metabolism against the Oikeios 46

Chapter 2 - Cyberfossil Capital: Machines, Energy and Information 59

The Eurocene: Technology and Nature between Forms-of-life 62

Machine as Relay: Division of Labor, General Intellect and the Collective Worker 72

Smoke, Steam and Energy: The birth of Fossil Capital 85

Information and Modulation in and beyond Cybernetic Factories 94

A relay in the information machine: Data and Metadata 103

Concluding notes or Recomposing the Hydra 110

Chapter 3 - Alienation, Inhuman Revisions and Tektology 113

Could Communism be the Collective Management of Alienation? 115

Alienation, The Human and Metabolism 123

Post-Humanity and Reification 139

Tektology and Metabolism for the Anthropocene 149

$\begin{array}{ll}\text { Concluding notes } & 160\end{array}$

$\begin{array}{ll}\text { Conclusion } & 163\end{array}$

$\begin{array}{ll}\text { Bibliography } & 170\end{array}$ 


\section{Introduction}

The recent rise of media products, narratives, policy documents, and general overspread anxiety regarding the end of the world is, in a way, an exercise both in coping with the certainty of imminent catastrophe and anticipating some of the grief that comes with it. The end of the world provides the perfect stage for allegories showing what humans are supposedly capable of, giving a particular image of what hope could be and attempting to set what is that particular factor that makes human existence supposedly worthy: human persistence, human solidarity, selflessness, love, the tenacity of family ties, the appearance of new life through reproduction that may remake the planet, the reader can complement this list as desired. Conversely, as ends of the world proliferate, futures breaking with the mere repetition of a crumbling past may appear rarefied. What Mark Fisher (2009) has called "capitalist realism” is, at once, a crisis in the articulation of global alternatives for Capitalism and a call towards making of those.

Crisis, opting for a somewhat vulgar definition, is an erosion of continuity qua certainty of repetition. It is a formulation of the perception that, for a variety of material and affective circumstances, we are more and more approaching the brink, dangerously close to catastrophe as a point of impossibility of repeating the same, by many possible reasons. "Catastrophe is the past coming apart, Anastrophe is the future coming together (...) crisis is a convergence misinterpreted by mankind". (Land \& Plant in Mackay and Avanessian, 2014 p. 305). While crisis introduces a disturbance in the possibility of endless repetition, it marks an invitation for anastrophe, the reordering of circumstances, the invention of a new arrangement emerging both from what is given and what we can make of it

Crisis is neither the redeeming hope that History will, by default, converge with justice, nor the reliance of that all of our present potentialities will deliver us a readymade deal of the future. Rather, crisis signalizes a need to align and understand tendencies at work both in the present and the future and the question of how we navigate thinking and acting upon them (Noys, 2010). A major tendency emerging from scientific discourse, the Anthropocene is the recognition of the planetary impact of human social organization, laying bare that the prevailing modes of human social existence on Earth have reached a point of impact that threaten both human and non-human existence. As a field of research, particularly how it is received in the humanities, it has come to be also an oblique response to such an emptying of the 
future. In its own way, it represents itself a sort of crisis for the humanities as the image of the human is faced with indifference by the planetary.

The force driving us towards the end of the world is composed of many vectors, two of particular interest: a vector of Capital and a vector of environmental crisis. Each find their own correlate catastrophes to be represented: conscious machines that, at first, leave us unemployed and then set out to kill us, nightmares of techno-control on one hand and the constant threat of natural disasters that often destroy the supposed normalcy of everyday life.

They also articulate very real anxieties. On one side, increasing growth in unemployment and underemployment often misrecognized as merely the consequence of automation and on the other the proliferation of environmental catastrophes that displace millions of people worldwide every year, particularly people that were already on the edges of our social economic and political system while also endangering multiple species and non-capitalist modes of social organization, directly or indirectly.

Of course, forgetting the relation between one and the other, that is, between production and its uses of nature is to forget that capitalism as a mode of production comprises specific socially mediated metabolic relations with the Earth. If in the humanities in general, the impact of the Anthropocene is already felt, IR is no exception to it. In fact, the reception of this problem and the challenges it carries generates a rather interesting and lively field of research.

It is in that field, through facing those two anxieties as problems overlapping right at the social organization of production that this thesis aspires to intervene. It attempts to assemble theoretical tools that might aid in formulating a critique of some recent approaches to the Anthropocene within International Relations from the perspective of production. This is performed through an assemblage that facilitates an encounter between those theories built within IR with some recently developed Marxist insights in the field of Marxist ecology read together with attempts to rethink the Marxist critique and understandings of technology. Through such a conjunction, not only I hope to generate insights for my own field of study, but also to perform a necessary conjunction between those two Marxist fields that have not yet been drawn together enough, one that might give us many crucial tools for understanding our present. 
Through this assemblage, I hope to both illuminate the political stakes of some of those theories and trace lines of dialog with them, a dialog around the need for understanding the centrality of production for critical scholarship in the Anthropocene within IR. Doing so might help in casting labor and environmental struggles as contestations of value as the mode of organizing production, not by attributing this as their hidden intentionality but by posing this as a politically important convergence in their demands as they challenge a whole mode of production of value.

It also helps opening a space for the critique of political economy in the Anthropocene's reception within the discipline, in this case, particularly through Marxist theory. Through that, it might propel some revision of the shared assumptions within the field, as well as offer a modest complement to some of their insights. Doing so is, of course, not an easy task, so I proceed to perform this centralization of production mostly through a critique of specific texts in each chapter in terms of their resonance within the field, the political commitments they sketch and how they might articulate common assumptions with broad consequences for how the Anthropocene is thought about.

Of course, a task as broad as suturing production as a central determination for how we think of the Anthropocene and how we speculate beyond it could be done in many different ways and is far from exhausted in this thesis. I have chosen three prevailing points that get a chapter each. Those condense problems and perspectives cutting across the reception of the Anthropocene in IR encountering insights within Marxist theory that might allow us to see them in a different light.

In particular, Marx is a thinker of the movement between the concrete and the abstract. By making abstraction into his method for understanding the historical implications of capitalism as a form of social organization of production, retrieving him is also a way of revising both the theoretical choices and what kind of politics can emerge from those theories about the Anthropocene. Seeing him neither a mere icon of long lost radicality nor a saintly figure, hopefully the path carved by this thesis is one that has at least a bit of loyalty to what is radical about Marx's work, that is, its capacity to be heretical. The center of this enduring capacity for heresy is, for me, how he provides the tools for refusing the separation between the two abovementioned vectors, that is, he provides the ground for an ecological critique of political economy. 
With that in mind, in Chapter 1, I perform a brief presentation of the conjuncture and impact of the Anthropocene into International Relations and point in particular to how it invites many forms of speculation and political implications. However, through the relationship between value as a historical mode of wealth production and labor and production as metabolic processes, I seek to emphasize how the little attention given to the way production and politics are intertwined gives way for quite problematic consequences. Through this encounter, I end up criticizing a particular way of posing the problem of the Anthropocene, that is, as a problem limited merely to political consciousness or to changing the ideas animating our mode of production. Doing so, I will argue, has both theoretical and practical consequences.

If in Chapter 1 the Anthropocene is presented through the concept of metabolism, In Chapter 2 we look at how technology, is, in a lot of ways, both made by and a crucial mediator in such metabolic processes of production. The recognition that the Anthropocene is intertwined with certain technological pathways is indeed a crucial point. However, a particular problematic slippage is to be found in some portrayals of this technological trajectory as a static one, in which changes appear as always already expressing a particular content that supposedly lies within western visions of technics and ideas regarding matter.

I seek to complicate this picture, showing how metabolism is mediated by machinery as the machine offers a diagram for the management of work/energy/information and also sketches crucial diagrams of power. Doing so has two main purposes: first, it recasts the relationship between the "new" digital economy and the "old" industrial economy properly through the material management of flows of energy and information and their consequences for labor; second, it propels a view of technology which accounts for the capture of technicity by capital without fully subsuming its potentials within it. Therefore, it maps into the contestation of a mode of production, hence another metabolism, the need for seizing and remaking what technology is, not only the ideas that animate it, but the flows it manages and the labor that makes it.

Lastly, one of the notorious qualities of the Anthropocene is how it destabilizes the figure of the human and casts any imaginary of emancipatory politics in a quite different light. For that reason, in the last chapter we look at the stakes of 
this destabilization of the human and its consequences for how we think about radical political alternatives and possibilities for emancipation.

In particular, we look at the concept of alienation and try to envision what a politics not for the overcoming but for the collective management of alienation could look like, mindful of how the term is inextricably related to production, both as alienation from nature and as alienation from the knowledge making technology and organizing labor. This reversal comes both through understanding alienation as a constitutive movement of human's embedment into history and also as a denial of any positive creative potential, be it inherent to the human or projected as inherent to all that is natural and therefore to be re-encountered. Having this in mind, we arrive to a final encounter between the inhuman and the post-human through this prism of alienation, siding with the first and formulating some of the stakes of doing so.

This trajectory of the Anthropocene that we follow (not without its detours) in some of its crises and multiple ends of the world is seen through a myriad of tools. One navigates such a space through carbon, silicon, wires, energy, information, infrastructures, labor, ecology, cybernetics, the global, planetary computation. Cyborgs, humans, inhumans, posthumans, machines, animals and other creatures populate it. In such an overwhelming space, a guiding point might be welcome. In this thesis it is, quite simply, that there is no way of addressing the Anthropocene without lifting the abode under which such a complex and messy predicament is produced in the first place. 


\section{Chapter 1 - Framing the Anthropocene through Value and Metabolism}

This chapter introduces many of the questions contained within the dissertation preliminarily but has as its main goal to schematically lay out the discussions around the Anthropocene, in particular their reception within International Relations. While doing so, it connects them to questions of labor, production and the crucial status of the Critique of Political Economy as a field of engagement for navigating the Anthropocene.

I divide such a task in three blocks: first, I introduce the question of the Anthropocene glossing over its material construction and the challenges it invites, arriving at its mobilization within International Relations (IR) Theory. Then, I move to assess the stakes of the entry of those questions within IR, trying to dislocate them from the field of the "ethico-political" or their framing as a problem that lies "deeper" within consciousness, highlighting the imbrication between consciousness and the way production is organized as crucial for understanding our predicament. After that, I give an account of value as the organizational form within capitalism, engaging with and against Jason Moore's (2015) "Capitalism in the Web of Life" arguing for production to be seen as a metabolism and signaling at the stakes of doing so.

\section{Making the Anthropocene}

The Anthropocene emerged in scientific research and discourse as a name for our current geological era. It speaks of the process through which human activity exponentially becomes a force of influence in planetary scale. This force, in particular, threatens the possibility of our own existence and has already deeply affected and ravaged the possibilities for many non-human beings to exist. Of course, to talk of the Anthropocene is to revise the very arrangement of those sets of human activities as such.

While the diagnosis is clear, its "origins" are quite contested: An enormous slow-paced historical process beginning 5,000 years ago in the Holocene? In the long XVI century in relating massive deforestation of Europe and the colonial exploitation of cheap nature and labor through global markets? Maybe the invention 
of the steam engine by James Watt in 1784? The great acceleration and Green Revolution after WWII? (Wark, 2004:2012: 2016a; Crutzen, 2006; Stubblefield, 2018; Foster \& Burkett, 2016; Moore 2015).

Those entangled temporal demarcations and the struggle between them show already the multiple contestations and possible historical narratives around this same seemingly simple definition. Apocalyptic fictions of an ever-heating world are paired with images of machines, cyborgs and other cultural markers of our predicament: what will be of the planet? What will be of the human and its social organizations when faced with accelerated planetary devastation and dizzying technical change?

Those entangled temporalities do converge at a particular juncture, that is, the social organization of production and its changes through time. Let us begin with an addition to our simple definition of what the Anthropocene is and see it as a series of planetary spread metabolic rifts. An often-forgotten point present Marx's work is that he viewed the process of production as one of metabolism with nature, an exchange of molecules that marked an imprint of human's social activity within the world. Marx was attentive, for example, to how the concentration around cities deprived the countryside of human manure used as fertilizer and its mismanagement spread all sorts of sanitary problems, and even how cotton production in England deprived soils of nitrogen that made a huge market out of fertilizers that would renew them (Foster, 2000; Marx, 2017).

What matters, at least to introduce this question, far beyond the examples, is that he connected those problems to changes happening within the social organization of labor and production. By drawing on some of the science of his time, he was puzzled by how the then-nascent capitalist mode of production was predicated in certain historically defined relationships and imbalances in nature. It is through this relationship between production and its imprint that will inform our perspective on this messy problematic of the Anthropocene. That is, to simply refuse to disconnect the Anthropocene as a predicament from the spread of a particular way of organizing production (Wark, 2016a).

This refusal is particularly interesting if one looks at the last 50 years in particular, a small piece of our trajectory that bring us to the brink of catastrophe. One can see generalized increases in consumption, considerably more so in the overdeveloped world, a rise in carbon emissions, exponential agricultural developments in the so called green-revolution allowing for monoculture geared towards producing 
cash-crops, advancements in deforestation, practices of exploitative mining supplying technological progress, rise in industries based on the management and collection of information, substantial changes in the labor market. Also, exponential increases in tourism, transport, paper-consumption, water usage, urban population, all which set the tone for our historical present (Crutzen, 2006; Crutzen apud Wark, 2016a p. 14; Harvey, 2006).

It is in such a scenario that the material constructs through which we apprehend the Anthropocene emerge, deeply entangled with those changes. Particularly, those last 50 years are marked by technological developments that change our perception of both what the world is and how we interface with it, changes that cut across production, consumption and governance; the social and the technical converge at the need for management at greater levels of complexity. Of particular relevance for building the knowledge regarding the Anthropocene are changes in information collection, processing and computational possibilities.

The Anthropocene is knowable today through Climate Science, whose emergency is particularly related to Earth System Science (ESS) as it inaugurates the possibility of an understanding of the Earth as an interacting system working through multiple forms of feedback. This type of knowledge is particularly fundamental for going beyond a study of the weather as a study of limited atmospheric phenomena happening in a short period of time, towards a study of climate as the reconstruction of a broader picture of those phenomena through statistical reasoning. Such an understanding of the climate have as a basis a planetary infrastructure based on heterogenous weather data collection allied to computational capacities that allow for such reconstruction (Srnicek, 2013).

Both the infrastructure and the knowledge animating it are, of course, embedded in a history that is far from innocent or impartial and that is materially built through the conjunction of many types of labor. This infrastructure is deeply intertwined with what we understand as globalization: colonial occupations and agreements, increasing fluxes of commerce, lines of information transmission, the internationalization of capitalist production, the increasing role of information management on production and governance, geopolitical violence and scientific cooperation. All of those made by an assemblage of human labor from the scientist to the soldier to the technician. 
A small hint of this is found in WWII, as ships served as movable weather data stations, airplanes provided weather data from atop, as soldiers cataloguing wind data and releasing weather balloons were also embedded in such a process of data gathering, rendered essential for managing artillery, generating stacks of data transcription treated as crucial assets by operations and sources of data for scientists all around the world (Wark, 2016; Srnicek, 2013).

In the Cold War those developments in data collection saw intensification through the invention of three crucial artifacts whose developments per se pushed a lot of other necessary apparatuses that had to deal with weather data and information management. Those were nuclear bomb, the satellite and the computer. Nuclear testing was crucial for developing models of atmosphere as the tracking of fallout from those was predicated on the development of three-dimensional models of the atmosphere. The satellites and their capability for recognition specially from 1969 with the Nimbus 3 were crucial assets as well. Their results were an instance of the Cold War in which despite the obvious political polarization, weather related sciences were also space of shared knowledge amongst world's leading researchers except for, unsurprisingly, data from very specific places such as military bases. Computation also developed coextensively with those efforts as better modelling could only be covered by means of better computational devices and their processing power (Wark, 2016a; Srnicek, 2013).

Those three apparatuses making assemblages of data collection $^{1}$ and transmission spreading through the world, allied to great computational processing power, rendered ESS possible. These changes enable, in general and for ESS in particular, a new kind of scientific paradigm, one predicated in computer simulation based on non-homogenous data generating multiple different "artificial" planetary atmospheres, each with different models of simplification and certain trade-offs in precision. The models are not compared to the data so the data could falsify it, rather, a model is compared to another model that often adjust the imprecisions present in the data input. In this sense, the data and the models constantly coproduce each other and allow for the production of models for climate both about the past and forecasting of future possibilities. As such, it spells a broader paradigm shift to how science in many areas mutates following those information processing capabilities (Srnicek, 2013; Wark, 2016a).

1 This is described in a much more detailed form in Nick Srnicek's PhD thesis (2013) "Complexity and World Politics". 
This story of networking the world through climate data and information transmission gives the technical and material context for Chakrabarty's (2018 p. 2) division between earth, the globe and the planet, setting the material grounds through which ESS scientists appears to us as "historians from the planetary". This writing of history is not only crucial as it goes far beyond human scales, but it marks the possibility of reconstructing trajectories to which the human did not yet belong to.

The planet appears as a new historical category comprehensible through its material reconstruction by sets of data modelling and simulation, turned possible by historical processes of technical development and through a certain trajectory of globalization as such. In this sense, the planetary is an ambivalent movement: it reveals a history to some extent indifferent to the human as it happens in a radically different scale and reveals both a past devoid of humans and a threat that the planet will for sure outlive us as we destroy our possibility of inhabiting it. At the same time, it reveals also an all too human history, not at all detached from the tensions inherent to the global and the metabolic impact of the overstretching of capitalism as a form of social organization that can be traced back to the overstated entangled genealogies and its overlapping's with colonization, imperialism and that loses its last opposing point (though one also with its own metabolic problems) in the fall of really existing socialism (Wark, 1994)

In fact, this computational infrastructure broadly spoken is related to some of the discussions on the Anthropocene as asking for certain forms of stewardship of our spaceship earth came as a promise to render tractable and solvable many of the social tensions of the $20^{\text {th }}$ century. The promise that technology might replace the political in toto or that it might deliver the dream of a networked society in which knowledge would flow freely facilitating further equality. Those dreams were not delivered, in fact they quickly turned into nightmares, not because technology is branded with an evil essence that ought to be refused but because those promises themselves concealed that, beneath the shiny veneer of technological potentialities, further forms of exploitation of humans and nature were being born (Wark, 1994; Chakrabarty, 2018).

This greater awareness of our role within and against nature through the very science that makes the Anthropocene knowable to us also renders any hope of a return to nature as self-regulating mother nothing but a fantasy. Places such as the 
Amazon, often pictured by public discourse as Edenic remainders of the past are already proven to be the offspring of native forms of organizing human labor and technics in ways that built a highly coherent ecosystem, but that are nevertheless "artificial". Nature is not discovered but constructed both as a concept and to some extent in its own materiality. It is embedded into our human history marked by what we make of it (Levis et. al 2018; Stevens, 1990; Haraway, 1991).

Contrary to cultural imaginaries of equilibrium, nature is increasingly proven not to tend towards any sort of homeostasis, being better defined as a dynamic, complex and non-linear system (Srnicek, 2013). The ecological tone of our times means that the border between the artificial and the natural is itself porous: machines are no longer places of solely mechanical causality in the strict sense as cybernetics, in the early $20^{\text {th }}$ century and also deeply implicated in the context of WWII, allow machines to reproduce some regulatory capacities of organisms (Hui, 2020).

Those historical dynamics mark radically different possibilities for what the human and nature mean. Different notions of what is natural and what is artificial are themselves ways of exert power, expressing what is and is not natural and striving for forms of return to naturality often portrayed as a return to an imaginary of equilibrium.

That the social organization of production plays a huge part in the material processes shaping the Anthropocene should not be a surprise. To think that the way we organize our political economy in capitalism towards value-production is hugely influential into how we encounter and interact, with and against nature. through production as the social organization of labor should also be a commonplace. In particular, the Anthropocene appears as a knot inviting us to look at the trajectories of environment, production and technology as intertwined not only as springing from similar ideas but literally, as many technical changes are transferred and spill over from field to field. This challenges both how we assess the present and what our role as researches might be (Levis et. al 2017; Saito, 2017; Zizek, 2015; Wark, 2016a).

The arrival of the Anthropocene as a concept to the humanities has been full of re-evaluations, requests for interdisciplinary, introduction of new themes but also full of attempts to contest the narrative framing that the concept of an Anthropocene brought with it. A lot of thought came quickly in many interesting directions. Curiously, in a way, the humanities and social sciences were often wrapped around the nexus of our own specialty: what was the proper name that had 
in itself the capacity to convey a better narrative of historical time to our current predicament. A very overspread charge, coming in different flavors, is that "Anthropos" effaces the largely divergent roles that Humans in general had in shaping our epoch. Trying to find what it has been really about or the act of fabricating the best narrative for it is still a common concern. Our present has been called many names and brings forth a bestiary of concepts, each with their supporting narratives: Carnivalocene, Capitalocene, Eurocene, Misanthropocene, Necrocene, Betacene, Chtuhllucene, Petrocene, Anthrobscene and Manthropocene just to name a few² (Wark, 2016a)

While certainly those efforts generate endless streams of polemic, one should think about what kind of productive encounter can emerge from this multiplicity. We must avoid a common vice of the humanities, the will to become a narrativelegislator, overemphasizing the act of naming as a closed exclusive narrative, as if the byproduct of the act of naming per se could contain some supernatural power of finally letting the people know what it is "really about", of revealing the essence of our times, as if awareness can do more than it actually can, that is, being the starting ground for praxis and not a discursive entry that merely gesture towards what would be the right nature of the times or the right solution (Wark, 2016a).

Regarding what to do in this predicament, I believe we must begin by deploying methods of knowledge production that allow for lines of comradery between knowledges, practices and narratives, seeing where they do collide and whether one can solve those collisions or would rather build a structure encircling them.

Bogdanov, an apocryphal Bolshevik philosopher and utopian writer, whose influence runs along this dissertation had some ideas about this. A physician by training, he had an interest for blood transfusion as a sign of comradery: blood exchange appeared as a way of mediating difference, not only of replenishing a lack but of invigorating the energy between the comrades, of opening a space of shared vitality in which circulation was not the realization of capital but the realization of comradery. He also attempted to craft a systemic approach to science and labor which in a lot of ways anticipated both Systems Theory and Cybernetics. By binding theory and practice, he sought to implement both theoretically and literally blood

\footnotetext{
2 The first three have appeared more cogently in the part of the debate inside IR that I cover in this chapter: The two first quoted by David Chandler and the third as a part of Jairus Victor Grove's (2019) Savage Geopolitics which will be discussed in the second chapter. For a general inventory of those concepts see Latour and Weibel (2020).
} 
sharing against Capital's vampirism, blood mixing instead of preservation, connections and imagination coming from the encounter with that which might seem alien at first glance (Wark, 2016; Bogdanov, 2020).

It is this atmosphere that I try to convey and it is in this sense that I read Donna Haraway's (2016) plea for binding different narratives about the Anthropocene and letting them bloom. That means refusing to read narratives as attempts to legislate what our present is "really about" attributing to the act of naming a force it doesn't really have. Rather, I engage those radically different attempts to think about it, inside and outside IR as attempts to narrativize an aspect of a fleeting totality and in terms of their political efficacy.

I stick to the Anthropocene simply an entry point: a concept that comes from scientific labor and that sets a new trajectory, one which is in our best interest to comradely relate to, rather than standing outside of scientific discourse and claiming that it cannot get the root historical causes. This means accepting the concept as a construction site.

It might be time for giving some love for the often-downplayed suffix "cene". It comes from the Greek radical "Kainós" denoting the emergence of a form or quality from a different sort than what it preceded, a radically different temporality entailing a radical shift. The Anthropocene appears, above all, as a call for the creation and arrangement of new forms on top of our current ones, new forms of thinking, producing, existing. I see this quality of Kainós, in connection to my focus on centering the questions of production and metabolism as an invitation for two steps: first, understanding how the capitalist historically determined form of wealth has endorsed certain relationships with nature and, second, an understanding that breaking with it requires navigating through the tendencies it articulates in our present.

In this sense, Bogdanov's (1984) Tektology inspires my approach in three commitments: seeing labor as metabolism and always as a socially organized intercourse with nature through dynamic organizational structures; offering an approach to knowledge and labor as systems which share structures that are transferred within fields of social practice (both for better and for worse) and, lastly, in its unwavering commitment to seeing the social organization of production as both a crucial predicate which is unavoidable for critique and which must be rebuilt if we want to truly build another world. 
Patricia Reed (2018) called Xenophilia a kind of openness to that which is alien, a way of looking at our space of experience so that a new horizon of expectations can emerge right from our own "realism", right where we often find no horizon to look forward. In such an impasse to imagine things otherwise while also living with the need and enthusiasm to do so, this is a critical and constant task that entail diagramming pieces of the past, revising the present and forming anastrophe's that might articulate possible futures.

This is an attempt at diagramming as above all an exercise in speculation, more precisely what Reed (2014) called "affirmative speculation", predicated not in domesticating risk but in seizing instability as openness towards that which is alien and the connections it may render possible. In this sense, speculation seizes the domesticated futurity lying within Capital venturing beyond the calcification of our own imaginations, calling upon an incision in our present in this gap between "what is" and "what could be". Speculation inclines the future into the present being both descriptive and prescriptive. Through that, one might hope giving birth to insights that might allow for the task of building and negotiating what commonality is through this open fissure that offers insight for rethinking the very way we ought to live (Reed, 2014 p. 7)

A quality of affirmative-negation or constructive-deconstruction is the very core of diagramming. The root verb of diagramming means not only something that is plotted, sketched out or rendered into figures, but also indicates a crossing out or the erasure of figures. As a method for thought, the activity of diagramming invites the fabulation of narrative and connection, it is an abstract language where gestures of 'pre-history' find a site for speculative definition. The diagram is not bound to the elaboration of a solely axiomatic argument, but, as Deleuze (1988) suggests, can gaze into the future with pronoia, hinting at a reality that is yet to come. It also is complemented to what Noys (2010) has called the articulation of tendencies as the need to build praxis for rupturing with our current mode of production through both a mixture between affirmation and negation.

This thesis does not try to be an absolute endeavor in which I seek to be fully right about something, rather, I seek to at least be a little bit right about as much stuff as I can while assembling a theoretic-methodological toolbox that might be helpful in mapping a critique of approaches to the Anthropocene that center the question of production. Therefore, this thesis is committed to, from the perspective 
of IR, assembling tools for recentering the critique of production in the Anthropocene and hoping that this move also aids in imagining other ways of laboring, producing, seizing and reassembling our own material conditions towards new forms from which another world could emerge.

In this sense, the connection to be made in this dissertation is to insert production as a crucial knot in which the Anthropocene was made, a knot to be untied and thought otherwise. Theorizing appear as a quite vulgar movement, occupied of seeing how our situation is built and assembling features that might help to cast it otherwise (Wark, 2016a p. 243; Reed, 2018).

Such a focus on production is a focus on how what we called global and the planetary are intertwined and the gap between them: the global as the realm of global political-economy and its organization and the planetary as the place of large scales technically accessible. While the first works through human categories and finds the sustenance of human life (and forms for its governing) as its main ground, the second is indifferent to the human and its maintenance, the human never encounters the planet in its totality directly, only through ESS as a simulated reconstruction. However, in a way, the human interacts daily with the planetary through labor and production as socially mediated totality and directly impacts it (Chakrabarty, 2018; Wark, 2016a).

The possibilities disclosed from those very same technologies are not used exclusively for that higher sphere but are deeply embedded in historical developments that have penetrated our everyday lives and our economic system. They are spread for multiple purposes ranging from dealing with the increasing complexity of financial markets to factory management to everyday communication, commodification of information and factory management.

These trajectories are intertwined with other realities of our time such as the commodification of data, the emergence of new types of labor and a whole new geographical layer of informational fluxes, what Wark (2012) called Telesthesia, the capacity of information to be transmitted much faster than things. That allows the now ever more present appropriation and commodification of information through platforms, devices and governments and the impacts generated through the labor and materials making them (Wark, 1994:2004:2012; Castells, 2008; Bratton, 2019).

As our context both spell new forms of exploitation and domination tempered with the threat of extinction, they articulate both potentials and things to 
be done with. The paramount question is what to do to turn the present into the future, a question unfolding in technical, political and ecological terms and that should inform strategies and tactics ${ }^{3}$ (Srnicek, 2013; Bratton, 2019). As we face the planetary neither resignation to the provincialisms of the local nor the attempt to merely rehearse the global are enough. We are invited for new connections, diagrams, new fronts of struggle and possibilities (Wark, 2019).

The category of the planetary constitutes an example of a "vector of revision" turning the assumptions of the project of the global into unstable ground: what was often assumed as the place and meaning of the human, the forms of governance and production, now must become construction sites emerging from this gap between what is and what could be. Under such revision, disciplinary boundaries start being questioned and our own space of experience of the historical present becomes destabilized (Reed, 2018; Chakrabarty, 2018). Keeping in mind such a spirit, as some of the problems have begun to be laid out, it is time to turn to IR.

\section{The Anthropocene Encounters the Discipline of the Global}

The discipline of IR overlaps with the emergence of the "global" and its myriad of material processes: from colonial enterprises to world wars and the relentless globalization of capitalism, all of those processes are predicated on the construction of a globe as the political arena, from casting the space called the international right at the borders of the nation state which is the relational condition of possibility of modern forms of sovereignty. To claim that IR is a discipline of the global is to say that it has been complicit with globalization as the construction of the global as a geopolitical fractured entity. In fact, it was one of the knowledges that rendered those projects both possible and understandable to us, a story that needs not to go further than the way the discipline was embedded in its complicity with war, strategy and coloniality (Walker \& Bigo, 2007; Chakrabarty, 2018; Grove, 2019).

\footnotetext{
${ }^{3}$ An attempt to think a politics that seizes these powers of abstraction rather than fearing them or equating them to instances of domination is something resurging specially in the last years. I would emphasize: Benjamin Bratton, McKenzie Wark, Matteo Pasquinelli, Nick Srnicek, Alex Williams, Patricia Reed. There is also a lineage of Marxist thought that deals with similar concerns seeing in technicality an interesting pathway. On that, I would emphasize: Radovan Richta, J.D. Bernal, J.B.S Haldane and Joseph Needham and to some extent the theorists around Italian Operaismo in their pioneer attention to the transformations in forces and relations of production.
} 
Chakrabarty (2018) shows the intertwinement between the global and the planetary, emphasizing that they do not form a perfect, symmetric fit but a scale in which the human and the non-human meet through technical means, no differently for the ones shaping the Anthropocene. Such is also the case for the labor process, in the intersection between the geo-climatical and the political economy. That being said, in this section I will proceed by first laying out some of the general lines in which the Anthropocene was received and in which directions it already disrupts our discipline, one so connected with the emergence of global. While doing so, I want to introduce a different angle from which to look at this disruption, namely, the angle of production and its adjacent questions of labor and value and argue that they, in fact, get little relevance in the current way the discussed authors frame the problem of the Anthropocene.

The Anthropocene initially found its way into IR through concerns regarding international security (Simangan 2020; Lovbrand et. al 2020). This entrance, however, made itself felt and could not be an insulated disturbance for too long: at its most fundamental level, the Anthropocene challenges many of the humanist assumptions in which the discipline was built and has in fact the possibility of spelling "the end of IR" as it is (Simangan, 2020; Corry, 2017).

Simangan (2020) asserts, converging with Mitchell (2017) in this sense, that the idea of extinction and its consequences for thinking politics in general are a crucial debate brought by the Anthropocene. Another crucial tension is the entrance of what they call "inhuman scales" upon the discipline (Srnicek, 2013; Chakrabarty, 2019; Bousquet \& Curtis, 2011) and also by the way in which the Anthropocene tensions binaries deeply ingrained within the discipline such as the foundational separation between Human/Nature, not to mention how it appears as a layer on top of many of the traditional concerns of the discipline.

Those tensions are often pictured as productive ones, fomenting new ways to imagine ourselves and our world, be it by rethinking this border or by opening ourselves towards learning from alternative cosmologies ${ }^{4}$ (Burke et. al 2016; Chandler et. al 2018). Lovbrand et. al (2020) identify that IR is guilty of assuming that nature would behave as an obedient scenario while the drama of politics, the main

\footnotetext{
${ }^{4}$ This move towards indigenous cosmologies and epistemologies and the need to "becoming indigenous" is far from unanimous, constituting a nuanced and rich field. A very interesting example is the work of Eduardo Viveiros de Castro. Some of those arguments have been recently submitted to criticism by David Chandler and Julien Reid (2020) in their article "Becoming indigenous: the speculative turn in Anthropology".
} 
disciplinary subject, could always be staged and, at worse, only be temporarily unsettled by the environment. This elevation of politics as a superior layer happening detached of an environment is precisely the kind of malaise the Anthropocene comes to problematize.

Lovbrand et. al (2020) points that theorizing the Anthropocene is often an experimental endeavor that brings about creative ways of picturing the world. We must understand "pictures" as ways of building narratives around the same geological reality, responding to specific concerns within the discipline and what its agenda ought to be, also projecting specific political commitments. They identify three main world-pictures: the endangered world, the entangled world and the extractivist world, each having their hybrid genealogies but being more or less related to, respectively: liberal institutionalism, post-humanism and post-marxist literature.

This act of picturing in itself is deeply related to the underlying concerns through which each of them look at our predicament, the first is concerned with securing life and populations from catastrophe and frames from which it could be done, specifically focusing on governance solutions, the Anthropocene as a challenge to usual policy. The second is dedicated to problematization of the disruptive character of the Anthropocene to Human/Nature and a certain anthropocentrism in which IR rests claiming that radical changes into how we live must be made, often drawing on other cosmologies. It mobilizes the Anthropocene as theoretical destabilization and existential risk as an opportunity for speculation and praxis. Meanwhile, the third occupies itself with mapping the way in which Capital is responsible for our current predicament and the intricate naming contestation around the Capitalocene/Antropocene, the mismatch between Capital as an organization of production and the possibility of really addressing of the problems within the Anthropocene, also concerned with connecting the trajectory of Capital to the Anthropocene through the critique of political economy.

Those separations in themselves are impossible to clean-cut but if taken as provisional ways of mapping, they serve us as guidelines to detect the main scenario in which certain claims are made. At the same time, theory for the Anthropocene, just as in the case of its many names, has the challenge of weaving those questions together: it is impossible to separate the task of crafting alternative governance from what the human means and from how both are shaped by production (Lovbrand et. al 2020). 
While inquiry must always start somewhere, to attempt to detach the question of production from the Anthropocene or to point it as a mere determination or echo or expression of some other more fundamental truth lying in another sphere is to blunt the critical edge the concept may bring to the humanities but also to maim possibilities of articulation between theory and praxis. This thesis seeks to refuse forms of separating or casting away those questions, through focusing on the last two diagnosis: the entangled world and the extractivist world as only through their creative conjunction one can suture a critique of political economy in the context of the Anthropocene. Let us now proceed to assessing how can we start crafting this blood exchange by looking at such entangled pictures and some of their limits.

Mitchell (2017) points that one the crucial dethronements that the Anthropocene brings within IR is the category of extinction: the ever more present awareness of our future extinction as a species and our acceleration towards this destiny, the need for preserving other species and also how the processes that made the Anthropocene are themselves highly predicated on the extinction of alternative forms-of-life, human and non-human. This effacement of diversity is often read as a characteristic of this phenomena not only limited to animals and plants but also to the death of other forms of social organization perpetrated by extractivist coloniality, capitalism and their historical unfoldings (Grove 2017; 2019; Moore, 2015).

This encounter with finitude is seen as something that opens us towards speculation, asking for an "embrace of the universe's indeterminacy and its creative forces" (Mitchell 2017 p 17). Extinction is taken as a speculative challenge, one allowing us to think critically about who we are as the possibility of extinction shows us our shared vulnerabilities. She proposes that, maybe, if we act as if extinction already happened and continuation under the same regime is no longer possible, this can open us in the present to possibilities of living and interacting otherwise. One might ask what is the nature of this openness and what kind of practice it entails. Mitchell, evoking Clark and Levinas, answers that the encounter with extinction as a possibility changes our own relation to each other and to nature as it:

\footnotetext{
"Profoundly shifts the emphasis of human action — instead of attempting to secure existing conditions, it encourages 'action for a world to come', and responsiveness to the ethical demands of the (remote, unknowable) Other (Levinas, 1998: 51). (...) embracing future life forms is not passive. Instead, it requires the ability to see 'the intolerability of the world as it is presently imagined and demands the seemingly impossible; the creation of a new one' (Clark in Mitchell 2017:22).
} 
Positions akin to this one can also be found in documents such as the "Planet Politics: A Manifesto from the end of IR". The awareness of our finitude appears yet again fostering a call for speculation and openness towards possibilities. Burke et. al (2016) in the manifesto work through this as the "emergence of a new consciousness" (p. 502), of a new "political imagination" (p. 500) and questions "What values must this new subject have? What must it love and protect? This is the real with which we must contend." (Burke et al 2016 p. 521) and the fact that those in turn require new political forms to be imagined.

Despite inspiring in pushing for urgency, the form of politics they propose becomes a bit confusing as it lumps together proposals for a Security Council-like international organization with demands for energy transition, biodiversity conservation, full decarbonization and an opaque "return to social justice". The manifesto, despite being a well-intentioned document, makes for a scattered reading as there is no clarity about what kind of commitments are at stake, its solutions range from lukewarm proposals of global governance to a supposedly revolutionary drive, arriving right at the end, through a vacuous evocation of a Marx calling for "Animals of the world" to unite (Burke et. al 2016).

Here we see an interesting shape of what Spivak (2018) called the reduction of Marx to a benevolent figure of the past: he appears as a distilled figure, a commodified icon of radicality but one which appears blunted of all his critical edge as politics and mobilization, the panacea here is not the radical restructuring of production but a matter of ethics. This is what my discussion of those texts tries to do, understand how their effacing of the dimension of production makes their politics a bit disappointing.

Among many responses, a particularly scathing piece of criticism was issued based on the manifesto; the main points of critique were that the manifesto was at fault for:

"First, seeking amelioration rather than transformation; second, advocating top-down coercive approaches of international law as an effective mechanism; and third, resorting to abstract, high-flown and idealist notions, such as 'global ethics'." (Chandler et al 2018:193)"”

While clearly polemical in nature, it does have some grains of truth in it. I think Chandler et. al (2018) hits the spot in a problem common to the picture I have been painting above, one that is also present in the rejoinder made by the authors of the manifesto: the move to projects of global-ethics often puts the problem at such an abstract place that it really seems like a mere matter of consciousness or 
awareness that is supposed to emerge everywhere through acknowledging extinction, an emergence that needs to be affirmed to deliver its promise.

This is closely related to the picture of the 'entangled' described above. There is, however, a quite ironic thing to notice, that in fact they do not seem to entangle enough: politics becomes a place of speculation far removed from production, labor is a vulgar topic left out. The coincidence between labor struggles and environmental ones, the convergence between the reorganization of production for labor and the environment is nowhere to be seen. It is as if once one promotes a new ethical relationality opposed to modernity, the meta-text that serves to group up everything bad, and that once this is sorted out, this does the trick of changing our predicament.

In the rejoinder to this criticism, answering in the name of Planet Politics, Fishel et. al (2018 p. 211) mentions more cogently the contribution of capitalism to the making of our own predicament and point to the crucial task of rethinking production and the political economy which is a gap they are aware of. For that, they make to International Political Economy (IPE) a sort of "call to arms".

However, by not directly engaging production as a determinant factor to how politics is carried out and not speculating into how they could be organized in the future, the authors rely in an academic division of labor to evade the issue of how capital has a hold of crucial processes for the making of Anthropocene that do not merely get tackled by so desired ethical changes: the material management and commodification of information, the systematic commodification of nature, the exploitation of energy sources, the daily exploitation of labor power, which are all intrinsically related to capital as a mode of wealth production and to the Anthropocene are effaced merely as a topic that is too foreign (Pasquinelli, 2017; Wark 1994; Stubblefield, 2018).

The combination of environmental degradation and the possibility of growth in automation accompanied by worldwide stagnation make demands for rethinking production converge, if we think about what challenges people really face in our current predicament: while automation makes the schism between intellectual and manual labor even bigger and creates new modalities of property and exploitation, unemployment, underemployment and "bullshit jobs" are rampant. (Graeber, 2018; Wark, 2005:2012; Srnicek, 2018).

As Davies (2010 p. 191-194) puts, one must look at labor as a crucial site of everyday experience but also as a critical category that can greatly illuminate political 
possibilities both as labor in its current form is a map for understanding some of the antagonisms in our current reality and also as it must become a field of speculation as well. Making work something meaningful must be made a crucial goal for any revolutionary politics, as work is indissociable from our own experience and social integration and, when organized by the pursuit of the reproduction of value, can never be truly meaningful for everyone. Above all, the focus on ethics is a foil for reinstating the Political as a legislative layer, an ontological sphere that will be influenced by the acknowledgement of extinction and might restructure all the other "ontic" ones. This move will me more closely criticized in Ch. 3 but for now let's pay attention to how those documents within IR are dealing with it.

Fishel et. al (2018) also try to defend the charges of what gets called "high flying abstraction" in global ethics by arguing that one needs not to assume that global ethics needs to be top-down at all. Now, despite the fact that this point is made poorly by Chandler et. al (2018) through an equation of ethics to a ready-made fits all approach emanating from international organizations, making some sort of straw man of the politics of encounter they try to trace, it has an interesting kernel of truth too. I believe that while the Anthropocene evokes many ethico-political problems, the problem lies in thinking an ethical change as a mere matter of changing consciousness, be it through encounters with indigenous modes of thought and life, international organizations or anything short of a radical political struggle that must reorganize production. Failing to articulate that ends up keeping a residual idealism located at this cult of the political as main sphere, one that renders the leap from theory to practice little more than a discursive move. Those so-evoked animals who are to supposedly unite under one flag, without a robust understanding of political economy as a sphere structuring reality and not a merely expressing ethical ideals, reveal themselves as quite tame.

In this sense, Chandler et. al (2018) are right to point that an emphasis on Capital and struggling against it is mandatory for addressing of the Anthropocene, as the only way of achieving any of those ethical commitments is to oppose capitalism as a form of social organization not as something that can be fixed gradually through governance or the political as a superior legislative layer, but something entirely embedded in politics itself, impossible to be distilled and handled through a superior ethical layer. Despite having that clear, they neither advance in this direction nor elaborate on what that means for their own contestations. 
To say that capitalism is a form of organizing means that it organizes it towards some relations of production, towards the production of value, the historical form of wealth in capitalism, one that is generated through the realization of the circuit between production of a commodity and its realization through circulation. Let us take a detour to Marx and try to formulate this further.

\section{A detour: Value and Labour in Marx's critique of capitalism}

Marx's (2013 p. 157) reading of the commodity-form, the "most general and least developed form of bourgeois production" is crucial for understanding how he sees capitalism. It is very simply laid out and defined by the chain represented below in which M is Money, MP represents the means of production, LP the labor power, C the commodity and M' stands for the "salto mortale" of the commodity, that is, its transformation back into money. This formula tells us not of a process through which wealth is increased but precisely one in which value is increased from M to M'. We will get to surplus-value in Ch.2 but for now it is enough to understand that value appears as a form of historical social mediation (Marx 2013; Tupinambá 2017; Spivak 1985).

$$
\mathrm{M} \rightarrow \mathrm{MP}+\mathrm{LP} \rightarrow \mathrm{C} \ldots \mathrm{C} \rightarrow \mathbf{M}^{\prime}
$$

We must understand two fundamental points within the exposition: the first one being that the equivalency of different commodities is operationalized by their representation through money (Marx, 2013 p. 132). It also means that the commodity is identical to itself, or in the sense that its value is set in relation to the socially necessary labor. Exemplifying, let's say the average productivity based on time and output for the production of a shirt is of 2 hours but I do take 6 hours to produce the exact same shirt, that means that the value it holds is still in accordance to the socially necessary labor time, not the one I individually spent producing it (Marx, 2013 p. 153).

Both of its qualities are to be understood through the fact that, within capitalism, the commodity has a two-fold character: an use-value and an exchangevalue. The use-value of a commodity is its fruition realized between a person and an object. On the other hand, however, there is not enough examination of the thinghood of a commodity that can take one towards understanding its exchangevalue. Rather, the exchange value of a commodity is only known through the 
socialized activity of its exchange tethered to the socially necessary labor time for producing it. The commodity is a quite strange thing because it is both a concrete thing and a nexus of social relations that have nothing to do with that material existence at all and that acquire their social meaning only through exchange, constituting a "phantom-like objectivity". It is this kind of objectivity, in which abstract social relations have material effects that constitutes the crucial point of insight in Marx (Marx, 2013 p. 158).

Capitalism is, by definition, a system of the social organization of production in which exchange-values takes precedence over use-values, hence, of a particular form of wealth production. Therefore, "value-forms" take precedence over "natural forms". Under such a paradigm, it is not hard to understand the subordination of nature to an instrument for the reproduction of exchange-values and the metabolic rifts it causes (Foster et. al 2018). Of course, value as a model of wealth is propagated through a movement that is both political, economic, cultural and technological (Blaney \& Inayatullah, 2010).

The production of commodities through labor is also deeply related to this schism between concrete and abstract labor but, as I hope to show, in a slightly different manner. This means not that there are two labors but that the labor process has, itself, a double character. Unproblematically, concrete labor is defined as the process of production through which man produces use values through the manipulation of matter. It is only through abstract labor, however, that values are produced for it is the substance of value. In which way, however, is a highly contested question.

In particular, the question is how is concrete labor "abstracted" and what is the particularity of this process under capitalism. The conflictual nature of this definition lies at a particular question: is abstract labor, just as exchange value, a purely social category, endowed with the same phantom-like objectivity as exchangevalue or is this symmetry a quite misleading one? The claim whether abstract labor is material is a contested one (Saito, 2017 p. 98). I do not have the space to sketch a dialog that elegantly poses such a question, so I will try to butcher through it as schematically as possible and formulate the stakes of the answer I opt for.

Cutting to the problem, Marx (2013 p. 124) in his famous chapter on the commodity states that:

"Every labor is, on the one hand, the expenditure of human labor force in the physiological sense and due to this property of equal or abstract human labor it generates the value of 
commodities, On the other hand, every labor is the realization of an end, and, in this quality of concrete labor, it is useful and produces use values.

Likewise, Marx (2013 p. 122) claims that there is even through different labors a minimal ground of their commensurability which is set across different functions by a certain generality of the human organism. Therefore, both concrete and abstract labor are categories that are, minimally stated, expenditures of human energy and therefore material.

Kohei Saito ${ }^{5}$ (2017) intervenes in the literature ${ }^{6}$ regarding abstract labor by pointing at a crucial juncture: his point is that abstract labor, different from exchange value, is not devoid of materiality as it is predicated into a socially arranged expenditure of human energy ${ }^{7}$. This finds backup in Marx (2013 p. 121) when he claims that: "Abstracting from the determinateness of productive activity and, therefore, from the use-character of labor, remains the fact that it is an expenditure of human labor-power".

Those quotes often receives an interesting treatment and are often seen as a sort of slippage in Marx, in particular, a slippage from how value as a category of social mediation obeys the clean-cut divide between the concrete and the abstract that must trace symmetrically also in labor, reproducing the distinction between wealth and value, use and exchange-value. In such readings concrete labor is qualitative, infinitely different in its determinations and where physiological expenditure happens but abstract labor is merely quantitative, its representation quantified and devoid of any material determination. A paradigmatic example can be found in Postone (2013 p. 170) that, when analyzing it, claims that:

"The definitions of abstract human labor offered by him [Marx] in Capital 1 are very problematic, seeming to indicate that it is a biological residue that must be interpreted as an expenditure of human energy".

His response postulates we should actually follow the Grundrisse as it, according to him warrants us to see value as a "historically specific form of social wealth" that therefore could not have a trans-historicity, a substance common for all

\footnotetext{
${ }^{5}$ It might be worth qualifying that Saito's intervention is through the reception of Capital Vol. 1 in Japan. His main inspirations, that one can say are predicated in going against the very heterogenous lineage of interpretations descending from the great influence of Isaac I. Rubin. Saito's interpretation is based in two authors: Samezo Kuruma (2018) and Teinosuke Otani (2018), both recently translated into English for the first time.

6 The main target of his intervention is Michael Heinrich and other interpretations of Marx derived from Rubin. Postone's interpretation itself, one that I will cite multiple times in this dissertation, is one that draws on Rubin in this specific point. However, I think that specially having in mind Marx's category of metabolism, this is maybe the best interpretation of abstract labor at least taking in mind the concept of metabolism.

${ }^{7}$ Mind that we are talking only about the expenditure of human energy here.
} 
social formations (Postone, 2013 p. 171). For clarifying this, he quotes Rubin (1972 p. 35 apud Postone, 2013 p. 171): "It is not possible to reconcile a physiological concept of abstract labor with the historical character of the wealth it creates". This position is also taken by Foster et. al (2018), referring to the same Rubin passage as well. At this juncture, while wanting to keep the historical character of wealth created under Capital, let's keep this in mind, at least for a little longer.

Postone's (2013) is in an either/or dilemma, either the physiological or the socio-historical, two facets that appear impossible to be reconciled. Therefore, for Postone, this reading of abstract labor as physiological is merely Marx reading it from the perspective of Capital. That is, for him Marx is immanently realizing how this generalization appears itself through the commodity-form and has no meaning prior to it. Doing so he argues that "even categories at the essence of the capitalist social formation are reified". His point being that Marx's categories serve only for a Capitalist society (Postone, 2013 p. 171).

However, staying with the tension between those two dimensions which appear in abstract labor might show us rather interesting things, for one, the tension inherent to Marx as he was both formulating an immanent critique and also trying to understand how Capital comes to emerge and its singularity when compared to other social forms of organization (Blaney \& Inayatullah, 2010). One can agree with the core of most of what Postone (2013 p. 172-173) says about the historical specificity of Capital and its critique, it is in fact hard not to, but there is still something uneasy about the hermeneutical procedure: Marx is stuck within Capital performing its immanent dynamics therefore, he turns back to the Grundrisse, the draft taken as a key, to prove that in fact it is a merely social category and that the physiological is incompatible with Marx's endeavor.

Not only the Grundrisse itself is far from giving an unequivocal picture of this view as it in fact stays with this duality ${ }^{8}$, but it seems that there is no attempt to really overcome the contradiction between those approaches. Postone sees great danger in leaving abstract labor as a category related to physiology, particularly because it might make it appear as a purely mental one, a mere generalization of bundles of concrete labor and not the expression of a real thing. That would be, for Postone, to surrender

\footnotetext{
${ }^{8}$ See for instance Blaney and Inayatullah's 2010 "Savage Economics" precisely on how Marx stays between generalization and specificity of some categories he finds within capitalism for understanding other economic formations.
} 
Marx's conception to Bohm-Bawerk' that claimed that abstract labor is merely generalized use-value and not a socially distinct category ${ }^{10}$. Therefore, the condition to hold the physiological in abstract labor must not come at the expense of effacing its distinctiveness under Capital.

It is from there that Saito (2017) begins his inquiry and formulates a different answer. For Saito, abstract labor is a general transhistorical socially mediated organization of labor through its homogenous generic side as organized physical activity for generating and distributing a certain produced output, it appears in the puzzle of labor as physiological expenditure and organization of physical activity that exists across societies in different forms. While concrete labors are incommensurable between themselves, abstract labors are made commensurable based on their character as physiological expenditure (Saito, 2017 p. 108).

This is a very minimal form so, in non-capitalist societies, this can foster many different social arrangements, as long as needs are known and negotiated before the producing act. The singular historical feature that defines the capitalist way of abstracting labor, and then historically specifies it is the fact that, in a capitalist society, one produces for a non-existing need which is only projected into the future with hope of absorption (Otani, 2018). This is synthesized in the concept of private labor, attaining to the particular way in which labor in capitalism is

\begin{abstract}
a private act, which does not become a part of the entire social labor at the moment of labor's execution. It is thus necessary to realize the adequate "allocation" and "distribution" not before but after labor is performed. Private labors as such thus do not possess any immediate social character and do not constitute a part of entire social labor. (Saito, 2017 p. 105-106)
\end{abstract}

This means the moment of production is marked by the lack of knowledge about the realization of labor and the productive process therefore answers to no socially negotiated need, relying on forms of privatized knowledge in order to allocate itself and rationally calculate its own realization. This has two consequences: first, that value, differently from wealth in general, only becomes realized through exchange. No one really knows the destiny of the output of activity and the relationship is traced precisely in such a future-bound realization.

The second and crucial point lies within the concept of private labor marked by the fact that the individual is working privately, not in isolation for personal

\footnotetext{
${ }^{9}$ Bohm-Bawerk was an Austrian economist that provided a classical criticism of Marx's Capital. The critique can be found here https://www.marxists.org/subject/economy/authors/bohm/ch01.htm. ${ }^{10} \mathrm{~A}$ crucial point here is the concept of alienation, which Saito also works with but that will be explored in a different manner in Ch. 3 of this thesis.
} 
enjoyment but unrelated to the end of his production, it is work without an immediately social character. It is only through the realization in exchange mediated by money that, retrospectively, that unit of labor enters a circuit of valorization. What mediates this privateness and render exchangeable different use-values is, of course, value as a form of socially mediated wealth and its representation by money. Therefore, value as a form of wealth is entirely social in fact. The same however does not hold for abstract labor: abstract labor is a physiologically, quite general way of organizing human activity that receives a unique social function in capitalism.

The merit of Saito's interpretation, therefore, lies in showing a fracture within the concept, but a crucial one: abstract labor qua the organization of the whole of human physiological expenditures managed through different divisions of labor can be formally observed across societies. It is not, therefore, abstracting labor from concrete determinations or calculability per se that singularizes capitalism but it is the private character production takes under commodity society and its mediation by money of those general physical expenditures that do so.

It helps in casting Marx's ecological edge as the question of how economic socially mediated forms come to structure use-forms, which fall within the realm of political economy precisely because they become modified by capitalist relations of production.

This has four immediate consequences: first, casting the private character of labor as a problem asks for the said speculative edge of those theories to take the task of thinking other forms of organizing labor as such, also laying bare the impossibility of articulating such a system based in value of being reconciled with a relationship to nature that is minimally coordinated in a broad sense; second, such a theory is highly compatible with the concept of metabolism as it is particularly concerned with the latching of economic-forms into natural-forms, both in the question of labor and in its broader effects; third, it sets a vision of abstract labor that is very fertile for thinking about the reorganization of production from a perspective of what communism could be, as it is not only able to mediate and compare different forms of organizing production through the common ground of the abstraction of physiological expenditures but it also aids one to articulate free time together with both the metabolism of the worker with nature through multiple forms of collective management; fourth, it does not mistargets quantification and 
management as the main social ills per se but opens quite fertile paths from thinking a reorganization and ecology of labor practices.

\section{Back to IR and the Anthropocene}

This detour allows to see from a vantage point that said slippages into idealism are not incidental, but deeply related to the lack of serious engagement with labor and the recognition of the structuring status of the political economy, its connection between concrete and abstract as it frames a specific relationship to nature that is actualized through the very shape that production has.

Both the Planet Politics Manifesto and its critics (to a lesser extent), while trying to speak to and to shape a politics with very refined ethical commitments, forget not only that the form through which many people encounter nature in their experience is through labor but through a form of organization of labor in which nature appears as nothing more than an object, even if it is discursively formulated otherwise. "They don't know, but they still do it” (Marx, 2013 p. 149)

They end up addressing the Anthropocene and solutions to it as "ontological problem" in a way that is limited to one of the predications of the modern subject (consciousness) and as if it could be revolutionized through a destabilizing encounter with the Anthropocene or by its reshaping through institutional politics fostering a new ethics and awareness. Meanwhile, by downgrading the way the other forgotten predication (production, the subject as labor-power and its usage by Capital) actually shapes consciousness as well, and the mutual influence of those determinations, they foreclose a field of speculation and struggle and of convergence between labor struggles and environmental issues (Spivak, 1985).

Ethics becomes a prosthesis for the political, the most fundamental basis of everything that when changed will "trickle up". Any meaningful speculation of radically reshaping and disturbing the predications of the modern/postmodern subject must involve those two porous fields that are politics and economy rather than putting one to legislate over the other. Doing so is crucial for understanding the full scope of the challenge posed by the Anthropocene in all its material conditions. There can be no politics for the Anthropocene without trenchant anti-capitalism that grasps the current structures of our current economic organization but also that seizes and repurposes a substantial part of it (Spivak, 1985; Kapoor, 2002). 
Marx's move was based precisely the rejection of consciousness as the milestone of political change or of philosophy as a higher legislator over our mundane problems, a movement towards an anti-philosophy, a revolt against grounding political struggles in abstract concepts as universal legislators such as love or friendship, precisely because those do not account for the allure of the "inverted world", the material circumstances that often operate far beyond consciousness, the system not of clearly framed exploitation but of abstract and diffuse domination through social practice that defines capital (Marx, 2009:2017a; Saito, 2017).

The other side of this is a dismissal of Marxism as merely another iteration of modernity that repeats its exact same standards and tropes and therefore should be "left behind" together with other old relics. Modernity supposedly appears as a sort of urtext through which one critiques the aggregate phenomena of politics and economy but in reality, ends up with politics as an ethical puzzle to be solved by awareness. Chandler et. al (2018), and also Chakrabarty (2019) for that matter, mention in passing that both socialist and capitalist governments dealt with nature in the same harmful "modern" ways ${ }^{11}$ but conveniently ignore that the main points of Marxist critique towards really existing socialist modes of production is that, despite having radically changed distribution, its fault was that it never really abolished the value-form as the regulative for production: they were merely fighting the battle of production in the same modes as Capital but through different regimes of property and distribution, without materially remaking its meaning, maintaining forms of the productivism typical of industrial Fordist capitalism (Postone, 2013; Richta, 1974).

This kind of reading is not strange to the reading that frames the whole of Marxism, an immense field of though, as merely productivist-industrialist thought. This is a picture that, regardless of the other avenues of critique that Marxism deserves, with the wealth of production from Green Marxism of the most various kinds, archival discoveries and the lack of references cited by the so said critiques

\footnotetext{
${ }^{11}$ This does not only foreclose the crucial need for a critique of the form labor takes, but is also a surprisingly historically inaccurate hypothesis. One can of course claim Really Existing Communism and Capitalism shared features with modernity but even so, they do it in highly different manners: to claim that, say, Stalin's plan for the transformation of nature is mere an iteration of the same rationality that guides Capitalist ways of interacting with nature is highly misleading and plainly false. This does not mean claiming one as good and the other as evil, but to think about the future it is indeed valuable that we can see that there are many ways of being wrong about something just as many as there are ways of being right. For more on Stalin's plan see Stephen Brain's (2010) “The Great Stalin Plan for the transformation of nature" in Environmental History Vol. 15 No. 4.
} 
should be deemed as willful ignorance (Foster, 2000; Moore, 2015; Burkett \& Foster, 2016; Saito, 2017; Grove, 2018).

What remains certain is that no revolutionary politics can exist without rearticulating what labor ought to mean and with the abolition of value. Foreclosing this or leaving it to be solved by an ethics, no matter how bottom up, poses ethics as the final legislator and is a lapse into idealism that can only expresses a will to wish production away without lifting its abode.

Critique must account at one hand for the kind of social practices and historical phenomena that render certain forms of consciousness and production reproducible and operant in the first place. It must also contain a speculative moment in which through the destabilization of those forms, alternatives can emerge (Saito, 2018; Sohn-Rethel, 1974; Toscano, 2008). Crucial for any further speculation is to have a picture of the disturbance in which we find ourselves: I have been only hinting so far at the deep relationship between Capital and the Anthropocene.

We must dwell deeper the stakes of claiming value-form as an organizer of production, what does it tell us about our own relationship to nature, in particular how we tackle the relationship between the way value organizes history and its conurbations with the planetary.

\section{Value between History and the Planetary}

Therefore, let us formulate some of the stakes of thinking about value and its metabolic impact in the planetary. First, as put above, value is the form of wealth characterizing capitalist economies based on the equivalence of different labors through money which channel both our relationship with nature and carries within itself social relations that go far beyond merely posing a labor regime but have consequences spread through many fields.

We should specify that, to claim that value is a way of organizing does not mean that everything is fully explainable by value, to advance the impossible claim that as we live in capitalism, everything is determined by value. Doing so would be falling into what Althusser (2009) called a model of "expressive causality", in which all the aspects of a social formation are seen as expressions of a certain kernel, in this case the value-form. It should be seen as, rather, a way of identifying a molar principle of organization of production and of great instances of our lives that spread through a historical process and made itself into a totality, a totality that exists as an 
"interrelationship between a totality and a set of empirical particulars" and while being a crucial aspect of the making of the Anthropocene both materially and in the very limits of our thought and cognition, it does not mean that everything is merely an iteration of it (Jameson 1992 p. 67).

To say that value as social-form frames a totality, therefore, must not be a synonym to self-enclosing, but an analytical way of grasping a historical ever-moving process of internalization and penetration facilitated but not all explainable by the value-form, one with material effects into our planet. Our own social ontology is in many senses produced by the way in which the value-form represents a back-andforth loop from the concrete to the abstract, between our everyday experience organized by it and its simplified "higher form" (Toscano 2008). To say that a form, such as value, is a predicate of consciousness and material conditions means to claim that it is a "real abstraction", a form that by realizing itself into the world through the circuit of production and exchange conditions the limits of our own consciousness and practice, guiding, often unconsciously, the way we organize and interact our material reality, our relation to it and our thought-processes (Sohn-Rethel, 1984; Spivak, 1984; Toscano, 2008).

Value is all at once a formal category, a material category conditioning a part of our concrete determinations and an epistemic one, travelling between all of those spheres. In this sense, it is an abstraction that makes itself concrete through its constant actualization through social practice. Marx's materialism is predicated in this loop between the inflections of forms into matter and of the partial capture of developments from material circumstances into certain forms (Sohn-Rethel, 1984; Toscano, 2008; Wark, 2011). The gap between the molar and the molecular, or, between the organizational principle and its empirical experience, puts people in a predicament in which philosophy and higher activities or the molar become truth without reality, while the molecular, becomes reality without truth, a residue, a testimony of the non-enclosedness of totality as such (Wark, 2016a; Davies, 2010).

When we look at that also considering the radical new scales of History that are involved in the Anthropocene, what Chakrabarty (2018) called the planetary, we see that, actually, wrapping all of those factors together is even harder. Of course, ESS are sciences of the planetary totality predicated in the successive creation, comparation and improvement of multiple meshes of computational models and empirical data and those scientists can definitely be seen as what Chakrabarty called 
"Historians of the Planetary". However, if we are to understand value as a form of organization and not fall to the allure of seeing it as an abstract regulative principle of everything, we must think about what are the implications of trying to think the imbrication of the Planetary and the historical totality (Wark, 1994:2019; Chakrabarty, 2018).

Totality for Marxism is itself a concept that always comes back in very different ways: it can either be a weapon against forms of "deconstructionist" criticism in its downplaying of the centrality of the political economy or as a point of internal criticism to the way this totality may end up flattening difference (Jameson, 1992 p. 34; Postone, 2013). Marxism's uniqueness as a critical theory is often formulated in its affinity with totality as a category. Allegedly, Marxism keeps within itself the potential for theorizing the totality, namely by imbricating ideational content with materiality, something the concept of "real abstraction" put above exemplifies quite well (Postone, 2013; Hamza and Ruda, 2016).

However, doing this is not without its risks. Marxism has indeed had its fair share of visions of totality that revealed themselves as too farfetched or that in fact risked to bring about misleading generalizations, multiple messianisms and toxic hopes of historical providence. Discussing that, Fredric Jameson (1992 p. 26) identifies a crucial juncture on the question of totality through his analysis of Althusser's work.

For him, a crucial point of Althusser's work is his aversion to closed totalities relying in what he called expressive causality: this compelled him to try to craft a vision of History that was devoid of both telos and of a main character, a transcendental subject of history such as the proletariat, for example that would contain within itself the key to its unmaking. What gets spoken about as the "relative independence of the spheres" is a part of his diagnosis that historical movements must be apprehended not only in the struggle between capital and labor (expressed by the class antagonism between capitalists and the proletariat) but that other instances and contradictions overdetermine ${ }^{12}$ that "main contradiction". His list is actually not ambitioning for completion but is rather a provisional one, related to the events he experiences and his own relationship to the party.

\footnotetext{
12 Overdetermination is a term Althusser borrows from Freudian Psychoanalysis, more specifically from "The Interpretation of Dreams". It is deployed in his essay "Contradiction and Overdetermination". This essay is available here https://www.marxists.org/reference/archive/althusser/1962/overdetermination.htm
} 
Althusser (2009) lists three of those instances: first, the tensions between other classes and remnants of old modes of production that still remain as classes with distinct interests (and one can speculate even new emerging modes of production, more on that later). Second, the relative autonomy of the spheres or superstructures (culture, science, politics and so on). The third would be the question of the international division of labor, the fact that "history progresses from the weaker link" and that a myriad of tensions can build up to revolutionary movements, a rupture with any determinism, i.e, with the idea that the revolution ought to happen due to a linear trajectory of capitalist development from which communism would necessarily follow, a note that anyone aware of both the Chinese and the Soviet processes would easily agree with (Althusser, 2005; Althusser and Balibar, 2009).

Its main merit as a vision lies in pointing to a different reading of Marxism, dialectics and of history, one devoid of the double binds of expressive causality, doing away with a privileged subject and a telos to History. It introduces into each of those superstructures their own contradictions that may affect how the total ensemble turns out, it introduces into them forms of increased complexity that contain within themselves a myriad of contradictions. What happens here is that this is far from solving everything, it actually creates other problems. Althusser as Wark (2016b) puts is a pharmakon, both poison and remedy at once. It offers other dangers: rather than subsuming everything into a single principle too quickly as expressive causality does, it goes on the opposite direction as it may insulate, creating a supposed autonomy between spheres that are reified and turned into unrelated fields (Wark, 2016b).

It is only through these kinds of devices and doubling down on them (and in refusing even the economic as the last determining instance as Althusser tried to keep) that one can speak in any form of the ethical as a "more fundamental level" sphere which can be distilled from the economic and then hopefully treated in separate, something we have seen happening in the problematic of the Anthropocene earlier in this chapter on some of the IR theorizations about it but that also appear in attempts to theorize the capitalized Political in its almighty ontological primacy (Spivak, 1984; Althusser and Balibar, 2009, Wark, 2016b; Jameson, 1992).

Ironically, Althusser's reception especially in the Anglo-American world can be seen as tethered to a schism between labor and the academy: the superstructures turned to be a refuge and a site of transformation often detached from questions of 
labor and labor organization in general, a march through the institutions became the promise of a rather slow-paced revolutionary vehicle (Kapoor, 2002; Wark, 2016b). A second shortcoming would be that despite the exponential evolution of the forces of production in Althusser's lifetime with cybernetics and the beginning of a shift away from Fordism, the forces of production and their trajectories do not really get a central relevance under his theorizing (Althusser and Balibar, 2006; Wark, 2016b).

Althusser (2009) also separates Marx's work between the ideological/scientific, a division between the Young/Old Marx which attains scientificity precisely in Capital. What this meant in broad strokes was that Marx for him was advancing through Capital a new method of objective historical materialism, a line also shared by the Party at the time. Now, however passé those kinds of claims may feel in our current predicament and subject, it is important that we follow them for a bit to discover what we have at stake in talking about value, totality and the challenges it imposes to us in the Anthropocene (Wark, 2016b).

The wager of the break between Marx and Feuerbach was a break with the idealistic underpinnings of his philosophy and the legislation of higher concepts onto empirical life without accounting for the allure of social practice and materiality. Althusser (2005:2009) talked of a break but meaning a quite singular thing ${ }^{13}$. For him there was a break between the ideological/scientific that also bracketed what the role of Marxism as theory should be. To understand this, we must understand how Althusser saw the "production" 14 of theory through the concept of "Generalities" (G1-G2-G3). For him, the work of theorizing flows from the concrete manifestations of concepts, often "ideological" ones meaning concepts that depart from the historical present from which one theorizes (G1); then, one applies to those the procedures for knowledge production at the time (G2). From that intervention then emerges scientific knowledge (G3).

In this sense, he recognizes Marx's formulations as a source of scientific knowledge "of what laborers experience everyday: class exploitation" so in a sense theory offers a method able to directly take truth out of empirical experience. He explains this scientific character of Marxism as the opening of a new "conceptual-

\footnotetext{
13 Althusser's was a three folded epistemic break, a concept taken from Gaston Bachelard between the early works, a transitional period and its realization in Capital. For more on that see Althusser and Balibar (2009) "Reading Capital".

14 Production here has none of its Marxist usual value, as Wark (2016b) puts it, it is but a 'metaphor'. The becoming metaphor of production can itself be an interesting thread to follow, just as the way in which production became an analogy for symbolizing processes for example.
} 
continent" meaning the invention of a conceptual apparatus that allows G2 to pierce into G1 and produce G3. As Althusser puts in his introduction to Capital Vol. I, just as the Greeks opened the Mathematics-Continent and Galileu opened the PhysicsContinent, Marx opened the "History-Continent", a ripe terrain in which other kinds of scientific knowledge could emerge, here he cites structural linguistics and psychoanalysis (Marx, 2017a p.39-43).

Subjected to Althusser's pharmakon, we can notice that the aftertaste is a position in which theory and philosophy become the legislators of knowledge. There is little in way of a politics of comradely knowledge with him. Of course, Althusser (2009) does not go as far as claiming to find a kind of dialectical law to nature or anything of the sort, but everything social becomes all too quickly subsumed into Theory and the scientific, despite a different sphere, still stays submitted to the “democratic centralism" of theory (Wark, 2016b).

His neglect of some modalities of materiality that are crucial for the current status of capitalism also may be problematic for our understanding of the world right now: the revolution of the forces of production is seen by him as a matter of a similar content subjected to intensifications but never as changes in their "nature". It seems that those visions would not offer a sharp enough tool for noticing the fundamental shift and particularity of the current place of information and technical innovation in our economy and social life and the entrance of the planetary as a site of concern (Marx, 2017a p.39-43).

Jameson (1992) in his revaluation of Althusser's work apprehends two crucial points: the first one is that this notion of "semi-autonomy between the spheres" has an important implication, meaning that for him this autonomy must unite as much as it separates: to understand how two different fields relate, one must be able to acknowledge that there is also difference between them. From that perspective, for example, the problem is advocating for direct homology claiming that one field merely expresses the other without minding that field's own particularities, presenting a mediator. One example would be claims trying to equal unconscious production of symptoms or images to labor as production. Another would be trying to equate processes of nature as being mere iterations of the laws of the dialectic, for example. Jameson is looking at literature and puts this in terms of "transcoding" as the refusal of submitting every sphere to the same principle, transcoding becomes an 
operation of mediating ${ }^{15}$ the difference between two fields while also showing their commonality.

This is not too far from Bogdanov's Tektology if we take it as a general science of organization that has as its object of study the distilling of practical knowledge acquired or predicated into our labor, our metabolism with nature and our tools into forms and diagrams and then its reapplication/repurposing elsewhere: difference becomes not a sign of disciplinary boundaries but an invitation for the construction of new practices (Bogdanov, 1984; Wark, 2016a; Reed, 2018; White, 2018).

The second point comes through his claim that "History is what hurts" (Jameson, 1992 p. 93) meaning that we do not really experience History as a totality but we encounter it as a constraint, as the "operation of objective limits"16. Those limits are precisely the pieces from which a kind of Necessity emerge, here understood as the proof that there is a potential for another assembling of our current circumstances, for a reorganization of our predicament and for possibilities of speculation. It is not a telos that propels us to a different future, it is the potential we find within our own predicament built retrospectively both through what we think we lost and through the material potentialities in the present from which we can remake our present and project new horizons.

The Planetary and how we get to know it in the Anthropocene can be seen in a lot of ways as an encounter with limits, the encounter with the possibility of extinction being one of them. But beware: limits here are not to be seen in a Malthusian sense as that which was essentially the offspring of a very crude vision opposing arithmetic growth in production to exponential populational growth and predicting limits as merely natural. Engels and Marx already at their time refused those fatalistic accounts and already bound limits to be, not only a function of nature but also a function of the form of society, in specific the form in which production is organized (Foster, 2000; Burkett \& Foster 2016). In this sense, Chandler (2018) is absolutely right in pushing for a connection between the Anthropocene and trenchant anticapitalism: one cannot address the Anthropocene without addressing the question of production head on.

\footnotetext{
15 Of course, Jameson here makes a very specific interpretation of mediation and its role in Althusser. For more see Ch.1 of "Political Unconscious" by Jameson (1992)

${ }^{16}$ I am indebted to this review for the urge to come back to Fredric Jameson's text "Political Unconscious" (1992) to assess how one can read him in relation to Wark's own reading https://cosmonaut.blog/2020/10/12/worse-than-dead-a-critical-response-to-mckenzie-wark/
} 
What we are looking at when we talk about the ways in which value organizes our relation with nature is about two overlapping spheres, one could say of the Global and the Planetary (Chakrabarty, 2018). While they overlap, the planetary is marked by its indifference towards human systems and life. As value organizes labor and it acts in nature, an activity knotting the human and the non-human through technology, complex, open and dynamic systems interact. The trajectories of production and its model of the Planet encounter each other. The challenge of seeing the imbrication of value and nature is one of seeing this overlap without reducing one to the laws of the other, without casting them as totally separate realms and forgetting about their relationality. It should separate as much as it connects without ignoring that this totality is open, provisional and violent (Jameson, 1992).

As Engels already realized, against people in his time trying to understand the whole functioning of the economy through the categories of thermodynamics, the economy and production are an open system, one that denotes an interaction with both human and non-human affairs and whose way of organization can turn to be deeply problematic. An attempt to think about this relation between value as the organizational principle of the economy and how it appropriates and historically frames nature comes through the work of Jason Moore (2015) which I will explore in this regard, taking into consideration some of the implications laid above.

I have chosen Moore's work as a productive field for discussion due to the fact that maybe his account of the relationship between value and nature has had the most appearances within IR, explored by authors such as Stubblefield (2018) and cited in varyingly critical notes by authors such as Grove (2018), Chandler (2018; 2019) and in pieces around the Planet Politics manifesto (Burke et. al 2017; Fishel et. al 2018) as an exemplary attempt of rethinking the relation between value and nature. Also, the fact that his book was received with some controversy among strains of Marxist ecological thought (Foster, 2018; Foster \& Burkett, 2018; Malm, 2018) makes it an unavoidable engagement for thinking production, nature and their intertwinement, be it with or against his claims. This whole trajectory is not only a mere hermeneutic discussion of the Marxian text, but a way of beginning to frame the relationship between the abolition of the value-form and its unique way of wiring work and nature. 


\section{Capital, Abstraction and Nature: Metabolism against the Oikeios}

In this section I critically engage with Moore's (2015) work to reclaim the usefulness of the concept of metabolism. The point in doing so is that I believe that his approach against metabolism generates the kind of problem I have been articulating above, as it incorporates the logic of value too deep into nature and ends up, despite all of its many merits, predicated in an unhelpful conflation that incorporates value into nature all too hastily. Metabolism approaches, I argue, when slightly tensioned, are better equipped to execute mediation, this exercise that "unites-separates" the global and the planetary, humans, machines and nature and that show that production itself is a form of metabolism conjoining flesh, tech and matter in the historically determined form that is value, rather than a hasty incorporation.

Moore (2015) frames a critique to what he calls "Cartesian Dualisms"17, which he recognizes on the dualism between Nature/Society and its offspring. He is challenging the problem of "Green Arithmetic", in which metabolism approaches tend to think about crisis in a way that, according to him, dissociate societal crisis from environmental ones.

For him, trying to understand this conjunction as a neat division is highly problematic as it supposedly reproduces the same kind of relationship Capital has built through nature in which it is external. While I have argued for a political convergence between those crises, what he is arguing is that in fact there is a crisis of capitalism-in-nature. As far as how to tackle it, he considers approaches drawing on metabolism as insufficient because they reify relation between nature and society as separated entities and do not convey how one is made through the other (Moore, 2015 p. 15).

I agree with Malm (2018 p. 134) that, the claim that there is a problem already at this juncture is a misrecognition that an analytical separation ought also to mean a separation of substance, something that does not quite hold for most of the uses of the concept of metabolism (Foster, 1999:2000; Foster \& Burkett, 2016; Wark, 2016b; Saito, 2017:2021 forthcoming; Foster et. al 2018). In fact, this clarifies that the

\footnotetext{
${ }^{17}$ How much ground he really has when tracing those dualisms to Descartes has been also another path through which his work was questioned but that I will not be focusing on. This is better exposed in Burkett and Foster's (2018) response in Monthly Review, with the telling title "Value isn't Everything".
} 
stakes of his own theory ought to be formulated as a full reformulation of a theory of value in nature through a common language that unites this Cartesian binary.

For that Moore (2015 p. 15) works with the concept of oikeios: "the relation through which humans act—and are acted upon by the whole of nature-in our environment-making”. In this sense, civilizations do not merely act upon nature qua external acting but act through it. This introduces climate and nature broadly speaking as a crucial instance of determination from nature to history too, he exemplifies that by mapping civilizational turmoil in relation to climate phenomena such as that between the break of the Feudal system and the Little Ice Age (1300 A.D). Nature for him, and in that specific sense he is also not that far from Marx and other Green Marxists, is also an historical category. However, in particular it stimulates novel readings of history, especially the relationship between nature, production and what Moore calls "epochal" crises and civilizational collapses.

His work interestingly pushes backwards the historical making of what he calls the Capitalocene, seeing it as a culmination of the long $16^{\text {th }}$ century. In a sense, his timeline relies on seeing through vectors of accumulation and their need for cheap nature. Moore (2015) does this through the work of world-historians such as Giovanni Arrighi and Fernand Braudel. One interesting point is that it already sees in colonization (and not only in the Industrial revolution) a crucial beginning of the processes of accumulation, scientific knowledge and political technologies making capitalism possible and emphasizes an already-exploitative relationship to nature that in fact begins crafting a particular concept of wealth (Moore, 2015).

He sees the movements of abstraction (here understood broadly as quantification and management of complexity towards the production of value) inscribed and enabling the organization of economy towards the value-form and its realization through the market as essential to the historical developments of the world-economy. For him in that sense the value-form is predicated on both a "material inscription" and also a "symbolic coding", facilitated through the loop between the changes in the mode of production and the integration facilitated by markets.

In this sense it is not hard to see how he also knots value to production and consciousness and how abstraction itself is deeply related to revolutionary developments in sciences, cartography and others developments. He sees those tendencies for abstraction as not solely confined to the realm production but also in 
governance: he specifically talks about the fact that both biopower and capital are operative through processes of abstraction in which such quantifications happen (Pasquinelli, 2018; Moore, 2015 p. 388).

This does not necessarily need to mean that abstraction is a force to be feared or worked against though, rather, it shows it as a crucial capacity on which Capital is predicated but not its sole owner. It is through this relationship between abstract and concrete within the commodity form that we can observe contradictions between "natural forms" (use value, concrete labor and wealth) sided with their economic “value forms" (Foster \& Burkett, 2018).

One classic instance of that is to be found in automation, for example: while it diminishes the necessary labor time and opens a horizon of a society predicated in a lesser deployment of human work, its revolutionary deployment is fully at odds with the current way the system works. That ascribes not a telos but a form of critique in which one must work through the abolition of the value-form as such, the full rearrangement of our circumstances into different forms of organization, abolishing the historically developed model of totality ingrained within Capital.

The abstraction of value is deeply related to the appearance and socialization of abstract time measurement in modern Europe: the history of mechanical clocks is the history of this movement of abstraction as this item, so pervasive in our lives now, encapsulates the unbinding of time to anything concrete (sun-moon cycles and etc.) and its usage for orchestrating the process of valorization as such. Crucially, Capital and the passage of concrete labor to abstract labor is a function of how it relates to socially necessary labor time: a measure of productivity striving to be lowered and completed more and more outside of concrete constrains. As we will see on the next chapter, machines play a crucial role on this process as well (Postone, 2013).

Capital's relation to time is not only seen in the field of production but also in how it writes and reads History. As Blaney and Inayatullah (2010) show, time appears as the temporality of development or "the translation of difference (...) into developmental time" is crucial for the "so called primitive accumulation" in which the savage can then emerge as the yet uncivilized, his difference becomes passible of being compared to the civilized through building a shared certain developmental time scale. This is of course a move re-enacted through developmental politics, in 
attempts of dispossession happening right now and on violent attempts to "modernize" natives through economic inclusion (Coulthard, 2015).

But not only the abstraction of time is at stake here but also the abstraction of space: the abstraction of space is the transformation of space itself into something abstract and quantifiable through grids and calculations, rendered comparable, equivalent and exchangeable. This is not a process that begins immediately, of course. James C. Scott (1998) exemplifies a roadmap of this process starting with taxation policies of European early states that saw forests through the fiscal lens of revenue needs and their outputs of timber, for example. This abstraction is of course the uniformization and quantification of nature for its capacity to produce output. This is formalized through scientific forestry, the science of the XVIII century that through even more rigorous quantification and intervention for forest management that was then rationally geared towards mercantile values: the concrete forest becomes the abstracted and manageable forest that has as its goal the production of a specific type of wood and is measured and managed as such.

This is of course related to the way labor must become a means of affecting nature crunching it into pieces as it allows for production, reproduction and circulation. Capital's intelligence manages time in every knot of the valorization process, it bends space by finding ways to traverse it be it through building ships to appropriate nature elsewhere, telegraphic lines to articulate information transmission and other artifacts: roads, highways, networks and simulations are all creatures of virtual geographies who are themselves embedded in the circuitries of sovereignty and the nation state, embodied also in the level of the city and of everyday life ${ }^{18}$. The passage from what Lefevbre called Absolute Space to Abstract space (Wark, 1994:2015:2013; Davies, 2010; Moore, 2015).

However, as we have seen in the previous section, any attempt to see how nature is organized by value must deal with two interesting questions: first, how do we account for this interaction between the historic and the natural by respecting their intertwinement but also their non-intertwinement, refusing to see one as a mirror of the other? (Foster, 2000; Saito, 2017).

\footnotetext{
18 An interesting example of that is the gaze of the city planner and his own view at the top of the World Trade Center: from atop, people seem like nothing but little moving dots, streets become lines and space seems orderly and controllable but mostly dead as it ignores the remaking and making of live that goes on in the pedestrian outlooks. For more on that, see Michel de Certeau's (1998) "The Practice of Everyday Life".
} 
Despite being aligned with historicizing nature and as said above and making interesting moves around that, Moore's (2015 p. 379) book locates the question of value as a transhistorical societal question, as in "every civilization must choose what is valuable for it" (p. 378). While one could argue that civilizations render social relations according to their own structures and formations and they indeed organize labor in various ways, value as a main form conditioning consciousness is highly particular and specific to Capital. As Postone (2013 p. 459) puts: "it is value understood as immediate labor time expenditure and not material wealth that is the historical form of wealth in Capitalism", a position Saito (2017 p. 98) echo.

As we have seen, this singular status of capitalism is evident within the commodity form as marked by an internal fission between use-value and exchange value. While use-value is related to the "natural form" and comprises a category under which humans create use values through their own labor, it is exchange value that marks the main standard for wealth creation within Capital. That exchange-value is, of course, merely social and an offspring of Capitalism's that only works through a specific socialization of abstract labor and structuring production around value (Saito, 2017). As Marx (2017a p. 459) puts one needs a "creation by a human hand to consume natural forces in a productive manner", hence this appropriation is always socially facilitated through labor.

Against that, Moore argues that we must understand also how the works of nature are appropriated. This sounds already rather strange but is crucial for how he tries to reformulate value-theory. For him, a crucial feature of the value-form is that it relies on an invisibilization and non-remuneration of labors allowing it to be possible, such as reproductive labor operated by domestic work or of coloniality as the often-hidden condition of possibility for accumulation in Europe. His argument is that the same happens with nature: we only get raw materials, energy and other crucial natural assets because the works of nature that provide them are invisible and unaccounted for (Moore, 2015 p. 379).

Of course, one is only able to see work within nature if one looks at work not from the perspective of it as a social activity but as a physical concept, as energetic expenditure that is then appropriated and trace that it is the appropriation of it that defines value. Note here that he applies the category of work in an almost physical sense, as thermodynamics ${ }^{19}$ would have it, and not of labor as associated to the form

\footnotetext{
${ }^{19}$ We touch on the role of thermodynamics and Capital in Chapter 2 through the thermodynamic
} 
it takes within Capitalist economic organization. Also, that the friction between a natural phenomenon otherwise indifferent to us and its entrance into a valorization chain seems to disappear. Of course, the name of this friction is abstract labor, what we defined precisely as the substance of value (Saito, 2017).

So, this that he calls the work executed by "extra-human natures" is actually an interesting thread to pursue in his argument. The problem with Moore (2015) is that he tries to incorporate value logic into nature too deeply, not as an interaction between open systems but by reifying them all through the language of capital and value and the conflation between labor and work. Nature is read through work so it can be identified with his argument about invisible work that serves as the master metaphor for how he understands the value-form. As for him "value does not work unless most work is not valued" what we have is that this characteristic becomes the overarching truism that allows for the methodological conflation of capitalism-innature (Moore, 2015 p. 54; Foster \& Burkett, 2018).

Once crunched into that mold of being defined by work as mere energetic expenditure it then can be made a part of how value worked as a totality. It was value all along. While one can say that the concept of work is a physical one coming from thermodynamics and one that indeed changed how Marx and people in the XIX century conceptualized work ${ }^{20}$, it becomes hard to take this homology forward considering how it neglects the aforementioned process through which something becomes weaved into the capitalist circuit of valorization. His words on that theoretical move are that it:

Help[s] us to rethink capitalism as a set of relations through which the "capacity to do work"-by human and extra-human natures-is transformed into value, understood as socially necessary labor-time (abstract social labor). "Work/energy" (or potential work/energy) may be capitalized_-as in commodified labor-power via the cash nexus—or it may be appropriated via non-economic means, as in the work of a river, waterfall, forest, or some forms of social reproduction. (Moore, 2015 p. 24)

However, the point is that in fact that extra-human natures are only capitalized on when there is a socialization of them through labor. The process through which a river's work is transformed into energy is indeed an economic one. While we must see that there is a common factor within energy as powering something (a machine made of human labor can replace the need for human strength

engine.

20 An outstanding work within that lineage is Amy Wendling's (2009) Karl Marx on Technology and Alienation. It goes also very well with Foster \& Burkett's (2016) Marx and the earth: an Anti-Critique and their commentary on Wendling's work through a novel translation of Podolinsky's attempt to craft a thermodynamic theory of economics and Marx and Engels opinion of it. 
in a certain job) we still stay with the fact that to capitalize on that natural feature of that material one still needs to enter it in a net of human relations that both discover the usefulness of the energy source, construct the machine, extract and commercialize the oil and organize labor in a private manner. Therefore, the relation between "work" in the physical sense and value is what gets effaced in Moore's theory when he opts to flatten everything into his rhetoric of invisibilization of labor.

This is crucial for his theory of crisis as well: crisis is the growing impossibility of cheap natures to continue to be provided.

In the drive to deconstruct the labor-theory of value in order to recognize the work done by non-humans, it falls in fact in a mistake that was largely addressed by Marx himself during his time in a dialog with the physiocrats. The appropriation of any kind of energy from nature are not the result of any free gifts but only happen through labor, while they are results of natural phenomena, those only become weaved through social relations for their extraction and the labor supporting them (Foster \& Burkett, 2016:2018).

Moore's (2015) claim of natural "work" also ends up wrapping already into value some completely non-human processes such as the formation of natural compounds like as oil and coal, for example. Burkett \& Foster (2018) weight in against Moore's exemplary application of his theory to the "work of oil" as being appropriated as unpaid work accumulate over thousands of years, crucial for a regime of capitalism relying on fossil fuels. However, such an example ignores not only that oil prices are valued through rent based on scarcity, its acquiring is only possible through massive amounts of human labor, often of a highly qualified kind and it only enters our own historical regime through extraction. Therefore, to understand it as work to be appropriated without looking at the conditions of that passage is to resume nature to value all too quickly.

That homology is, at best, shaky in other grounds: oil formation has no human agent at all, it overlaps little with historical time and consists in a metabolic process between, among many other things, organic particles and pressure (Wark, 2015). Seen through the angle of organization, that is, value as a form that organizes production and reproduction, Moore's reasoning becomes even less adequate: the value-form does not directly organize the generation of oil by nature. The generation of oil occurs in a highly incommensurable time-scale. Therefore, homologies between this work and the invisible unpaid labor which on the other hand is 
appropriated for the development of the commodity economy, such as reproductive labor (a form of labor deeply organized by the value-form and exploited even if not recognized by it) are predicated in a very questionable equivalence from the outset (Moore, 2015 p. 71; p. 87).

Also, there is a quite harmful decentralization of human labor at work. The play between concrete/abstract labor and its form within capital all disappear. Abstracting labor towards value production is a form of organizing human energy expenditure and the capacity humans have to interact with matter, one that is shown at odds with any form of sustainable metabolism already through this private character of the labor activity (Saito, 2017).

This incoherence in Moore is mended in the interpretation I provided above through Saito (2017). Labor reappears as energetic expenditure that is shaped by a specific social form but still maintaining its singular character in capitalist socialization.

As for non-human expenditures of energy, let's say how energy generated by burning oil makes a machine work replacing what previously was a laborer. Marx's engagement with thermodynamics and the social movements of his time in fact sees the potential within machines to execute work as energetic physical activity and adopts labor-power as a category directly influenced by it (Wendling, 2009). However, this did not mean that Marx was abandoning the social towards the energetic. As a matter of fact, the opposite is true as Marx struggled and debated harshly attempts to executing this theoretical replacement for creating a supposedly ecological economics.

Note here that, as a homology, if we submit it to the critique we already seen in Jameson (1992) above, we are let with little more than the overstretching of between natural processes and human processes. There is no attempt to show their conjunction in terms of union-separation but rather a collapsing of nature into value as the core of social organization, one that leaves both of these interacting but asymmetrical spheres harmed in the process.

I fully agree with Moore (2015) when it comes to the need to recognize the strains of invisible labor that render possible the constitution of Capital, as the genealogy of slavery and colonization, or domestic and reproductive labor, that despite not being recognized as such, definitely are predicated in huge expenditures of and facilitated by many social structures make possible the process of valorization. 
I also do not deny the known relevance of the concept of energy for Marx's theory of labor, one that maps back to his engagement with thermodynamics and in which he fully recognizes the material dimension of labor as energy expenditure. Amy Wendling (2009 p. 82) explored quite well in her book how those were a crucial scientific development for Marx, changing the way he saw crisis, labor and perceived his own materialism in relation to the sciences of his time ${ }^{21}$.

What I am arguing is simply that, the way Moore (2015) advances his argument about energy effaces the difference between concrete and abstract and that it risks incorporating value into nature all too quick, making nature fit into the axioms through which he reads the law of value.

I believe those problematic conflations could be avoided through the concept Moore himself rejects, metabolism. Moore (2015 p. 84) warns against the seductiveness of metabolism as a metaphor as it promises to dissolve the binaries between Society/Nature but "Rather than ford the Cartesian divide, metabolism approaches have reinforced it". Marx's “interdependent process of social metabolism" became the "metabolism of nature and society". Seeing that the nature of the concept of metabolism neither as deployed nor in Marx supposes a substance dualism, it does not have to be like that. As a matter of fact, maintaining this analytical distinction is desirable not to collapse processes of one as fully determining the other.

I follow McKenzie Wark (2015: 2016) in this when she says that the point is not to take metabolism as a metaphor, but literally: as a speculative insight from Marx, from the globalization of Capital as a regime to the vision of the Planet as a whole interacting organism with its own frames of non-linear and complex causality, its own metabolic rifts.

Sticking to what Moore calls the "metabolic fetish", in this light, pushes forward a metonymical vision in which the labor process as those partial interactions between human, technical apparatuses and non-human become constantly entangled and can be analyzed not only as parts that must obey the law of the whole (value) and its narrative of invisibilization but also through their radically variable appearances and degrees of influence (Wark, 2015). Metabolism also can cover the relationship between phenomena at the molecular level and at a broader perspective

21 A critique of Wendling can be found in Kohei Saito's (2017) Capital, Nature and the Unfinished Critique of Political Economy. That Marx was deeply engaged with the relationship between the economy and the developments of science and technology of his time is an uncontestable fact, in spite of their divergences regarding exactly how this relationship was grasped. 
i.e: claiming not the work of oil but the relationship between the scientific process through which oil emerges, its social incorporation and the metabolisms of the economy without collapsing one into the other.

Metabolism offers a more interesting account, connecting our very human affairs to what Chakrabarty called the planetary but without subsuming one to the other (Wark, 2016 p. 10). This is far from a deviation of the concept of metabolism (Stoffwechsel) in Marx and how it comprises the inflection of economic forms (Formwechsel) into matter (Marx, 2017; Foster, 2000; Saito, 2017). Taking the simplified M-C-M' scheme above, metabolism is the observation of the inflection of the realization of that scheme, written through highly abstracted forms through matter. As Saito (2017 p. 73) puts, having in mind both the Grundrisse and Capital, "Marx's original methodological approach treat[s] the objects of his investigation from both "material" (stofflich) and "formal" (formell) aspects".

What Marx already was grasping, as Saito's (2017) systematization above makes clear, was how capitalism was predicated into a deeply unequal relation to the environment not by mistake but by design. Its rhythms of pushing towards the lowering of socially necessary labor time, its effects on the body of the laborer, its need for constant appropriation of cheap natures through cheap labor, the commodification and the overspread exhaustion of land ${ }^{22}$. Namely, the tension between the economic cycle of valuation and its material grounding is one that emerges in many ways but particularly for the private nature of those labors, it is rationally planned.

It is this play that is collapsed into the homogenization of work in Moore (2015). Wark (2015) is right when she charges Moore (2015) as being stuck in a correlationist $^{23}$ circle of sorts: a correlation is an arrangement in which a subject is always presupposed in order for an object to be known. Metabolism, on the other hand, allows for a methodological tool that works without the need for the metaphors of value onto natural processes through a "metaphorical doubling" that

\footnotetext{
22 A curiosity that shows this dependency is that a crucial commodity for agriculture is the commerce of guano, a mineral which is made by the solidification of birds and bat's feces, used as a natural fertilizer to mend some of the metabolic rifts. Marx's interest in Justus von Liebig's work on agricultural chemistry was particularly focused on the social consequences that could come out of the possibility of systematic usage of fertilizers which rendered natural limits as flexible and transposable. ${ }^{23}$ For more on that, see Quentin Meillasoux's (2009) “After Finitude” trans. Ray Brassier. Audra Mitchell's (2017) article also touches on the critiques of correlationism relating them to the kind of openness fostered by the Anthropocene.
} 
must see nature fully integrated recognizing it as always producing ${ }^{24}$ and making the homology we have been discussing and the silences it brings (Wark, 2015).

Instead, it endorses an approach relating complex systems with one another, connected in ways that already disturb the border Society/Nature. This approach allows us to account for them in a way in that stresses not the symmetrical doubling and then integration, but the interactions between parts and wholes, without collapsing one's order into the other, but understanding their relation ${ }^{25}$, something mapping neatly to what we discussed in the section above regarding mediation and the refusal of direct homology (Wark, 2016a).

The Anthropocene now appears grounded as a "series of metabolic rifts", caused by this relationship between the economic and natural forms, one facilitated through the often-unconscious embodiment of value as a molar principle of organization. Capitalist production is thus the abstract organization of a specific form of social wealth production that generates a planetary metabolism binding human, technological apparatuses and nature, minding all the porosity between them, and that materializes as a series of metabolic rifts.

In this way, the relationship between value and nature are still entangled but without reducing one to the "law" of the other. We can, crucially, reconcile the importance of the labor as energetic expenditure within Marx's work while still retaining the play between concrete and abstract within value minding its historical specificity and also the gap between the global and the planetary and their organizational principles. It does also, at last, recognizes a crucial part of the Marx \& Engels' insight brought about by thermodynamics: a materialist vision of history can only be one that sees the economy as an open system, something that the metabolic in its capacity of seeing parts and wholes as deeply integrated but not merely echoing the exact same logic are better equipped to do than Moore's solution (Burkett \& Foster, 2016).

\footnotetext{
24 Ontologizing the category of production has been a common theoretical move and an argument some raised in different manners such as Deleuze \& Guattari in Anti-Oedipus and Negri's praise of living labor and the creative potential of the multitude in his later work. That, of course, leads to many theoretical and political problems. For a discussion of Negri's work see Gabriel Tupinambá's (2017) "The unemployable and the generic".

25 A different solution is given to this problem by the works of Foster, Burkett and Saito. I join McKenzie Wark in here first because of her focus on the question of knowledge and its reorganization and second because I believe that she does a good job at accounting for the schism between the molar organization and the molecular experience of the historical present, while still not subsuming everything under the principle of value. More on that on the next chapter when approaching labor and technology.
} 
Despite directing some criticism towards Moore (2015) I should say that his work is insightful, in particular, when it recognizes that the stability of this form of organization (value) is predicated in an arrangement that always tries to drive nature towards cheapness. Also, that this helps reviving accumulation in specific sectors at the expense of the environment, in particular as it allows for lowering the organic composition of capital (the ratio between fixed capital such as materials machines and wage-workers) as a whole, at least for some time, by opening an influx of a certain important raw material such as energetic compounds that might have effects throughout the economy (Wark, 2015).

He emphasizes, specifically, four of those cheap natures: labor-power, food, energy and raw materials. In that list we have a circuit that takes us from the labormarket, its conversion into the possibility of buying goods for social reproduction, the extraction of energy from materials from nature on which both social reproduction and production rest and, lastly, the hunger for cheap raw materials on which our own industry is so predicated (Moore, 2014:2015).

Mckenzie Wark (2016c) is quick to note another "cheap" becoming crucial for accumulation, that is, the cheap of information, made right out of the movements of production and reproduction often turned into commodities, the transformation of many activities of leisure and existence transformed into unpaid labor. The businesses of this economy revolve around logistics, branding, digital storage services and etc. are all enabled by a deeply intricate mesh of networks, materially assembled around the world and forming another layer of interconnected geography that enables both novel forms of valorization and are also predicated on certain vectors of appropriation (Wark, 1994; Pasquinelli, 2017).

This vector of unpaid work is not tackled enough by the commodification of information, often cast as the appearance of a new economy that spells a crucial place to see its new developments. This new economy did not quite get its due in this chapter and is often cast in terms of overcoming many of Capital's contradiction or of forming a "new" economy that represents the future. In the next chapter we see that information has a deeper story, it is not a novel capacity but has been present in the history of capitalist development.

For that, we turn to Grove's (2019) attempt of theorizing the relationship between what he calls the Eurocene and the effect that a supposed European trajectory of technical development has for understanding the Anthropocene. We 
analyze machines as a historical category that materializes a certain division of labor. The machine will appear as an apparatus mediating the metabolic process of production. This apparatus materializes both a condensation of divisions of labor and a relay between energy and information. Machines will help us both to elucidate these two economies, the industrial and the "post-industrial" economy and synthetically look at historical movements of capitalist development that influence our present. Doing so, we counter Grove's (2019) slippage into viewing technology as a mere expression of a certain view of matter, showing how those machines mediating production are a crucial knot for understanding shifting relations of production. 


\section{Chapter 2 - Cyberfossil Capital: Machines, Energy and Information}

In the previous chapter we focused on opening the realm of production to criticism in the Anthropocene, respecting its imbrication with politics rather than distilling the political as the upper layer from which theory sovereignly legislates. I sketched two points: first, how does one look at value as an organizational principle without solidifying it into an explain all category by showing value as a non-enclosed way of organizing different realms. Second, that understanding production between History and Planetarity should stress the non-symmetrical feature of these realms which meant not to collapse the logic of one merely into the other.

To perform such a particular way of uniting/separating I introduced the concept of metabolism. I also signaled, in passing, the problem with reducing labor to mere energy expenditure without looking at the difference between wealth and value and the meaning of abstract labor as a form of organized human energetic expenditure. I also elaborated on the historical determinacy of capital as a mode of production and metabolism, a historically specific organization binding human, technical and non-human elements.

Lastly, I ended with the brief recognition in Moore's terms of a "new cheap", information, and the question of how to read this "new" informational economy and its relationship to the old industrial economy. Completing those lines of thought in Ch. 2 is what will lead us to the core of our main objective: stitching the question of labor into the fabric of the Anthropocene.

The hook from the last chapter into this one lies in the theoretical connection between labor in capitalism as socially specific form of metabolism and understanding how it is mediated by technology and also on the very immediate need for building a narrative that might help us to understand our current predicament, in particular the role of information. Both McKenzie Wark (2016a:2017) and, even more overtly, Matteo Pasquinelli (2008:2017) have emphasized that, in order to understand capitalism in its current iteration and its metabolism with nature (of course, nota bene, Wark [2004:2012:2016:2019] has been in fact claiming this is not even capitalism anymore, but something worse), it is crucial that one understands the relationship between the industrial and the digital economies, the "Carbon" and "Silicon" economies and their conditions of possibility. 
While we live amidst an era of both rampant underemployment, unemployment and environmental crises, the concept of Cyberfossil Capital will serve to us as a navigational tool for tracing a synthetic history of how machines are imbricated in multiple forms in capitalist development.

For Pasquinelli (2017), this means recovering the way capital manages both energy and information historically through technical developments in machinery. $\mathrm{He}$ proposes that the industrial revolution is predicated in a fundamental split between energy and information that is deeply related with changes in the division of labor and that the management of those flows deeply inform how capitalism manages itself and some of the rifts it causes.

In this perspective, Capitalist production appears as a historically determined way of managing flows of energy and information through machinery towards the production of value, such a way of reintroducing energy (and information) into the construction and understanding of the Anthropocene, while trying not to lapse into the limits I have already highlighted as problematic within Jason Moore's (2015) arguments. Management is of course generative of the material predicament we call the Anthropocene and also illustrative of novel political and economic relations.

By energy, we are talking about it in the physical sense, a concept which Marx confronted through his engagement with thermodynamics and the movement through which machine's motion was increasingly predicated by the energy liberated by driving lumps of coal and less by brute human force. In a broader sense, we are talking about the energetic regimes that sustain productive activities and also activities of social reproduction.

Information is considerably more dubious but it will be used in two senses, which will be developed in the text. The first sense is information as a weak energy modulating an energy that give form to matter i.e.: what the worker imprints through his skill in the means of production on the basis of practical evaluations, measuring and elaborations to modify matter which is effected through applying very small and located amount of energy (Pasquinelli, 2015 p. 3). The second sense is more general, as the transmission of, for example, a message from a sender to a receiver.

The general purpose of this chapter is to weave a synthetic narrative of the Anthropocene through the prism of regimes of energy and information as a way to see changes within capitalism through technology and better understand our current predicament in this relation between the industrial and the digital. The machine 
appears here as a mediator of metabolism and also a diagram for changes in the social division of labor. Following Pasquinelli (2015), we analyze paradigmatic technical changes and their effects and see technology not as expressive of any social essence to be fought against but tensioning them between the potential they have and the need for abolishing and remaking them. Seeing energy and information in the construction of capitalism might help us to understand the commonality between struggles for labor and struggles for the environment and how they relate to the organization of production.

My efforts begin by looking at how technology is talked about in connection to the Anthropocene. For that, we look at Jairus Victor Grove's (2019) book and how he frames the crucial point of recovering non-western approaches to living and technology. However, he still remains within a problematic frame, for his approach to technology reduces it to an expression of Eurocentric ideas about matter. I perform through his work a recentralization of the question of labor and production qua metabolism.

Then, we move to recovering how Marx develops the question of machinery as it condenses the division of labor and argue that the machine is a relay between information and energy. This means a separation between the form-giving gesture and the energy propelling it, the plugging of a tool into an engine. Such a separation crystallizes diverse sets of knowledge and allow for more and more complex forms of management of surplus-value extraction opening an epistemic rift regarding this separation of knowledge embedded in machinery and how the worker comes to encounter it solidified.

After that, my exposition follows three main scenes that illustrate "breakthroughs": the thermodynamic engine in $19^{\text {th }}$ century England to explain how fossil fuels became crucial for capitalism and are embedded in the process of valorization; electricity and communications as infrastructural changes for materializing a particular stage of global capitalism which are elucidated by the Turing Machine; and the cybernetic management of the Olivetti factory.

Lastly, we look at our present equipped with the tools we assembled, to what Pasquinelli (2015) says was a crucial development within the information machine, the split between data and metadata in a world of global computation. We end sketching a plea for different technological imaginations, located between seizing and repurposing capitalist infrastructure, rupturing with its essentialization as containing 
any sort of transversal essence. This builds a bridge allowing us to move towards questions of the possibilities of reorganizing production.

\section{The Eurocene: Technology and Nature between Forms-of-life}

As we saw on the previous chapter already, the Anthropocene is apprehended through a path that is deeply intertwined with the latest technological developments, of a type of technology and arrangement of material circumstances that Marx could not even dream about. The Anthropocene is, above all, an epistemological achievement made possible through computation in all its historical intertwinements.

An interesting account of technology and the making of the Anthropocene is to be found in Jairus Victor Grove's (2019) book Savage Ecology: War and Geopolitics. It is an inspiring work that will probably resonate for a long time within the discipline of International Relations and beyond its confines as well. It weaves together many strains of contemporary theory for the Anthropocene and connect them in a highly original manner. While its main goal is to develop a "martial genealogy of the Eurocene" it goes far beyond this objective as it skillfully conjoins questions of politics, economy and technology.

I want to argue that despite all its originality, Grove's book has slippages towards an idealistic account of technology in which it becomes merely an expression of a cluster of ideas that effaces the shifting social ground making them. Now, I want to render clear the fact that my way of reading Grove's argument is an oblique one: as far as security is concerned, I cannot discuss the implications of his formulations in the terms of the field to which they are aimed primarily. Rather, I will read the way he portrays technology having in mind my own task of this chapter of portraying the genesis of "Cyberfossil capital" while still trying to represent his overall argument in a succinct way. I believe such a reading is coherent both with the text's breathtaking range and the author's clearly transdisciplinary ethos

Grove's (2019) argument travels many paths but one could say that its core lies in making a critique of Geopolitics as a project of violence underlining the pursuit of an "European" form-of-life at the expense of others. A form-of-life for him is a way of collectively being in the world as a mesh of both human and nonhuman elements. He makes a case for the affirmation of forms-of-life that run against this homogenizing drive and have survived the onslaught of the Eurocene. 
Those involve particular technologies, sets of knowledges, affectivities and norms that have both survived and opposed the violence of global geopolitics.

Entangled, geopolitics and the Anthropocene emerged together politically, geologically, discursively, and violently. Concepts make worlds and planets make concepts. And the crazy assembly of technics, persons, habits, places, spaces, microbes, meaning, sensibilities, and economies, all known as politics, savagely distributes "who gets what, when, how." (Grove, 2018 p. 47)

I want to outline how climate change, species loss, slavery, the elimination of native peoples, and the globalization of extractive capitalism are all part of the same global ordering. That is, all of these crises are geopolitical. (Grove, 2019 p. 38)

The trajectory of geopolitics is, succinctly put, a project that is predicated in a constant drive towards homogenization, which he understands as the interruption of forms-of-life in multiple ways. Interruption is not only annihilation or direct violence but can also be "making them play roles in which they do not recognize themselves" (Grove, 2019 p. 4). While Grove recognizes a kinship between life-work-war through Darwin-Marx-Clausewitz as one fundamental for understanding modernity, there is still an aftertaste of the primacy of the political in some of his formulations, as I hope will become clear.

Homogenization is understood as, first, the construction of a vision of the planet as a "cybernetic whole" and the attempt of transformation of the planet into the map, the erasure of difference towards a global project of expansion (Grove, 2019). The emergence of geopolitics is, for him, a way of global management of life and as such is interested in erasing and interrupting particular forms-of-life ever since 1492 , the making of the globe into an operational space and its colonial background. In that sense, what he offers is an elaborate geopolitical narrative of the violent universalization of what Chakrabarty (2018) called the global but looked at, this time, through the prism of geopolitics and some of its economic and political entanglements.

One of his points is that often the Anthropos in Anthropocene forgets about the historical making of our predicament and that it ignores how the geopolitical was always geological in the first place. For him, while scientific discourse lumps together Anthropos as a single "genre of the human" and begins to push for the urgency of a "technical" fix, it is actually complicit with the existing frame of geopolitics and violence, perpetuated for 500 years and having a deeply ingrained Eurocentric core. In a summarized manner, the Anthropocene often relies on a discursive move in 
which we are led to beg for a hegemon rather than see the link between the trajectories of geopolitics and our predicament (Grove, 2019 p. 43).

To address those erasures, he puts forward the concept of the Eurocene:

"The Euro of the Eurocene designates a vanguard among the European people who developed a distinctively mechanistic view of matter, an oppositional relationship to nature, and a successive series of economic systems indebted to geographical expansion." (Grove 2019:212)

Let's linger on the Eurocene a little longer. In this excerpt, we can see many layers of what the Eurocene as his key category might entail. The exposition starts from a "mechanistic" view of matter, tethered to how do human and non-human entities interact and portray nature which we could more or less connect this to the organization of labor and technology; the second part is a discursive mobilization of how the barrier between the human and the natural is pushed forward which is both seen in terms of a cultural belief that humans might not be a part of nature and that nature is merely a boundary to be overcome; a third level is where he signalizes the relationship between the economy and a certain geopolitical regime, the incestuous relationship between accumulation and the nation state in the offset of "Europeanization" (Grove, 2019).

My concern lies with the translation of a view of matter into an actuality through technology by an economic system. There are two particular sides to this:

It is important to take seriously that other technological lines of development have been marginalized, even driven extinct, not because they are less functional or less innovative but because a particularly abstracted and mechanistic view of technology grounded in Western Enlightenment got lucky. (Grove, 2019 p. 197)

To explain how a primarily defensive weapon with an ancient past became dominant in contemporary warfare requires that we break from the developmentalist account of technology. Such accounts start with a simple version of any given device that is then refined or innovated to become more sophisticated (...) Following Simondon, Félix Guattari inverts Martin Heidegger's thesis on technological thinking, arguing that it is the machine that demands of us the question of technology, not the other way around. So rather than a general question of technology, "for each type of machine, we will propose a question, not about its vital economy - it's not an animal-but about its singular power of enunciation ... [its] specific enunciative consistency." This is the problem to be addressed. What is an IED [Improvised explosive device] if it can be seemingly anything? We are looking for its "enunciative consistency." Therefore, to account for the emergence of the IED as a kind of consistent effect, there has to be an explanation of the world that emerges with this technical object. (Grove, 2019 p. 119)

We must note that those quotes operate at two radically different scales: while the first one operates at a higher level of genericity, the second one operates at the specific aim he has of analyzing a certain technical entity. However, in those two 
quotes read closely we see two ultimately clashing views on the causal pathway of technology.

Technology appears as either a mere expression of "Enlightenment rationality" and, in that sense, all the forms in which it appears are merely different iterations of the same homogenizing drive. Or, we get technology as being analyzed as a conurbation of flows that both respond to a certain world, but also create a new one through the same process whereby they emerge. It is with the second view that Grove really thrives and is able to make an analysis that renders porous the dichotomy between the form and content of technology stressing both their relationality and inseparability. ${ }^{26}$

What this slippage between one approach and the other make explicit is the difficulty of speaking about technology without subsuming it into a static narrative from which we just craft a linear line knowing by looking at the present how it will end. The story of technology is one of the condensation of societal changes driven all at once, of virtual potentials becoming actualized. It is counterproductive to analyze technology as if its form may change but it keeps still an unwavering content that is represented by a conception of matter and for me that renders the Eurocene itself a somewhat odd concept, sharper for stressing a certain frame of imputing responsibilities than as a tool for clarification. Elsewhere, Grove formulates:

\footnotetext{
"Modes of production, like modes of war, are more like abstract machines than structures. That is, as forms or attractors, capital and war intensify tendencies rather than constricting possibilities for mutation and change. The Eurocene emerges out of a particular, contingent, and singular ecology rather than as the inevitable outcome of superior technology, or some banal argument about human nature and the will-to-power." (Grove, 2019 p. 81)
}

One could add a third element in the list formulated in the quote. If the Eurocene is to be coherent with the fact that those are "tendencies" and not expressions of a certain view, it must ditch any slippage that reduces technical developments to the expression of ideas. Now, there is nothing wrong with saying that there are certain tendencies in the development of global capitalism and of geopolitics and that they overlap with modernity, particularly with the modes of value as wealth and the social forms it spreads (Blaney and Inayatullah, 2010).

\footnotetext{
${ }^{26}$ This breaching is one that is necessary if one is to pay his respects to Simondon's (2020) insights on the technical object. Marxism itself has been accused of being a hylomorphic doctrine in which labor in its form-giving capacity would merely crunch nature and in which technology appears as but a restriction of the capacity of invention. In Grove (2019) invention inhabits what he calls extramodernity.
} 
Nevertheless, it still must be recognized that those ideas themselves are highly mutable and modified through the encounters in which modernity is predicated and through the different ways in which modes of war and production interact. Failing to overcome this form of expressive causality is to transform the openness of a play of tendencies into the determinism of a trajectory.

It paints a picture as if technology merely trumps the technologies of other forms of "life", often downplaying the crucial role that the incorporation of those other technologies and techniques have in the building of that artificially "unified" trajectory. Now, this is somewhat eclipsed by Grove's (2019 p. 43) wary approach to "western" technologies as he puts "homogenization" as inherent to them. This pairing between western technics-homogenization is how Grove (2016:2019) means to talk about both the advances of capitalism as a system predicated in geopolitical violence spreading modes of social and economic organization and also of the effects of the operation of that mode of technology.

In fact, while he is right to say that technology may threaten cultural boundaries, stating an identity between the homogenizing thrust of the geopolitical enforcement and the effects of a certain type of technique as always expressing homogenization is an overstatement. It ignores that, while those technologies threaten other cultural visions, they are never so seamless, they create new kinds of differences, what Mckenzie Wark (2013) calls antipodality, novel relational spaces brought forth by the connection of our world by communication networks that destabilize and re-instate different differences.

He insists on the legitimate need for opening ourselves up to neglected technical trajectories. In this, he is absolutely right: those alternative lines of technological development offer indeed a possibility for practices of comradely knowledge, work and politics that are often neglected by strains of "futuristic" theory.

Still, setting a 500-year trajectory of technical development seems to reach for a unit that is not really there: it confuses a vector of accumulation and spoliation with the existence of a single technical trajectory expressing the essence of a certain lump of ideas rather than looking at its own development through the prism of organization and precisely at how this main trajectory would never have developed itself without also the expropriation of knowledge and its repurposing. 
Let's compare his solution with Chakrabarty's (2000) History 1 (H1) and a History 2 (H2), meaning, in short, that $\mathrm{H} 1$ entails the totalizing thrusts of capital while $\mathrm{H} 2$ is the ever-present resistance and failure of incorporation. Translating Grove through this frame we would have some sort of Eurocenic Form of Life 1 and Plural Forms of Life, the first with a specific homogenizing technical trajectory and the others with each their multiple technical trajectories, even if he grants that there are recessive traits in the Eurocenic Form of Life.

While Grove escapes the threat of translating difference into historical developmental time and accounts for the coevalness of different forms of existence into our world (something that Marx himself does in passing) ${ }^{27}$ he dislodges difference to the question of ontology in the meaning pointed above: no longer difference between approaches but now difference between forms of life, cosmologies and their successive "ideas of matter", ideas that make new social relations spring as if by magic (Inayatullah \& Blaney, 2010; Grove, 2019).

A model like his, in my view, can be assessed through two angles. First, a good thing is that differently than the critique Inayatullah \& Blaney (2010) make of Chakrabarty's split between $\mathrm{H} 1 / \mathrm{H} 2$, for Grove those alternative forms of life which share the world can actually not only interrupt the thrust of H1 but they already do so as potential places of ongoing survival. What he calls ratio feritas stands precisely for attempts of not foreclosing other futures. He also pushes his concept of forms of life beyond the Anthropocentric confines to also forms of knowledge disclosing the possibility making non-human entities and their practices "comrades" in a very interesting way, offering "possibilities of mutation" (Grove, 2019 p. 9: p. 56).

Interesting also is his option for both a form of realism and a form of perspectivism in some dialogue with the authors from the ontological turn ${ }^{28}$. Grove (2019) associates ontology with modes of living often conditioned by different ideas and practices held by a certain form-of-life. He often conflates a form-of-life with an ontology and the way those empirically manifest in the world.

\footnotetext{
27 A brilliant discussion of this, stressing very fairly also the vacillation with which Marx treated those themes can be found in the Chapter on Marx and the coevalness of different historical forms in David Blaney and Naeem Inayatullah's (2010) book, Savage Economics.

28 The ontological turn is a movement in Anthropology which comprises many figures and that has propelled both crucial interdisciplinary debates, particularly with philosophy, and also an array of new ethnographical practices. For a mapping of the stakes within it, see Eduardo Viveiros de Castro (2014) "Who is Afraid of the Ontological Wolf", available here https://sisu.ut.ee/sites/default/files/biosemio/files/cusas_strathern_lecture_2014.pdf
} 
As Graeber ([2015]2016) puts, this is a different reading of that ontology, one that does not quite take the traditional as the project of formulating a unified discourse on the nature of being. Rather, there is an understanding of ontology through a modified meaning, akin to modes of existence or forms of life practically articulated. Those embody different experiences and understandings of nature and discursive mobilizations regarding the nature of the being-in-itself that appears closely related to one's culture.

As we can see, such a move understood in the context of Grove's (2019) work lumps together the prerogative that a discursive mobilization of what matter is turns into the determinant factor of how a society works. When the said conception lies outside of what he deems the capitalistic "mechanistic" conception of matter, it forms an opposition. The obverse side of such a project lies in the affirmation of "other ideas of matter" and though ideas are pointed as related to practice, there is still a lingering taste that the social procedures of a society are determined by the idea it has of itself.

The implicit ontology of this move, that I above deemed as an idealist slippage, is precisely an ontology in which ideas determine reality, dangerously close to classical idealism and far from the actual cross-fertilization of knowledges and social forms being incorporated that characterize modernity. It erases the traces that other cultures and encounters have with those ideas: to pose an entirely western science or technique ignores not only the bulk of science being produced throughout the world right now in places that disturb the almighty western frame, but also downplays the value that encounters with other forms of thought had in materially making the ideological construct one knows as "western science" (Graeber, [2015] 2016).

Graeber's ([2015] 2016) own solution is one towards an anarchy of epistemology and one ontology which makes a lot of sense for me. By trying to maintain a language that juggles both many ontologies and many epistemologies but still claims to be idealist, I take Grove's slippages ${ }^{29}$ into an "idealistic" view of technology to be illustrative of that tension as a technological trajectory must be made to fit a unified cluster of ideas which is as fleeting as it is undermines his own purposes, performing another register of the homogenization he criticizes.

\footnotetext{
${ }^{29}$ Mind the term, as it is not my point to seem he is systematically repeating or labelling him as an idealist tout court. Rather, I am merely attempting to work through the oscillation.
} 
Nevertheless, the book offers a powerful plea and a methodological clue about the need for making alliances between species and between genres of the human, other forms and practices of existing with nature. While his conceptualization of technology sometimes errs close to an idealistic frame, I consider those a mere slippage and his theorization, nevertheless, fertile. His account of capitalism also errs in the same way between both a main structurer and a mere iteration within the Eurocene, an ontic sphere devoid of the primacy of the geopolitical. In that ambiguity, I, naturally, veer more towards its role as a structurer as I highlighted through my reading of Jameson and Althusser.

His rendering of the Eurocene as a unified trajectory is problematized by himself in some manners. Throughout the book he claims that he is aware of fundamental contradictions within the Eurocene but it appears in its most telling form in a commentary before the book's release. I will illustrate that with two of his quotes:

It was a European elite that developed a distinctively mechanistic view of matter, an oppositional relationship to nature, and an economic system indebted to geographical expansion. The resulting political orders measured success by how much wealth could be generated in the exploitation of peoples and resources. The geological record bears the mark of this European assemblage of hierarchies. Understanding the forces of Europeanizationthe forces of racial superiority, economic hegemony, and global resettlement-is essential to understanding how the planet got to this point, and how "we" could possibly become democratic

(...)

The Eurocene is not perpetrated by all people of European heritage, many of whom oppose the existing geopolitical order-myself included. This distinction-between being European and being an agent of the Eurocene-only intensifies the need to rethink democratization as demanding a politics of inequality rather than a politics of incorporation. (Grove, 2016 n.p.)

All in all, there are two problems: the first one is that there is all over again the arrangement in which views of matter are what structure the way economic activity happens rather than their mutual influence, the play between matter and economic forms. The threat here is that by emphasizing "forms of life" there is a slippage towards idealism in the way to understand this vector of modernization and spread of capitalism and an attempt to use the modernization of a form of life as the aggregated and more fundamental narrative, as if capital is a mere layer.

There is also a conceptual haziness lumping Capital as a vector of exploitation that renders operationalized an idea of matter while neglecting what Postone (2014) called "abstract social domination", as a structurer of consciousness and a diffuse real abstraction and how said ideas update themselves together with historical material processes. While both categories are equally important, if one 
focuses only on the first, we end up with a moral critique of bourgeois exploitation, the same kind which Marx himself debated against, only this time rehashed through a critique of colonialism.

It remains telling also that there is a resurrection of a certain attempt to look at the imaginary of an exploitative elite that actually "develops a view" consciously as if the view precedes the actual movement of things, its existence as a diffuse structure of domination and of the allure of materiality. If we note that the Eurocene does not claim all people from the same space are working towards a goal but a view of matter which supposedly is European-branded and carried out by an elite while opposed by Europeans, it seems as if we lose sight of labor. Not only of labor as what obviously makes technology but of technology as being a crystallization of the real movements of the division of labor. If the bourgeoisie are such an elite, we get a bourgeoisie that is both the inventor of a view and moved by whim, sadism and a thirst for accumulation. As Kapoor (2015) puts, the bourgeoise is not the creator of the cruelty of the world but it's often unconscious operator: neither whim nor all too powerful elites but a structure of abstract domination, value as socially determined form of wealth, cognition and social mediation.

All that being said, I want to perform a conjunction with Grove, a Bogdanovite comradely blood transfusion, if you will: the point for me is rather to see forms of life as forms of metabolism. Technologies are both facilitators of metabolism and made through it, forms of mediating the human and the nonhuman, apparatuses for production and organization. Nevertheless, those are culturally different and what one calls the human and nature are constantly changed throughout the process, both as how they are mobilized discursively and materially (Wark, 2019). As Grove (2019 p. 17) claims: "All encounters are a sensuous process of labor with the world and not before the world or after it.". Here, Grove sounds a lot like Donna Haraway and for that matter a lot like the Marx encountering the concept of metabolism.

I would rather look at capitalism simply as one way to organize technology towards the production of value, producing uses that both conform to its goals but also exceed them in a lot of ways: technology is nature cooked up with labor in certain historically dynamic forms. It offers no truth or idea behind it to be revealed by the imperial decree of Theory. What it offers are its uses, its consequences appear not as the unfolding of a theoretical essence ingrained in the vector of modernity 
but as the unfolding of the relationship between the concrete and the abstract and the social practices they articulate, right at the knot between politics and economy, reverberating in both of those fields (Wark 2019).

Technology is a result of multiple forms of labor and of social conflicts over its form and what it may look like and that it not only seeks extraction of value per se but also strategically tries to disempower workers and reflect other relations of power and domination locally and globally. Technology is in short what one makes in interface with nature but also to interface with it (Wark 2019). This reading slides naturally into Inayatullah and Blaney's (2010) attempt to ground the coevalness of different forms of life through the way Marx pictures labor as the metabolism between humans and nature. It invites us, when taken together with Grove's (2019) and Wark's (2019) insights to claim that technology and techniques are at the center of how humans relate to nature in a way that it remakes both what the human means and also what nature historically ought to mean across different forms of life. Maybe labor as metabolism with nature could be fundamental for setting a generic category that Marx was trying to push forward as a comparative convergence between different forms of life and for how they can be built in the Anthropocene, but this line of thought must wait until Ch. 3 (Wark, 2016a: 2019).

The problematic slippage happening with Grove's (2019) summed up, as we have explored, is that it sometimes makes machines and technology an expression of content that appears to be almost impervious to historical time and sensuous experience: the mere expression of a certain cluster of ideas. They are cast outside divisions of labor, social tensions and fill the place of being the expression of a principle set by modernity as a main movement of giving form to the world.

Now, we are set to look at tendencies in the development of technology, labor and the development of the forces of production. First, we go by looking at and beyond Marx and how he saw what at his time was the question of machines. Then we set to recover how the machine organizes those flows of energy and information, manual and intellectual labor, inside and beyond the factory.

Grove talks about how in the $18^{\text {th }}$ and $19^{\text {th }}$ centuries one notices a change in terms of the management of the masses and how those imposed needs for different forms of ruling life, work and war. Those entangled shifts make "Darwin, Marx and Clausewitz (...) the ruling trinity of the nineteenth and twentieth centuries." (Grove, 2019 p. 88). In that sense, if his view is one that at its best looks at the technological 
tendencies pushed forward by this ensemble through the perspective of war, I set myself now to look at how technological tendencies are embedded within production and how production in the current iterations of Capitalism governs flows of energy and information, attentive to how those might influence governance and politics. Certain technological shifts in production will serve as knots through which I can tell the story, through machinery, of the bifurcation and governance of energy and information and then between information and metadata.

Looking at Marx's approach to machinery in his time begin to show us a hint of how today's capitalism governs flows of energy and information and formulates a theory of technology that in its many iterations refuses to see technology merely an expression of an idea and that conditions it to the shifting grounds of the division of labor and that poses technology as the mediator of the relationship between labor and nature, that which allows for the messy imbrications labor are made of.

Grove (2019) has a very interesting idea about the future of our economic and social predicament: for him there is fundamentally superfluous quality for labor that render it now disposable in the new forms of information-based and increasingly automated economy but we will turn to that only by the end of the chapter.

\section{Machine as Relay: Division of Labor, General Intellect and the Collective Worker}

Marx studied "the question of machines" through technical and economical literature around the theme since at least 1845 (Roth, 2010). It opened three main paths of inquiry: the effect of machinery among the laborer daily life, the economic structural effect that technological process would entail and the usage of technology as a historical category, a materialization of changes in the division of labor (Roth, 2010 p. 1247). This third line is of particular interest to us right now.

Living in England in particular from 1849 onwards as a refugee, Marx found himself amidst an environment in which, indeed, all that is solid was melting into air. Social changes meant that labor routines, factory layout and the texture of cities such as London and Lancashire were rapidly modified. The situation of the working class as documented at that time also lays bare how capital is a regime predicated on the overcoming of natural constraints, pitting value-forms against natural forms as, for example, ongoing struggles for the length of the working day generated heated 
confrontations and challenged the biological limits of the human as labor-power (Engels, 2008).

I will argue two particular points in this section: first, I present how, for Marx, the machine offers a nexus of social relationships, particularly by solidifying certain divisions of labor, marking his encounter with the growing relevance of science for value production; second, how this new division of labor is expressed also functionally in the division between information and energy that those machines themselves allow.

Beforehand, let us get a common misconception out of the way. There is often anxiety about Marx's "techno-determinism" particularly through a quote in "The poverty of philosophy", popularized to the point of pastiche: "The hand-mill gives you society with the feudal lord; the steam-mill society with the industrial capitalist"30 (Marx, 1995; McCarthy, 2018).

However, the book is in fact an argument against Proudhon's considerations of the division of labor, particularly opposing the positing of the division of labor as mere transhistorical feature of all societies, in which machines represented the emergent synthesis, which would find their resolution and allow that, in the newly integrated factory, the worker would finally be able to feel a part of the productive process. Not only that quote usually summons quite an inexistent Marx, who thought that societies were determined by a self-reproducing technology but it is inherently misleading to Marx's main point. As a matter of fact, one of the main goals is a critique, extensively drawing on Babbage ${ }^{31}$ of how Proudhon ahistoricized the division of labor and worked with it as a principle (Marx, 1955).

Marx follows Babbage pointing that machines condense divisions of labor, an insight that, together with his focus on the social organization of production as a determination lying between politics and the economy, already eschews determinism and in a lot of ways forecasts later interests in technology as an object of inquiry (Schatzberg, 2006). What we get, instead, is quite a nuanced theory in which machines appear both harboring potential for being repurposed and as offering a diagram for understanding the naturalization and enforcement of a certain shape of production.

${ }^{30}$ Full passage available here: https://www.marxists.org/archive/marx/works/subject/hist-mat/pov$\mathrm{phil} / \mathrm{ch} 02 . \mathrm{htm}$ 
Marx's interest in viewing machinery as a historical category drove him towards extensive studies less by seeking a deep philosophical truth of technology or machines and more as a socially mediated process underpinning changes in life and history, propelled by changes in production and consciousness (Roth, 2010; Marx, 2017a). Therefore, machines pose a question about their emergence, meaning, what division of labor and social grounds they are birthed in and what they do in relation to it. Machines are condensed social relations made of labor and raw materials. They are also artifacts that change the grounds in which they happen, both amplifying and conditioning our capacities, remaking what the human and nature itself mean in the process (Wark, 2019). Such a vision finds itself at odds with parts of Grove's (2019) work as it is not anchored in the solid kernel of a continuous principle of homogenization propelled by a cluster of ideas, but in the ever-shifting grounds of the social organization of production.

Babbage ([1832]2010) had two main principles regarding machinery: the first is that machinery imitates a human task in a mechanized way and second that the machine pushes forward a "modulation" of surplus value. Modulation here is related to the possibility of measurement and control of the factory. The productive process splits the laborer into tasks and reintegrates the whole through machines and in each node of the process allows for better metrics in production, each activity broken down, measurable and therefore more skillfully managed towards the production of value (Pasquinelli, 2015:2019).

A crucial laboratory for the modulation of labor can also be found in the plantation $^{32}$ and its colonial history. The plantation is often evoked when talking of the industrial revolution in terms of feeding the appetite for consumption of the wage-laborers and the steeping demand of raw materials in cotton fields, mines and others. That the plantation and its ensemble based on slave-labor and exploitative practices are the condition of possibility for Europe's industrialization and the dislodging of India from the top of the textile game is nothing new (Marx, 1996). However, it also was fertile ground for proto-mechanisms for modulating labor, we

\footnotetext{
32 The concept of the plantation is a disputed concept and I do not seek to focus my inquiry on those intricacies but to illustrate. I use here Mintz (2003) as my base. Put very shortly a plantation is characterized by certain features: connection to a large-scale market, deployment of a dependent worker's force, usage of abundant capital geared towards the accumulation of value in which the subsistence of the owners is not at stake and those owners are usually organized as an enterprise. For more on that and the difference between a "farm" and a "plantation" see Mintz (2003) essay "Farms and Plantations in Mesoamerica and the Antilles". Others could be added: tendency towards monopoly,
} 
might find that it figures also as the building of capital's material management capabilities itself (Tsing, 2015). Maybe, between the workshop and the factory, one finds the plantation not only enabling a larger scale but as a laboratory for scaling up production and integrating it with global markets.

Wolf \& Mintz (2003) emphasize that in the implementation of a plantation many mechanisms of calculus, rationalization and intensive division of the productive process through technology are deployed both due to the large availability of capital and to the scale of the resources, not to mention the complex logistical chains involved in its integration to newly shaped world markets. The plantation requires an infrastructure that is able to manage and integrate radically different kinds of labor through a far more diffuse than anything available in terms of traditional farming.

Those different parts had to be integrated in a general picture: in the case of sugar, one can see that from managing the workforce to the planting process to the refinement of sugar and towards distribution, every process required different managers and managing their connections required each process to be reintegrated as a calculable piece. All in all, the administration of plantations, often delegated to nonowners, presented a rather complex endeavor from the perspective of the amount of information to be managed and orchestrated, even more so for its global scope.

Tsing (2015 p. 40) condenses this problem in terms of scalability: the plantation is a laboratory for the capacity of scaling and managing production wired to global markets and an increasingly financialized global economy. I am a bit wary of putting the question solely in terms of scale in this because it might reproduce a binary in which scalability necessarily equals a progress towards an oppressive labor division. However, the hypothesis of proto-modulations of labor in the plantation is indeed plausible, despite the fact that entertaining it with more depth lies beyond the scope of this thesis, we might find the plantation as a missing link between the workshop and the industrial factory.

As far as changes in the industrial factories are concerned, one of the most famous examples of Marx's interest in machinery and its emergence lies on the "Fragment on Machines" (FoM) published in the Grundrisse, containing many ideas which were revised or taken further in Capital Vol. 1 (Marx, 2017). Particularly, the FoM is notorious for three things, the first is the concept of General Intellect in Marx, which made a connection between the way scientific progress was objectified 
in machinery and came to increasingly condition social life, a concept that despite appearing only a few times, has taken a huge importance, particularly for the Italian Workerist tradition ${ }^{33}$. The second is its ambivalent attitude towards machines that appear neither as saving grace nor as mere creature of capital, Marx begins asking the speculative question of what could machinery mean in a communist society and how it could aid in formulating another social organization of production. Third, the machine appeared as a diagram of capitalist crisis $^{34}$. With all that, it is no surprise the FoM has taken a rather particular place in Marxist theory:

"In westerns the hero, when faced by the most concrete of dilemmas, cites a passage from the Old Testament (...). This is how Karl Marx's 'Fragment on machines' has been read and cited from the early 1960s onwards. (...)" (Virno in Pasquinelli, 2019)

One idea is particularly interesting for us in this text: first, Marx's visualization of the increasing relevance of science for production already in his time, which translate in how he conceptualized the question of the General Intellect (GI):

The development of fixed capital indicates to what degree general social knowledge has become a direct force of production, and to what degree, hence, the conditions of the process of social life itself have come under the control of the general intellect and been transformed in accordance with it. To what degree the powers of social production have been produced, not only in the form of knowledge, but also as immediate organs of social practice, of the real-life process. (Marx in Mackay and Avanessian, 2017 p. 72)

The origins of the GI and its developments as a concept were particularly interesting for Italian Workerism. However, I will not cover those extensive and creative deployments. Rather, I follow Pasquinelli (2019), reading this text against a particular image, largely diffused in newspapers and related to the public debate around the question of machines and the "March of the Intellect".

This image, commissioned by the Tories in 1828, was drawn by the cartoonist William Heath and displays an automaton with a steam engine as a belly, a head made of books of history, philosophy and mechanics and topped with a crown that had "London University" carved in it. While it marches, it tramples bureaucrats. In the background, the goddess of justice makes a plea to the mighty automaton: Come and deliver me! (Pasquinelli, 2019 p. 1-2). It was an ironic remark on the political climate of that time, poking fun at the concrete political demands for the

\footnotetext{
${ }^{33}$ See, for one example: Negri's (1991) Marx beyond Marx classical analysis of the Grundrisse or the Quaderni Rossi which united many of those intellectuals

${ }^{34}$ For two positions on this particular part of the Grundrisse, one can look at Robert Kurz's work with the Exit! group and Michael Heinrich's work. However, appropriations are multiple. For a more contemporary one, check also Robin Mackay's and Armen Avanessian's (2014) \#Accelerate and the debate around this particular text.
} 
popularization of knowledge among working class people as they envisioned a revolutionary potential in the spread of knowledge through the social body against, among other things, an increasing fear of automation instantiating a replacement of the human itself. The attempt to fight centralized knowledge is propelled by its other side, the promise of a better society through knowledge distribution (Roth, 2010; Marx in Mackay and Avanessian, 2017; Pasquinelli, 2019).

This spread unrest took many forms: What was already evident in Marx (in Mackay and Avanessian, 2017) is that machines as deployed pose a dissociation between the worker and his own knowledge: the passage of the tool from the hands of the worker to the machine is related to this. Rather than operating the machine it is as if the machine operates the laborer, he becomes an appendage to the machinic activity and ceases being the propeller of the labor process, becoming merely its overseer.

As science becomes an increasingly relevant productive power to be mobilized, there is a fundamental change in the division of labor: the micro-actions of expertise that usually characterize the labor of a peasant or an artisan are increasingly embedded in the automatic operation of machinery. The factory becomes a system of machinery in which laborer becomes a "watcher or regulator" of a process composed of human, technical and nonhuman elements rather than its maker. "The appropriation of labor by capital confronts the worker in a coarsely sensuous form; capital absorbs labor into itself as though its body were by love possessed” (Marx in Mackay and Avanessian, 2017 p. 69; Pasquinelli, 2014:2019).

The increasing role of machinery illustrates a qualitative and quantitative change in the old schism between the "man of knowledge" and the "manual workers", but was not as Proudhon would have it its resolution. While the manual workers operated the machines producing "content" or commodities, "intellectual" workers were charged with the production not of machines but of "forms": new machines, new ways of organizing and managing the factory.

One must notice two levels in that case, while the usual logic would have that those different kinds of labor, in their different ratios of brain-frying and musclegrinding remain, in the eyes of capital, abstracted in the same private labor regime through abstract labor. However, machines stand as an interface between the worker and the productive process, an interface that allows for a constant revision in the process of abstraction of labor through which it is quantified, one propelled also by 
the place of those workers that make and remake them: the quantification and modulation offered by machines is precisely what makes them so suitable and facilitate abstraction as such (Marx, 2017; Wark, 2019; Pasquinelli, 2019).

While Marx is very aware of this function of machines, he does not take them to their full consequences in that particular text. What Marx called the General Intellect is nothing more than the way in which general social knowledge, produced by inventors and scientists, was congealed in machinery and put to usage by Capital in a privatized form, becoming "powers of social production", from which the worker was separated. The concept pits the idea of an individual inventor with its inversion, the idea of a collective social knowledge. Such an injunction calls forth the normative commitment that, knowledge that is produced must be socialized.

The problem is that, when we consider the FoM, we see that this inversion carries a residual fetishistic vision of science: knowledge appears as inhabiting an upper layer that determines labor negatively from above. As Pasquinelli (2019) puts, the point of shift in Marx away from the General Intellect is understanding that it is precisely labor that determines the "General Intellect" and not the other way around, understanding that there is no non-incarnated intellect in an upper layer affecting machinery, but that the emergence of intellect even if a certain potential beyond our current order is immanent to it. It is not only that knowledge produces the factory layout but that labor itself, in a fairly everyday manner, is constantly producing the knowledge that is then congealed into machinery by managers and inventors' but also drawn from the gestures of the machine's overseers (Babbage, [1823] 2010 p. 312). The managerial activity is itself labor. This quality is concretized by cybernetics which we will briefly get to later in this Chapter.

Another slippage in the FoM is when Marx (2014) addresses the factory system as a self-moving automaton, a "moving power that moves itself" he seems to forget that the automaton is merely a trick: in the $17^{\text {th }}$ century behind the automaton displayed for entertainment there was a horse or a mill propelling it, providing it with energy. Today, the automaton is only possible through that same energetic input and the manual and intellectual labor that keeps even the seemingly automatic operation running (Marx; 2014; Wark, 2018; Pasquinelli, 2019; Jones-Imhotep, 2020).

It is crucial to notice that Marx (2013 p. 446-447) himself addresses this neglect when he claims that the industrial machine consists in three main parts: the driving force, the transmission mechanism and the tool-machine. Instead of a worker 
hitting a nail with a hammer, here we have basically the hammer connected to energy source by a transmission mechanism which modulates that big source of energy to the task at hand. We will get to this particular motive force in the next section when we talk about coal and the fossil face of Capital.

Nevertheless, those two slippages in FoM tell us is that there is both a vision of knowledge as immaterial and that dismisses the work (machinic or not) of acquiring and formalizing it, and that the energetic content of labor, revealed by thermodynamics is not taken into its last consequences (Wendling, 2009; Wark, 2017). White work ean be redueed and its form ean radieally change, a post-work society then and now ean only be one that abolishes work as such, but it forms other ways of organizing itself.

In fact, it was Thermodynamics as a science and its role, both in the machines of his time, notoriously the steam engine but also in the cultural impact it brought that has not only led Marx to formulate the concept of labor-power but operated a change also in the cultural climate on how people actually saw work as less of a moral or dignifying expression and more of an energetic operation that could be executed by machines as well. This new combination of machines render the role of the worker as the source of energy diminished imposing a different rhythm to production but also opening the possibility of lessening the necessity for work as such, a horizon not of realizing labor as genuine human potential but of getting free from it (Wendling, 2009).

Let's remember the first law of thermodynamics: in the universe, energy is at a constant level and it merely changes form from one place to the other, it cannot be created nor destroyed but merely changes place. In the XIX century, thermodynamics formalizes the conversion of heat originated from burning coal releasing chemical energy as heat, that by transforming water into steam propels turbines that generate work. The calculation and optimization of this convertibility of energy into work was facilitated by machines, which embody a crucial quality for the capitalist system, meaning, the flexibility through which it can unbind itself from some human constrains and that, when allied to the modulating capacities of both improvements in the division of labor and constant monitoring, open windows for optimization (Caffentzis, 2013; Wendling, 2009).

Some resonances, nevertheless are striking. Marx in his time had crucial theoretical contacts with thermodynamics and their concept of energy and also with 
Babbage's inquiry aimed at the role of knowledge in the division of labor. His fundlacking attempts of, together with Ada Lovelace, automating the intellectual labor of calculation through both the differential engine and subsequently the analytic engine, computers powered by steam, gaze at the future with pronoia revealing a tendency towards the modulation of surplus labor that is nothing less than the tendency towards other forms of management that spilled, back and forth from science to the factory to politics and elsewhere or, succinctly, the importance of the management of production and how it was related to knowledge and its formalization as information (Wendling, 2009; Pasquinelli, 2013:2019).

In Capital, the General Intellect as concept disappears together with some of Marx's excitement visible in FoM. Understanding the machine as he did in Capital, it becomes clear that there is a radical change in the productive process as the tool is not anymore limited to being an organ of man but that multiple of these organs can be attached to a mechanic organism, to a system of machines which decenters man himself (Marx, 2017a p. 452).

What succeeds it is a far more "incarnated" concept to attest to how machines embody the division of labor: the "Collective worker" (Gesamtarbeiter). The collective worker for Marx is the conjoining of the totality of the labor process arranged by Capital based on a division of labor sedimented and revised in the construction and management of an assemblage of both human, technical and nonhuman elements (Marx, 2017a; Pasquinelli, 2015).

It is here that Marx incorporates the principle of the modulation of surplus value by Babbage, as he recognizes not that there is knowledge shaping production but the mutual relationship set between knowledge and production, incorporating Babbage's ([1832] 2010) claim that workshops contain "a rich mine of knowledge, often neglected by wealthier classes" and that the process of labor as such is predicated on energy and knowledge, or as we will call, information produced by the operation of this productive organism (Pasquinelli, 2019).

This concept traces what Pasquinelli (2019 p. 53) called, from the perspective of the laborer a "prehistory of the cyborg" and the formalization of capitalism as a diagram of organization of flesh and tech qua value-producing organism a "protocybernetics". We see that organized labor becomes a crucial vector from which humans frame themselves amidst their entanglements and that this division is based on the squandering and remaking of it in order to fit into the productive processes. It 
is crucial also that the Collective worker is seen as being the material incarnation of the entry of the individual into social production and also that the labor process as metabolism often is made with and through the machine (Haraway, 1991; Wark, 2016).

From that, we can begin understanding and questioning Marx's somewhat optimistic utopian edge in FoM over the question of machinery: first, that the growth of dead labor (machines) over living labor (human labor), if seized, could also have a revolutionary potential. In an automated society in which there was no need for work as wealth could be produced by machines in ways that were not geared towards the production of value, humans could spend their nerves and muscles elsewhere. Emancipation in such a picture is already less and less the realization of labor as genuine externalization and imprinting of human essence which Capital corrupts but progressively becomes a question of getting rid of work. While machines lower the social necessary labor time and diminish the needs for human labor, in communism one could finally enjoy and engineer such a potential. Communism does not realize labor more than abolishes it in the form it exists and remakes it by focusing on its reduction (Caffentzis, 2013 Marx, 2017a; Burkett \& Foster, 2016).

The collective worker is a theoretical progress in Marx's system as it implements Babbage's vision of technology and labor as surplus modulation and understands that machinery is both an apparatus to discipline labor and also to extract value. The discussions of relative and absolute surplus value in Marx's work are precisely the way in which some of the faults within the FoM are fixed. Let us briefly turn to those concepts to make sure they are rendered clear.

Marx laid out two main types of surplus value extraction: absolute surplusvalue is derived from the relation between the price one pays for hiring and maintaining a laborer and what value he generates after, so if the laborer produces what he is paid in the equivalent 2 hours, what he generates after the rest of his working journey is absolute surplus value. Obviously, if one hires more laborers there is more absolute surplus-value extracted. The other possibility is that one extends the journey of a worker from say 10 to 12 hours. Historically, during Marx's time, social struggles around the length of the working-day constituted an important movement for the developments of capital, but this also marks certain particularities within the energetic matrix, but we will turn to that in the next section while looking how this relates capital and its love for fossil fuels (Marx 2017a p. 142-148; Malm, 2013). 
The second type is relative-surplus value and comprises rises in productivity and is predicated on changes in the production ratios, be it the reduction of the value of certain raw materials and/or the revolutionizing of the technical and social conditions (Marx 2017a p. 237-244). It is predicated in lowering the socially necessary labor time taken to produce a unit of a certain good. The kinship between relativesurplus value and Babbage's principle of modulation of surplus labor is a development from the FoM to Marx's further work helping to cast light in crucial aspects of it, also strongly related to why the discussion on relative surplus-value is articulated in Capital together with questions of cooperation and division of labor (Pasquinelli, 2019).

Surplus-value extraction is, in fact, the beginning of the answer for the question of machines, an answer we may get in full by looking at those machines themselves as they modulate, measure, solidify and render tractable the productive process as an organism.

Now, if we read what we have already been laying out through Moore (2015) and Pasquinelli (2019) analysis, it becomes obvious that the way in which Capital sustains its value generation and extraction is through both relying on cheap natures and on the constant revolutionizing of production both through machinery and new technics of organization and division of the labor. The machine becomes the crystallization of the division of labor because it is a knot that allow for its optimization not only as it mimics a human activity but also as it mediates the integration of labor into the collective laborer and how it can unify within itself processes that before were separated. One must remember that there is no production of surplus-value by machinery because machines are not exploited per se but crystallize the value used to produce them. While they do automate work, both physical and intellectual, they do not produce value per se as they rely on and express the labor contained in their making, maintenance and operation monitoring.

Mind that the distinction between relative and absolute surplus-value are not categorial in the sense that old-capital equals absolute surplus value and contemporary-capital equals relative-surplus. Not only the International Division of Labor show us that global capital lives far beyond the factory since its buildup in the $16^{\text {th }}$ century but also Capital's development always deployed a nice fair share of each into its historical development and still presses on its two different sides depending on the current predicament (Moore, 2015). 
As I have formulated in Chapter 1, my critique of Moore (2015) was based in two points: first that, by collapsing work as merely energetical, he risked losing grip of the distinction between wealth and value and embedding an alien logic (value) into nature too deeply, which I addressed by reclaiming the concept of metabolism. However, a deeper account of energy was something I did not offer yet. The second was that he did not linger in the role information may play within production and capitalist development, specifically in the new iterations it might have in what one could have called Cyberfossil Capital.

A particular feature of this organization of the collective worker which complements Marx's own developments is well elaborated by Simondon (2007 p. 20), pointing that the distinctive feature of the industrial revolution is in its capacity to split and govern the flows of energy and information:

The industrial modality appears when the source of information and the source of energy separate, namely when the Human Being is merely the source of information, and Nature is required to furnish the energy. The machine is different from the tool in that it is a relay: it has two different entry points, that of energy and that of information.

Let's bring an example through the most cliche metaphor of labor, a man with a hammer. Willing to attach an iron nail in a wooden surface, in a gesture, he provides the energetic force that will push the nail against the wooden surface's resistance, diminishing the wood's entropy (level of molecular disorganization), dissipated in the form of heat and noise. His single-movement also contains tiny bits of information, his form-giving capacity, in channeling his strength as a specific form-giving gesture that must set the nail straight in the wood. The industrial machine, simply put, attaches a tool to an energy source and propels its capacity for giving form to matter indefinitely through other sources of energy. It is through a device such as this kind of machines that Marx could note the human passing from being an operator to being operated by machinery (Burkett \& Foster, 2016; Marx, 2014:2017a).

To say that a machine is a relay is to put it as an organizer: it arranges those flows in specific forms and puts them towards the attainment of certain goals. This arrangement itself is deeply related to the division of labor and to the reproduction of value, as we have seen. Energy becomes progressively tethered to a certain form of relation to nature and forms not an insulated progressive pathway in the factory but transcends its barriers: "from the thermodynamic element we pass to the thermodynamic individual and to the thermodynamic assemblage" meaning that 
there is a process (which he calls hypertelia) through which technical elements within an object are repurposed and may "trickle down" to other technical objects. Simply put, the steam engine's technical improvements allow it to be taken from the factory and power locomotives, for example (Simondon, 2007: 2020 p. 120).

If we are loyal to Marx as well in that we see the social organization of production as deeply imbricated into consciousness and power, we may also see the deeply social content of those progresses, something that could indeed be related to the concept of the "Collective worker", one that hints that the disassembling of the worker is already dictating not only the space of a social task but remaking what sociality as such means (Pasquinelli, 2019).

That being said, the story of the management and governance of those flows is a way of narrating the story of capitalism not as the realization of a vision, an essence present in technology as such but rather looking at the ground in which they emerge and the shifts they cause in this same ground. Technology under capital is not a destiny nor a trajectory but a play of tendencies both contained within the object's material reality and the social relations of which it is made. This helps to craft a view of technology that is not concerned with the essence it supposedly contains within it (a vision that as I argued Grove sometimes slips into) but with the play between the social and the technical as found in production.

The point with Simondon's (2007) insight of reading the industrial revolution through this split between energy and information goes beyond claiming that the ghost of information was always in the machine. Of course, we can see that Babbage's calculating machine and his attempts to automate knowledge gathering and information were projected before the systematizations of Sadi Carnot's ${ }^{35}$ thermodynamic engines. However, this also does not mean that we must trace "industrialism" and "informationalism" as merely the same thing that has always been there just waiting to be unfolded. Drawing on Deleuze \& Guattari's, Pasquinelli points that actually what is at stake in this relaying is a bifurcation of technological lineages and that those lineages produce new regimes lying right at the knot of economy and politics, but that still maintain a relation: information bound to

\footnotetext{
35 Sadi Carnot is the French engineer which first formulated the second law of thermodynamics that verses around the progressive loss of entropy within transferences. He is also credited for systematizing the notion of the Carnot Cycle, basically an abstraction of a non-existent perfect engine in which all the converted heat would indeed be preserved. While an abstract construct it had very practical reality in that it provided a way of calculating and working around the efficiency of those machines throughout the productive process.
} 
optimize value production is the modulator of surplus value in the factory (Wark, 2004:2013; Pasquinelli, 2013).

Looking at this split management facilitated by machinery, Pasquinelli (2017) called the carbossilicon economy a two-headed hydra made through an architecture of energy and information weaved by labor. This architecture is enlaced with the Anthropocene both as it spells the concrete means through which economic forms inflict themselves in natural forms and as it is through an architecture of that same combination that the Anthropocene is knowable.

While the bifurcation reveals new machinic lineages, we must keep in mind that the separation between a digital and a fossil economy is not total. Already in this excursus through machinery and the complicity between the ghost of information and those "old" economies, we are invited to linger a bit more on the metaphor of the hydra and understand that behind its menacing heads, it is still attached to the same body.

Now that their imbrication is clarified, looking at each of them in separate might offer further insight. Therefore, first, we look at the affinity between fossil fuels as a source of energy and capital. Then at how information evolves from its modulation functions and opens new, unexpected possibilities. Those historical divisions are heuristic, of course, but they will help us understanding our current predicament.

\section{Smoke, Steam and Energy: The birth of Fossil Capital}

I will sketch how fossil fuels became crucial for capitalist production and reproduction, framing $\mathrm{CO} 2$ as a byproduct of the process of valorization. I begin by giving a brief context on the enclosure of the commons, to then argue that the lingering convenience of fossil fuels is not merely a contingent factor but has to do with its affinity with the abstraction of time and space in which capital is predicated, with how it allows for unique ways of exercising power over labor and also with the way in which fossil fuels were also outstanding for carrying out the modulation of surplus value and ended up becoming a form of "abstract energy" which forms the reliable zero ground of capitalist production and is constantly reinforced by the shape of production.

For making this claim, let us take Marx back to his smoke-filled landscape. His conceptual persona here of course is the proletarian amidst the industrial revolution, 
one going an "epochal change" marked by deep transformations in relations and forces of production in England, which were only possible through a particular environment that was being born worldwide. Enclosures of land in the countryside, colonization, slave-labor, unpaid domestic labor, cheap nature all form the conditions of possibility of capitalism's birth (Pasquinelli, 2017).

As we have seen, the collective worker allows us to make an interesting approach to machinery and see it as knots from which we can begin to pull threads that show the entanglement between politics and economy. Those changes are deeply related to changes in cities, transportation and logistical networks, forms of government and also the textures of everyday life. New forms of sociability and forms of exercising power are also born. Let us remember of Foucault's diagram of the disciplinary society. A creature of the XIX century: the panopticon, creatively seized from Bentham's never realized prison project (the Bentham whom Marx [2017 p. 685] called the "oracle of bourgeois intelligence") actually comes from the modus operandi of a factory in Belarus which Bentham encountered in a trip while visiting his brother.

The panopticon as a model is a diagram introducing labor-saving practices in surveillance and the exercise of power. It also advances a kind of biopolitics of laborforce preservation in the center of the world. However, it is a model that is tested empirically in the colonies in many forms, long before it can be fully realized in Europe (Deleuze, 1988; Foucault, 2011; Berlant, 2011; Barder, 2015). Pasquinelli (2018) puts that both biopower as the abstract process of political management of bodies and capital as it works through abstractions of space and time, all of those enabled by networks of energy and information processing that mix both human, technical and non-human elements.

This of course not to say that the outside of the factory merely expresses technical developments serving technical determinism in a new way, wine turned vinegar now packed in a new bottle. Rather, this points to the stakes of this discussion and expressed through technical apparatuses, there is no political upper legislative layer, no way to address problems deeply made around energy and information such as the Anthropocene without lifting the abode of production, actualizing the theoretical move I discussed through Jameson's (1992) concept of mediation and also offering a different valence to the procedure Grove (2016:2019) himself was executing. 
What is referred often as "enclosure of the commons" by Marx was happening in different iterations both in the colonies and in England, being predicated in the advancement new property forms to land ownership and at the same time to the increasing subjection to the global market and its fluctuating rates. In the case of the colonies specifically, not only property rights were intertwined with the extermination of indigenous populations and carried out with the utmost brutality and with slavery ${ }^{36}$ as its main source of labor-power.

The globalization of this process of cash-crop agriculture sets about a series of those very metabolic rifts that Marx was already observing by looking at Liebig's work on agricultural chemistry (Burkett \& Foster, 2016; Bhambra, 2020; Clegg \& Lucas, 2020) ${ }^{37}$ Such developments in cash crops are the dynamic processes against which later in the XIX century we can understand the energetic shift of the industrial revolution and its hunger for cheap natures (Marx, 2017b p. 135; Moore, 2015 p. 100). Therefore, Marx's (2017a) affirmation that Capital is born dripping in blood can only be taken literally.

Andreas Malm (2013 p. 30) sets out to study of the marriage between capital and fossil fuels ${ }^{38}$ as the main power source for production, a regime he calls "fossil capitalism" and that is a vector enabling the Anthropocene to emerge, particularly if we see the role of the industrial revolution in accelerating carbon emissions.

Likewise, the technical improvements done in the steam engine by John Watt and its diffusion throughout the industry was coincidentally a process that was highlighted even by Earth System Scientists as a historical beginning of our trajectory towards the Anthropocene through what was actually a rather slow process of diffusion (Crutzen, 2006).

A puzzle appears when one mentions the affinity between fossil fuels and capitalism. On their emergence, in particular, the usual story tells that it is either due to the inherent superiority of steam or to a Malthusian trap, in which the lack of other energetic possibilities made it to be the only pathway. However, there is strong

\footnotetext{
${ }^{36}$ This is not saying that slavery is a thing of the past. For a very nuanced account of slavery and Capital and the way in which one overlaps with the other and represent no sort of definitive contradiction, see Marcel Van der Linden (2008).

37 Clegg and Lucas (2020) periodize things in the following way: the neolithic revolution which introduces both the tax-collector state and slavery as the main source of labor and then the capitalist mode of agriculture. I have chosen not to include the neolithic period as that would exceed the scope of this text.

38 This is not to say that the usage of coal is any kind of never seen before phenomena, of course. There were for example in China and in Europe usage of coal specially in furnaces for melting metals, but what is at stake in my argument here is their particularity as a form of abstract energy.
} 
and diverse historical evidence pointing to the fact that water-mills were actually more productive than steam mills per horse-power: from 300-500 horsepower versus 20-60 horsepower in a steam engine in the early stages of their development. Also, the installation costs of steam machinery were higher even than the costliest water installation. This is not to mention that coal-based engines, obviously, required the continuous purchase of coal, while the water-mill was predicated on the continuous flux of a certain body of water and the conversion of its kinetic motion into energy. Maintenance costs were also reportedly much lower for water-based mills rather than steam ones. There was absolutely no shortage of available water-mills and no visible dispute between places in which it would be possible to install one. What could be behind the fact that steam gained supremacy in spite of the apparent superiority of water? What does it tell us about Capital's management of energy? (Malm, 2013; Altvater, 2005)

The main reasons were both the flexibility fossil fuels offered, in terms of modulation, and the power over labor that they allowed. Water-powered factories were bound to the presence of a body of water and had some trade-offs: first, the proliferation of many factories in a place could actually jeopardize its capacity to generate energy through motion. Second, while moving closer to bodies of water and further from some highly inhabited places, sometimes the factories would have to form "colonies" around them that would have to become attractors of labor power. That introduced a myriad of costs to the factory owners but, of course, those were highly manageable and constituted a very common way of making business (Malm, 2013)

However, it was with the growing articulation of the proletariat that a lot of those weaknesses became quite concerning: the cotton workers, one of the most organized sectors of the working class, had high negotiation power on waterpowered factories as they were usually most of the working-force available around. As bodies of water were often far from urban centers, they were delivering blows to the profits of the capitalists. After the wave of strikes during the early 1800 's, waterpowered colonies were falling by the hour, while city factories were prospering (Malm, 2013). Not only this: water was subjected to the whims of nature: floods, droughts and diminished flows all made them quite unreliable.

On the other hand, steam-power was glorified, both unstoppable and fully docile to the demands of our average bourgeois, knowing no bounds: day or night, at 
any season, as long as it was fed with coal, it provides energy. It could be put right in the middle of a city and enjoy an enormous pool of labour-power, despite it still having to move coal from the mines elsewhere ${ }^{39}$, another fixed instance of extraction of cheap materials that demanded yet another geography of railways and ships and new assemblages of labor to be set.

While water-based factories could not intensify their energetic input, the steam-based ones could do so to a certain degree just by increasing the machine's intake of coal. At this limit, they could just get more power expanding the plant without the need to look for another river, still enjoying the labor pool. It is not hard to see how coal allows a better modulation of surplus value in which one could organize and flexibilize efficiency of the process to overcome constraints, was already more adequate than water for the $19^{\text {th }}$ century. "The great genius of Watt is evident (...) as his invention is described as the general agent of the great industry" was Marx's way of noting that the endless growth of the industrial apparatus, unbound by its limitations to nature, would appear as a crucial asset and that fossil fuels through their social and natural benefits became the standardized way of thinking and planning production (Marx, 2013 p. 451).

The decline of water-mills was connected to the passing of laws limiting the work-journey to ten hours. While the limitation of labor-hours was a dealbreaker for many water-mills that declined in quantity, fossil fuels were a crucial way of keeping accumulation possible even in such a scenario while mitigating the possibilities of the kind of problematic strikes happening in the limited working pool through which water mills relied on (Malm, 2013).

Altvater (2005) also weights in mentioning that fossil fuel adoption is predicated in a break: while previous forms of life such as agriculture relied heavily on natural time-bound cycles through which rain and sun would be generative and regulative of most dynamics, fossil fuels are crucial for bypassing the natural limits of those forms of production with abstract time and also can move the limit elsewhere, the cycle of valorization M-C-M' (money-commodity-money with surplus) can be realized outsourcing its propelling factor (Malm, 2013; Grove, 2019)

While coal today is no longer the hegemonic fossil fuel, the passage towards oil is a combination of both an attempt to bypass problems related to the increasing mobilization of coal-miners, which undergirded a lot of the hunger for coal in the

\footnotetext{
${ }^{39}$ Some cities like Lancashire, for example, had mines very close to them and definitely managed to
} get competitive advantages due to that. See Malm (2013). 
eve of the industrial revolution and also the spread of diesel motors in the beginning of the $20^{\text {th }}$ century as the main source for transportation (Daggett, 2020 p. 30).

Malm (2013) advances the argument that CO2 is the "biophysical shadow" of value, now appearing not only through coal but through other fossil fuels such as oil and gas. Carbon appears as the byproduct valorization inevitably leaves behind through its functioning, imprinted into the world both through transport and social reproduction but even more crucially through the act of production per se. not to mention how they form a vector of financialization through petrodollars and future markets.

However, let us note one cannot restrain the metabolic rifts left by Capital to it, to the risk of ignoring other impacts factories have in their environment. Sassen (2014) talks about expulsions both in a more general register as the logic of access denial within today's capitalism and how it abandons and brutalizes individuals and more specifically by keeping in mind forced dislocation of entire populations out of environmental impacts. Factories and their activity also carry with themselves other biophysical shadows that often even have international effects: the pollution of rivers, soil, sea and native lands and populations poisoned with heavy metals and other toxic compounds are iterations of those metabolisms and spread through activities in many levels be it mining, textile production, chemical industries or many others.

As we have seen about the value form as a historical determinate form of wealth then, Malm shows that the reproduction of such a form relied and still relies on fossil fuels to cast away "natural constraints". Malm (2013) points to the fact that fossil fuels become a crucial leverage for surplus-value extraction, not only an often employed one but a generalized one powering most of the economy and rendering possible circulation and other forms of consumption.

Valorization is a process of combustion. Fossil fuels lubricate the spatiotemporal regime of capital: the abstraction of space and time. Fossil fuels, therefore, become the form of "abstract energy" within Capital, a crucial piece for the overcoming of constraints. As Malm (2013 p. 56) puts:

The necessary material substratum for this spatio-temporality - long hidden from the view of most Marxists, however sharp their eyes have otherwise been - is fossil fuels. They represent the geological compression of the time and space required for photosynthesis hundreds of millions of years ago, when no humans roamed the planet; sui generis, their dense energy permits capital to produce its own abstract spatio-temporality for the production of surplusvalue. They are incorporated into capital as its own motive force. 
What Caffentzis and Federici (2013) call the temporalization of space, the attempt to dissolute it into manageable flows that are then squandered for production, is haunted by the releasing of $\mathrm{CO} 2$ into the world, with all the consequences this entails for the Earth at a molar level.

That is hardly difficult to agree with: fossil fuel overall consumption has been on the rise since the 1800, exponentially rising overall with gas and oil, even though coal consumption has been dropping. Industrial development often pushes those borders further and while there is definitely a rise on the outlook for energetic alternatives, we are still talking about around more than $80 \%$ of the total energy consumption worldwide if we count production and individual usages, despite their magnitude compared to productive activity being much smaller (Richie \& Roser, 2017).

Now, while this helps us see a trajectory that makes such a hypothesis plausible in the affinity between fossil fuels and abstraction, their compatibility with modulation, transportability and other material features, it is still not enough to merely trust that this affinity a relic of industrializing England, still poses energy and fossil fuels as ways of exercising power over labor, so we might have to jump forward in time for a bit. Caffentzis (2013) provides us with an example as he substantially agrees with the argument that the valorization process is a combustion process, deriving from this particular facet in the fact that energy, broadly spoken, is among the most basic of commodities under capital for both production and reproduction.

This basal character of energy and commodity is understood by him in the context of a globalized economy, particularly of one that orbits around US Imperialism that continuously charges against those organizational forms through the geopolitical economy of war (Midnight Notes, 2009). In that sense, Caffentzis (2009;2013) frames the oil crisis of 1973-1980 as a tragic resolution of two poles of crisis pitted against each other: on one side, proletarian struggles in the US were fought along the lines of Keynesianism, in particular of demanding more from the state which through social spending was posed as a mediator between both unionized and non-unionized working class and Capital. Workers demanded both an increase in already large rates of state social investment and more from Capital and its machines that, together with cheap energy which was facilitated also by the oligopoly of oil in the US, should provide better salaries and less work-time. 
On the other side, in the periphery, working classes were polarized around the exact opposite feeling, the hope that by taking charge of the exploitation of one's natural resources, the nationalization of oil companies at home and the international agency of actors such as OPEC could emerge as vehicles of reparation for the unfair division of labor that shaped class struggle. That Capital could not accommodate both of those desires is true, but it solves them in a particular form of opposition: the Arab Sheikh responsible for nationalizing, sitting on top of a mine of oil was the barrier to the American working class just as much as the American capitalist's villainy echoed in the periphery (Midnight Notes, 1980; Caffentzis, 1994:2013)

This impasse highlighted above is the failure of a particular articulation of the promise of wealth under capitalism in the overdeveloped world, that is, a combination of the Keynesian state with the Marginalist promise that each could get their shares, that rises in profits and productivity could imply in rising wages and shortening of the working day and in the case of peripheral countries that the nationalization of oil could at least bring this same condition home.

What Caffentzis (2013) points to is that interventions in the price mechanisms of energy have a particular way of restructuring how profits are distributed, particularly the ratio between wages and profits and the mediating role of the state. While the concentration and elevation of oil prices together with US's military interventions end up being a bad deal for all working classes and some of the capitalists, they are a great deal for Capital taken as a totality: while there are of course the horrors of closing factories, steep rise in energy prices for small business, the spilling over of those costs for social reproduction that finds itself without its previous safety-nets, it impacts the ratio between profits and wages by concentrating a large mass of profits in the energetic sector, both as a highly automated one and that operates on prices controlled by few people that can easily be manipulated. This is not to be read as a conspiratorial claim, as if an individual sector has a strategy set in a table, but rather that continuous tensions within the system as a whole, together with the frame that Capital as such is made of, led to this particular ensemble (Caffentzis, 2013, 1994).

The massive closing of factories and this concentration of profits were effective in mitigating social working-class struggles and generating a concentration of Capital in a sector that, in particular, accumulates through each pore of our world. 
For the working class, those two tensioning poles we have seen, were reconciled against each other: the kinship between massive influxes of loans and debt traps to peripheral countries and, in the overdeveloped world, workers were left both short of some of their previous securities and the destruction of the promise of marginalist economics, of providing to each their share in growths of profit and productivity through wages.

In overdeveloped countries, this allied to many cultural changes that also freed women from house labor progressively and that found its expression in the trend of steeping growth of the service sector which turned what was a refusal to work into a rearticulation of work into other sectors and a further concentration of profits also in the finance sector. In underdeveloped ones, the conditions for those loans and the progressive opening of those economies further hindered the possibility of import substitution regimes. Since the 1970's, the posing of the US as the main intermediate of financial transactions, allied with the financialization of everyday-life, brought, on one hand, benefits for third-world countries as the inflow of capital helped their balance of payments but created a structural dependency from direct investment and a particular inequality among countries with smaller investment flow (Caffentzis, 2009; Arrighi et. al 2003 p. 17)

While factories became strong knots of opposition, the service industry became a driver of growth. It provided forms of care outside the house as previous social reproductive space, provided many jobs that were often low paid (far from how the utopia of a service economy was pictured as highly qualified with diffused knowledge throughout society) and interchangeable, while also paving the way for the many strains of work that would sustain the rise of an information economy and widen the gap between qualified and unqualified labor even further, also giving a final dispersal of labor struggle from the insides of the factory to the outside (Caffentzis, 2013; Benanav, 2019a).

To sum up, struggles around oil, energy and decarbonization in general are not outside the environmental struggle, they are, fundamentally, struggles around the structure of how labor is distributed, which includes what kind of social reproduction is "powered up" by a certain structure. If capital is a system in the management of energy, its contestation is not only a contestation of who owns energy or how energy is made, even though those are crucial. It is, rather, a contestation of the work/energy nexus as a whole, of how much work is necessary to be done by 
humans, how much is done by machines, how social reproduction is organized, what kind of metabolisms the materials and energy powering it generates.

These connections help us cast labor struggles as, even if often not vocally, a rebellion for a rearticulation of this ratio, a convergent demand for a different organization of social production, another metabolism. It also casts doubt into attempts to set Marx's work as antagonist to an ecological critique and enlaces the demand to live in an inhabitable world with the demand to abolish value as a form of wealth. As John Bellamy Foster (2000:2016:2018) and many others have argued, Marx's critique of political economy is also critique of the kind of metabolic rifts set loose by the capitalist form production as it exploits energy both from human and non-human sources, it is a critique of the form of metabolism advanced by capital as socially organized production and the rifts it opens.

We have laid out the first head of what Pasquinelli (2017) called the "twoheaded hydra" that defines the Carbossilicon economy, the fossil-head of Cyberfossil capital. We have concluded that Capital is predicated on a regime deeply reliant on fossil fuels that become the main propeller of the cycle of valorization. We have also shown that that this split is intensified by the division of labor and reliant in many forms of exploitation of nature, violence and expropriation for the advancement and maintenance of value as a form of organization. Let us now turn to the second head of the hydra, to information and its related technical improvements.

\section{Information and Modulation in and beyond Cybernetic Factories}

As we have discussed above, there is no shortage of the ghost of information in machines as well. Pasquinelli's (2017) two headed-hydra of fossil fuels and information condenses two main insights: first, that information represents another step in the modulation of work/energy management; second, that information allows forms of commodification and production that go far beyond the modulation of surplus value, particularly towards the commodification of living activity as a source of information as such.

In this section we focus on the first one in particular, even if there will be moments in which we glimpse at how it paves way for the second. Let us recall that already in the steam-filled world of Marx, intellectual labor emerged as a way of modulating the productive process. Babbage (2010) and Lovelace, ahead of their time, were trying already to automate intellectual labor through the Analytical 
Engine, what would be the first steam-powered computer. They claimed that "The workshops of [England] contain within them a rich mine of knowledge, too generally neglected by the wealthier classes". Thus, the factory becomes a "mundane place of intelligence" ${ }^{" 40}$, intelligence to be extracted and managed through machinic means. This requires us to look at two technical trajectories: electricity as a way of unifying and speeding up flows of energy and information and the Turing Machine as the abstract machine facilitating and changing the gathering of information, particularly the status of managerial and intellectual labor. Let us quickly frame the first and move straight to the second one.

While many of the developments in the study of electricity could already be observed in telegraphs throughout the $19^{\text {th }}$ century, one of the first instances allowing for what Mckenzie Wark (2012) called "telesthesia" or, the capacity for communication to be faster than things is electricity. Electricity is compliant with the detachment between allowing for perception at a distance, a change that underpins internationalizing capital and is also crucial in building tertiary sectors such as tourism and its reliance on communication. Nevertheless, for electricity to be featured particularly in factory production, it took until the end of the $19^{\text {th }}$ century. Faraday and Edison were often portrayed as wizards: electricity was just as fetishized as steam (and feared) as steam, if not more.

Seen as something that could bend the laws of nature, Mary Shelley's Frankenstein captures a bit of its allure: the monster made of cut human parts was brought to life by the power of electricity, one so fierce that could bypass death and animate a monstruous automaton born out of recombined pieces of human flesh, now endowed with a mind of its own. We might discover that such exercise in splitting/reconstitution might be a prescient characterization of the collective worker in the age of information management (McNally, 2012 p. 100).

It is more into the $20^{\text {th }}$ century that electricity as a way of moving energy and information spreads unevenly around the globe, diffused as Capital's way of consuming and moving energy through space. Electrotechnics emergence is predicated in both an improvement in the individual elements contained within some thermodynamic machines and their reproduction in other machines, a lineage that is no strange to our world now pervaded by highly-conducing silicon wafers. What is

40 For an alternative history novel in which the analytical engine is successfully built, helping to establish a world with steam-based computation, see William Gibson's “The Difference Engine”, a landmark of the steampunk genre. 
crucial in the development of electricity is that it can at once unite and speed up the movement of energy/information flows, while at the same time allowing for their split management. The case of information networks is that of networks of energy distribution: electric energy is at
the same time information and energy: on the one hand, it can be indefinitely paired down
without a loss of productivity (...) On the other hand, the very standardization of the
conditions of energy production, which allows for the interconnection and normalized
distribution, turns this energy into the carrier of information: one can ask the alternative
network to make function (as the source of energy) a watch whose workings it regulates as
carrier of information. The simultaneous usage is concretized in the synchronic motor
(Simondon, 2007 p. 22).

The regimes of information and telecommunications are also crucially predicated in that same rejoining through electricity: electricity is not only the form in which information is transmitted but also the condition for the miniaturization of both those devices and factories. Simondon is very optimistic regarding those two sectors: first, because they represented what he thought was an advance in which the distance between the operator, the inventor and the constructor offered the possibility that their integration in the figure of the technician might emerge and, second, for hoping that when the factory was becoming more like a laboratory, relying on less energy and working at a smaller dimension that was "not crushing", there was something of the old paradigm of invention, lost by the industrialization of the workshop to emerge back. Not only might he be disappointed at current divisions of labor in the IT sector and elsewhere, that find more and more divisions between those two edges of the process, but he might be surprised at what the assemblage between those information networks with the industrial apparatus and our old thermodynamic engine might represent for labor and for the planet as well (Simondon, 2007 p. 22).

It is not by chance that the first mathematical concept of information in its relation to communication emerges through Claude Shannon's (1948) article published by his employer, the Bell System Company, while working for an encryption system for the U.S Government during the war. It was, of course, consequential from fields ranging from applied computation to genetics.

What is crucial to understand, in the context of labor, is how to facilitate the transition between the form-giving gestures of the worker in the industrial scene to the mathematical and through this loop revise the industrial as such. We find the paradigmatic machine for that in the Turing Machine ${ }^{41}$, Alan Turing's work in Project

\footnotetext{
41 The Turing machine is an abstract model of a computer that can theoretically simulate any
} 
Manhattan and WWII breaking Nazi cryptography share with Shannon's work a military background, but one that quickly becomes useful for Capital. Simply put, a Turing Machine is an abstract machine (in that it is a mathematical useful fiction) that is capable of computing any mathematical function supposed it has no memory constraints. It has the capacity of receiving an input, following a step-by-step sequence of mathematized instructions (algorithms) and pointing to a final result, an output (Caffentzis, 2013 p. 164).

It is crucial that we insert those step-by-step algorithms in their right context, so to both not render them as a mystical product of rationality, inflected upon matter and to see their relation to labor and also contextualize them as a quite generic category that has been deployed far before capitalism, though it gets a particular application in it.

(1) an algorithm is an abstract diagram that emerges from the repetition of a process, an organization of time, space, labor, and operations: it is not a rule that is invented from above but emerges from below; (2) an algorithm is the division of this process into finite steps in order to perform and control it efficiently; (3) an algorithm is a solution to a problem, an invention that bootstraps beyond the constrains of the situation: any algorithm is a trick; (4) most importantly, an algorithm is an economic process, as it must employ the least amount of resources in terms of space, time, and energy, adapting to the limits of the situation. (Pasquinelli, 2019b)

In this sense, every computer is a realization of an abstract Turing Machine and this, allied with the formalization of information gathering and transmission and with many design improvements paved way for possibilities through these emergent machines, which very quickly penetrated into production (Turing, 1950 p. 3-5; Caffentzis, 2013 p. 164-166; Pasquinelli, 2015 p. 27).

Let us also note that, as the thermodynamic engine becomes the paradigmatic vector for thinking about energy/work as related and that this relation is remade through the Turing Machine as it allows for a different wielding of information. As exposed above, the thermodynamic engine paves the way for the formalization, calculation and management of the work/energy nexus with implications far beyond the factory. The formalization of energy and its conversion into work recast labor division and organization through this prism, transferring this abstraction also to other facets of production as it fosters both possibilities of automation and new forms of labor.

algorithm, an algorithm being simply understood as a set of implementable instructions reducible to zeros and ones. A didactic video graphically demonstrating it can be found here: https://www.youtube.com/watch?v=dNRDvLACg5Q. 
Meanwhile, the information machine spells a similar movement: while the collective worker was originally a function of organizing the ordering of the work/energy nexus modulating surplus-value extraction, the information machine spells a mathematical formalization of those sedimented form-giving gestures in each of the nodes of production recasting how one deals with intellectual labor as through the information machine, the nodes of production appear in terms of their computability.

The thermodynamic engine formalized the abstraction of labor through its common energetic content, breaking with the mysticism of labor as mere externalization of human individual potential, showing its thermodynamic core, being able to calculate it in the same metric as one calculates machinic activity, a development we related to even pre-industrial features as the plantation's protomodulations and other forms of abstraction. Conversely, the Turing machine erodes the myth of skill contained in form-giving gestures and in some reasoning and counting procedures that often were connected to managerial work. It does so by formalization through computability, mathematizing and integrating them into protocols, as well as introducing new divisions of labor into the picture (Caffentzis, 2013).

Of course, each of those broken enchantments return in their own ways: in the case of steam, it was its fetishized strength, dreams of perpetual motion which made the imperfect machine that is men look quite feeble in comparison and erased the fact that the machine is animated by energy taken from elsewhere and that multiple forms of labor are behind such perpetual motion. In the case of the information machine, it is the myth of intelligence: that the machine is just about to begin thinking, overcoming the human, and that computation offers the paradigm for automating intellectual labor (Pasquinelli, 2016)

Looked from the perspective of energy and information, capitalism today can be grasped as an "assemblage between the industrial and the informational apparatuses", as Cyberfossil Capital. It is the linkage between two paradigmatic machines: the Turing machine plugged into the thermodynamic engine, all aided by the circulation enabled by electricity forming a paradigm in which information becomes the adaptive and improving intelligence of energy. This linkage does not spell a surpassing of one by other nor a new and an old paradigm: as the analogy of parasitism show us that the trajectories of information and energy have been 
intertwined and form a particular metabolism wrapping biosphere and technosphere (Pasquinelli, 2009: 2015: 2016: 2017 p. 322).

If the collective worker is a "proto-cybernetic" feature in Marx, its anticipatory character comes because it speculatively forecasts the systematic integration between the human and the machine through their commensurability in the management of production. The formalization of this, however, only comes through the inauguration of Cybernetics by Norbert Wiener and the intellectual milieu around him, little after Shannon publishes his article ${ }^{42}$. Cybernetics defined classically as the science of communication between the animal and the machine finds its gateway into management defined as the science of effective organization by Stafford Beer (Wiener [1948], 2019; Beer [1972] 1985)

It breaks with a mechanistic vision of causation (something that already casts even more doubt to a supposedly mechanistic view of matter as definitive of whatever conception of matter underpins the "Eurocene") as it seeks to liken the machine to the organism's capacity of responding to an environment. While Marx already casts that the collective worker invites other kinds of dynamic modulation embodied in production but often fails, in his picture of machinery, to see the metabolism advanced by machines, cybernetics both formalizes it and takes this further. Hui (2020 p. 104-106) is precise to note that it is not a coincidence that cybernetics, relating the man, the animal and the machine through engineering their adaptability rises together with discourses on ecology as the attempt to understand the relationship between a living being and its environment ${ }^{43}$. A particular implication of this is the need for rekindling Marx's concept of metabolism with the machine, seeing the machine mediating metabolic relations and seeing that any attempt to rethink production, to abolish labor as it is and radically redefine production has to

\section{bear with}

Such approach to machine is a direct response to complexity of what it manages by seeing that rather than making a protocol to every contingency, it has to

\footnotetext{
42 This is not to say that the concepts of information of Shannon and Wiener are the same. In fact, they are radically different. While both envision information as homologous with entropy, Shannon has a concept of information that is far more permeated with uncertainty than Wiener's one. For more on this debate and its implications for how we think about epistemology, as well as about the cultural imaginaries around the concept of information as a whole, see Cecile Malaspina's (2018) "Epistemology of Noise".

43 One of the main points of Hui with this text is to contrapose Western Technics as enframing, following Heidegger, with the potential of this problem of the technic (the integration between the machine and ecology one could say) through other perspectives that are not necessarily the western one. I would question if we need to even follow Heidegger's diagnosis in order to execute the project of cosmotechnics.
} 
grant response power to a certain extent to those systems. In that sense computation is also an economic process. Through this adaptability and mindfulness towards the environment, control pulverizes management's rigid structure, becoming the continuous design and adaptation of structures that are to some extent able to manage themselves. This creative flux of optimized arrangements renders possible autonomous adaptation and improvement, without the need for extensive top-down management but still holding it as a possibility in times of crisis. If many of the insights appearing in a book such as Beer's ([1972] 1985) appear now as a commonplace managerial knowledge in its tropes of design thinking, growth hacking, lean structures, resilience-based policy that crowd the discursive space, it is largely due to the intertwinement between complexity and how it appears in our current social organization of labor (Pickering, 2010 p. 227; Pasquinelli, 2017 p. 318; Wiener [1948]2019).

It is Romano Alquati's ([1961] 2013) the merit of being among the first Marxist to offer insight into cybernetics and its application to the factory floor in his work on the Olivetti factory, showing how this penetration happens in the collective worker. Set to look at the split between the worker and the machine through the prism of the integration between cybernetics and Marxism, he responds to the increasing implementation of it in factory management and how it knotted labor, technology and information flows. What he finds is the concept of valorizing information. Those are the micro-actions, productive form-giving decisions that the worker executes and that are mathematized and formalized by machines. This extraction of valorizing information means the capacity to codify the knowledge used by the worker to execute those micro decisions into numbers and then deploy both for real-time optimization but also for strategic usages of that set of information, that can be used for augmenting surplus-value extraction and even inform machinery design as a whole (Alquati [1961] 2013; Pasquinelli, 2015).

In this sense, the rich mine of knowledge within the factory is finally recognized. This could also be formulated through what Deleuze \& Guattari called in Anti-Oedipus the surplus-value of code (knowledge) and the surplus-value of flow (Marx's surplus value) which in fact allow us to open two questions: how information is a modulator of relative surplus-value and how it can be turned into commodity of its own right (Pasquinelli, 2015:2017). 
Alquati's main conclusions are formulated by Pasquinelli (2015, p. 8 ) as follows (emphasis my own) and leave no doubt:

1) labour is a source of information for the industrial apparatus: actually the most valuable part of labour is information; 2) the information machine is crossed and operated by flows of valorizing information that are produced by workers and gradually improve the design of the machine, the management of the division of labour and the final value of products; 3) it is the numeric dimension of digital information that makes it possible to translate knowledge into information, information into numbers, and numbers into value; 4) the cybernetic apparatus of the factory grows and improves thanks to the contribution of workers' socialized intelligence.

While Alquati deals with information deployed as modulation within Capital, it is crucial to see note already this is not the only function it acquires: information becomes also a commodity of its own right. McKenzie Wark (2012 p. 15) called attention to a particular lineage leading to the formalization of information and its capillarization that, through the infrastructure of electricity and communication, allows information to be moved faster than things. The infrastructure in which the telegraph surpasses the post-office in speed allows for new ways of knowing, mapping and working on the world, centered around what she called "telesthesia": the possibility of perception at a distance through information transmission. It is through structures such as Telex Networks, Satellites, telephone networks, fiber optic cables, global mediatic transmissions, the internet and the labor creating and maintaining them that such a movement becomes even more developed.

We interact with this materially projected space of flows through many different devices, all of which effect a particular interface and experience with that space. This global assemblage is a vectoral infrastructure that sets a new stage for the global as such: it is vectoral because it is in the business of appropriating, directing and managing flows through intricate material lines of labor through the very materiality of energy, networks and the labor making and maintaining them that we can think about (Wark, 1994:2012: 2019). It stands as often concealed infrastructure through which the global is projected as a frictionless totality. Not only those networks are material but the continuous metabolisms making them are often forgotten: inside the latest apparatus offered by Silicon Valley, tethered to each bit of information, one can find connections to the dust in the lungs of silicon miners, as well as to the Navajo women whose weaving skills were highly appreciated for producing microchips (Parikka, 2015; Nakamura, 2014 p. 934),

This infrastructure is also what makes Cybernetics a very special technical protocol, taken not as a "spill over" or a mediating response but literally: it makes a 
protocol of government and the protocol of managing production coincide and be computed by the same technical form (Pasquinelli, 2017b p. 290) This coincidence is attests to a pulverization of both governance and production. Growing complexity, miniaturization of computation as such pave the way for this convergence, thus, one can have valorizing information far beyond the confines of the factory (Pasquinelli, 2017; Wark, 2019).

Deleuze (1990:1992), in contact with cybernetics and other technical changes almost at the end of his life, addresses the way in which the disciplinary societies were a phenomenon that was already fading away and how what he speculated as their successors, the "societies of control", were basically about how cybernetics as a protocol for information management could actually become a diffused and adapting protocol for governance. While Foucault's institutions had their boundaries based in confinement, such pulverization represents a break: no longer the disciplinary pairing between individuals/mass but the splitting of the individual into a dividual and its reconstitution as code (in the sense of a numerical double) as it interfaces with markets, platforms and bundles of data (Deleuze, 1990)

The disciplinary man was discontinuously connected to production while the potential within cybernetics for management of those totalities render the human as always in flux and allows his insertion into productive activity, even if not consciously. In sum, the collective worker finds out that the disassembling of his body is not mitigated after he gets back home, that the barrier between what he does as labor and what he does as play, from the point of view of Capital is not really a pause at all (Deleuze, 1990:1992; Pasquinelli, 2015).

"Everywhere, surfing has replaced older sports" (Deleuze, 1992 p. 6). While labor is nowhere close to becoming play, play not appropriated as labor is increasingly hard to be found: as Facebook, Instagram and other social media wire the attention of our monkey-brains into streams of images and content we produce, consume and generate data by interacting with, the vector flows to one direction (Sharpe, 2020). Facebook, for one, is cast as a space for the exploitation of the unpaid labor of users both in content producing and of information regarding content visualization and consumption, particularly through advertisement and targeted ads, casting another vector of surplus-value extraction which is constantly modulated by changes in the platform and responses to hardware improvements (Fuchs, 2015). 
This recasts completely the analogy of unpaid work in Moore (2015) pointing both that recasting information into the picture we find a new vector of appropriation, a new "cheap" to be grinded into value and also how information itself becomes the formalization of the intelligence of the productive process as Caffentzis (2013) has shown us. Information is both a way of mapping cheap natures and of managing the energetic expenditures of capital in locum, of entering circuits of the everyday life into valorization in unprecedented ways, of seeing the relationship between Capital and governance and also the condition of possibility and operative mode enabling the proliferation of finance ${ }^{44}$, for example (Wark, 2015).

The information machine conjoined with the global infrastructure of communication and data propels information far beyond the factory. But we should delve deeper into this transposition.

\section{A relay in the information machine: Data and Metadata}

Looking at this ensemble of the information machine and planetary computation, Pasquinelli (2015:2017) asks a question about the status of those machines, that is, if Simondon (2020) is right in claiming the machine as a relay, what would information machines as such split? What consequences this split articulates, particularly for the division of labor?

Information machines appear as a new relay between data and metadata, a split between two types of algorithm: first, algorithms that convert a form of information into another, such as a word processor in which you type and have your commands transformed into letters and numbers in your screen. Second, algorithms based in the production of metadata that is basically information about information. Search engines, to give a vulgar example, work by mapping your preferences and capitalizing on them for suggesting you ever more accurate products/results. The conjoining of this machine with the global infrastructure spells our contemporary technical structure and its vectors of accumulation (Pasquinelli, 2015 p. 14-20).

Metadata needs to be understood as a break with the dream and mystique surrounding the network as an egalitarian form: its history is the history of specific nodes in what was seen as a horizontal space started recording information about the circulation in that infrastructure.

\footnotetext{
${ }^{44}$ Finance was bypassed in this chapter but it should be understood as having its own metabolic imprints as well.
} 
Google's first datacenter "The Cage" in 1998 transforms the dream of the networked society, that appeared as an expansion of the public sphere and a space for socialization and sharing of knowledge. Encaged, it becomes a highly centralized alliance in the business of producing information about information which has large ties to the government and to particularly big companies and profits on the appropriation of movement by transforming it into information, tendency and intelligence for states and companies alike (Castells, 2008; Pasquinelli, 2017b; Wark, 2017).

This "new relay" between data and metadata represents a new diagram for power, no longer the control society but a certain "society of metadata" in which information machines and global scale computation, condensed and materialized in the growth of databases all around the world appropriate and commodify information while also managing themselves through it. Those disclose a new dimension to life in capital in a multiscale shape: (Pasquinelli, 2014 p. 7)

Human intelligence transforms and ramifies: thoughts become words, words become signs, signs information, information numbers, numbers data, data metadata, metadata patterns, patterns tendencies, tendencies machinic intelligence. Every second capital is burying knowledge. The numeric dimension of capital is not just monetary, but also informational and computational - encoding knowledge any moment of its circulation. (Pasquinelli, 2014 p. 7)

Regarding finance: the relevance of algorithms and information ${ }^{45}$ for finance is easy to spot. Nanex, a firm processing data from US markets stock trades, has databases 20 times the size of NASA's and if we look at how part of financial stock trades is automated based on algorithms, traders often acting as supervisors. We see that "finance turns computation into direct economic agency" and also that the size and speed of today's financial markets are only possible through massive computational apparatuses (Pasquinelli, 2015 p. 5; Srnicek, 2013). In terms of culture and entertainment, Wark finds a prescient example in Hiroki Azuma's work which can quickly be related to today's streaming services appearing as content curators, producers and data collectors. Otaku ${ }^{46}$ culture and the phenomenon of moé, meaning, how a certain feature a character has (cat-ears, white hair, red eyes and so on) become an attractor for affects and consumption and the combination between

\footnotetext{
45 For more on that see Nick Srnicek's (2013) PhD thesis "Representing Complexity" available through this link etheses.lse.ac.uk/803/

46 Otaku, as a word, can relate to pretty much any kind of deep (verging obsessive) interest into a subject. Culturally it has been used with much more frequency to define people that are into Japanese anime and other cultural scenes emerging out of those products.
} 
those features lie in databases whose trends inform media production and its adjacent industries (Wark, 2017).

Metadata helps solidify information as a quite sui generis commodity. Wark (2004:2019) is worried about how is that information acquired through that new economy is in tension with older property forms: The commodification of information is not merely a seamless affair as information has features that are themselves at odds with the commodity form. While a commodity is universally equivalent but limited both by its unitary nature and its consumption through usage, information is both inexhaustible and infinitely replicable. It redefines what labor looks like as activities not marked as labor traditionally are turned into sources of value extraction and more than anything it marks a tendency of information rendered as an attribute of capital.

"Information wants to be free, but everywhere it is in chains". The relay mentioned above realized through a global infrastructure maps a new place of enclosure of the commons, the enforcement of a new regime of property: we are both produce information without ever having access to its destiny in our free time and often stay in brain-frying jobs that produce forms for Capital to profit in its marketing agencies, programming, blogging, analyzing data, doing customer service. Those infrastructures enslave us but harbor no evil essence but the congealed appropriated knowledge and labor making them (Wark, 2004 p. 68 :2019).

Taking it further, what Caffentzis (2013) was pointing already in his analysis of the work/energy nexus is that the concentration of profits in highly automated sectors of Capital was both a strategy for answering to contestations in the work/energy arrangement that had international implications and that they generated particular rearrangements in the division of labor: growth of the services sector, threat of automation, growing concentration in the energy sector.

The first two tendencies seem to spell a specific formula for how we understand the effect of those dizzying economic changes. Benanav (2019a:2019b) does an interesting account of our current economic predicament and of the relationship between the "old" and "new" economies and the place of the services sector in it, it can be summarized in three points. First: despite the fact that fears of automation are fomented by a scenario of increasing interfaces with technologies, the question is not of a replacement of one by the other. Rather, the fact that the technological economy so to speak doesn't mask the stagnation of the "old" 
industrial economy. It is stagnated in terms of the generation of new jobs and also in its very modest rises in productivity. As the capitalist circuit requires an engine of job-generation, the industrial sector is not really able to deliver those and advancements of highly mechanized agriculture in cash-crop economy, form one of the biggest deficits in job creation, not to mention its effects for urbanism and the environment.

Second: As we have seen already by looking at value, ours is a society with the promise of employment both as a legitimizing social relation and as a requirement for our capacities of entering the market as a consumer. It is the service sector that actually absorbs most of the blows of this stagnation but even so, it cannot do it properly. While in high income countries one sees a growing tendency towards the creation of non-standard jobs $(60 \%$ of the jobs created in the OECD between $90-$ 00's for example), in low-income countries the service sector is already what employs most of the people in countries such as Brazil, Mexico, South Africa and the Philippines, for example (Benanav, 2019a).

The case of countries in the Global South is also aggravated if we look that the division of labor poses them in a position in which not only there is a tendency towards their deindustrialization but even when that industrialization happens, it is ridden by obstacles such as patents and other forms of commodified knowledge and by a lag in between the centers of innovation to their implementation in the periphery. They cannot extract the offspring of innovation in the same rate as those first-world countries, there goes sedimented a lag in the extraction of surplus-value by them (Arrighi et. al, 2003). Of course, one can see echoes of that in the terms of energy and information as an international work/energy division: in the peripheries energy supplies and cheap labor-power and in the center the informational activities of logistics, branding, databases spell how they differently embody the vectoral infrastructure (Pasquinelli, 2017).

Third, we must be careful to understand that we do not live all under the direct threat of replacement and that this is not necessarily only a function of the skillfulness of labor: it is hard to automate some sectors of textile industry that are not qualified but still are cheaply done by third world workers. What we are seeing with this tendency towards underemployment is from another nature: neither a world of full disposability of human labor nor an automatic revolution towards a postcapitalist economy but a world of stagnation, with a saturated third sector: street 
food vendors, barbers, home-based sales of food on demand, precarized online professors, the proliferation of a gig-economy and an unending stream of invented services inhabit our future (Benanav, 2019b). From such dispersed ways of making a living among an ever less prosper system, platforms such as delivery apps are a form in which the information sector to further capitalize and intensify in labor exploitation (Srnicek, 2017) Briefly back to Grove's work, he pictures the threat of automation:

Labor automation in both economic and security sectors, vastly augmented by heuristic machine learning, can quite literally live off itself. This is assuming "the self" can continue to expand to asteroids and nearby plants. The limits and the catastrophe that we have been reduced to hoping for may be temporally and spatially out of reach. For those in what McKenzie Wark has called the vectoralist class, there is no catastrophe. (Grove 2018 p. 224)

To put it another way, civil society, humans, and the political are-for a capitalist metabolism run on minerals and regulated by lethal automated force-luxuries, not necessities. (Grove, 2018 p. 224)

The main problem in those quotations, a kind of fetishized vision of labor independence. While grasping the prospect of increasing automation of killing in the field of security and how this unleashes potential cruelty and is itself a vector of accumulation, a point he always emphasizes. This a blatant an overstretching of Wark's $(2019 ; 2020)$ argument. Vectorialism (how she calls the class profiting with the commodification of information) is not labor independent and neither can be, its labor independence is merely a semblance which is precisely the ideological construction that tries to project the global infrastructure as frictionless and laborless. It seems as if the automaton as a trick of the $17^{\text {th }}$ century still fascinates the internet age (Jones-Imhotep, 2020)

Such visions ignore that value is precisely created by labor and cannot be created ex nihilo. It misapprehends the myriad of movements in which value creation becomes indeed more distant from labor but judges this further abstraction, this separation as a complete one, rather than understanding that its freedom from labor is not a case of autonomy as detachment but of an apparent detachment with continuous reference to labor as its ground (Paulani, 2011; Tupinambá, 2016). Such continuous reference is blatant when one sees labor as a metabolism mediated by technology and also as a social form related to a specific form of wealth production. 
Such a vision is also not compatible with a concept of technology delegated to being a function of ideas unfolding.

Even further, Full-automation as indifference to labor is a trick. As Joler and Pasquinelli $(2020)^{47}$ put:

machines, including AI, constantly call for human help, some authors have suggested replacing 'automation' with the more accurate term heteromation. Heteromation means that the familiar narrative of AI as perpetuum mobile is possible only thanks to a reserve army of workers.

I do not seek to recover what Grove (2018) called Marxist fake hopes of redeeming the world through crisis but it is crucial that we understand that the type of society we were predicated on is dying. We are at the crossroads from a society of employment to one of underemployment and unemployment. In this arrangement combining stagnation and escalation we have been portraying, the future is less flashy than it seems: Capital is both powerful and disintegrating and forfeiting the intertwinement between both of those dimensions. However, this situation spells not a disposability of labor-power but rather a vector of its further exploitation: underemployment and precarious labor express precisely this growing tension. Less the distribution of death through sudden independence from humans and more the slow wearing off of said humans, the bodily shattering business as usual that we encounter through our everyday grind (Berlant, 2013).

The story of the Anthropocene is not the unfolding of an inert impervious rationality, a concept of matter or a trajectory ingrained within modernity. It is, rather vulgarly, a story of social relations of value production through labor as a metabolism aimed at valorization concretized by material nets of flesh and tech. Capital is a creature of abstraction: it is predicated in those processes of management and quantification.

As we have seen, technology is a crucial vector for understanding the nature of those abstractions and their oppressiveness, but technology also expands cognition, opens new pathways of understanding, new possibilities and is made precisely through the labor that it then exploits. As we have seen, value is a process of abstraction with material effects. However, abstraction is not the evil to be fought against, the irredeemable process from which to run away or seek refuge from but it constitutes also the place of struggle.

\footnotetext{
${ }^{47}$ One can see this text in website form at https://nooscope.ai/
} 
As Reed (2018) puts, abstraction is a function of how we speculate and attune ourselves to creating things or relations that are alien to us and that both may come to expand our capacities and to create harmful effects as well. It is this ambivalent power through which capital is latched onto. Tensioning it begins by tilting the world's horizon of possibilities and beginning not only to recover other technics but to ask how to work in the ruins of this world we ought to wreck.

For Reed (2018), alienation need not be seen only as something to get rid of, but something to be seized. A provocation is that communism might just be the collective management of alienation. That should not be confused with alienation as managerial ethos: it is the capacity of abiding for protocols of our creation and of overthrowing or withdrawing from them as well (Tupinambá, 2017). Our political task, regarding technology as it is geared indeed towards capitalist reproduction and commodification is one of "redesigning on the fly" (Wark, 2012:2019). We might make history but as we know the means of making it are not always the ones of our choice.

The contrast between the potentiality of computation and the damages of the technosphere has become manifest today, with global data centers accelerating networks of logistics, the extraction of natural resources (often in the global South), and fossil fuel emissions worldwide. The incestuous relation between planetary control and planetary disequilibrium is the riddle at stake in the hiatus between the Cybernetic Hypothesis and the Anthropocene Hypothesis, the civilizations of Silicon and Carbon, the lineages of Information and Energy (...) The relation between the chimera's two heads of Energy and Information happened to be a turbulent double bind: of mutual amplification (in the game of capital) but also of containment (in the game of politics). Rather than reiterating the opposition of monotonic paradigms, it may be better to try and consolidate the assemblage of energy and information into new systemic notions. (Pasquinelli, 2017 p. 321)

Pace Grove (2019), the formulation of those future systemic notions must be done through new grammars and mix multiple forms of life and their knowledges also in different measures while minding their autonomy and sometimes their indifference to our endeavors. To that, we add it is crucial we conjoin struggles, calling attention to the puzzle of doing so in ways that are not appropriative of each demands merely turning them into another act of enclosing, but such an act can only be solved in practice.

Weaving the paths of carbon and silicon opens both a connectivity between struggles for labor with struggles for the environment, it also weaves back labor as metabolism in the fabric of the Anthropocene and offers a demystified account of technology. Even more crucial, it poses technology as a mediator between the human and nature through labor, a mediator that makes and remakes what organizing 
ourselves might mean and changes both human and nature in the process (Pasquinelli, 2017).

That, in its ties with metabolism as we have laid out earlier in this chapter, may also offer away of bridging other forms of life and their relationships to nature as Inayatullah \& Blaney (2010) show through their analysis of Marx's problem of coevalness of different forms of production. The recognition of labor as composed of energy and information weaved by socially organized production may be a possible bridge for the construction of an ecology of theories, practices and knowledges for the Anthropocene.

\section{Concluding notes or Recomposing the Hydra}

What I wish to take out of such an exposition is first about how we treat technology and capital in relation to the Anthropocene: what I offered throughout this chapter is a very "low resolution" technological sequence of paradigmatic machines within capitalism. I sketched a synthetic narration of how capital manages flows of energy and information and how machines may intertwine with both production and politics. We went from the relation between energy and information and then to the one between information and metadata. This counters what I called out the "idealistic slippages" of Grove's (2018) argument. The technological line developed throughout the Eurocene becomes not the expression of ideas or rationalities but grounded in changes within the division of labor and within dynamic forces, an offspring of work.

I would promptly make a mea culpa to the fact that the trajectory I have tried to account for is a sort Western-centric one, even if still juggling with attempts to point at contradictions within the division of labor. I did so first because I find that Grove's conceptualization of it when, at its worse, risks essentializing technology for both extra-modern forms of life and modern ones, detaching them from a movement between concrete and abstract and bracketing the fact that the struggle is not only about the diversity of technics as echoes of conceptions but as problem solving activities one develops in their sensual experience against and with nature, as hallmarks of social tensions, divisions of labor and also metaphysical longings.

However, the main point of approaching the machine as such a diagram is that it brings closer the possibility of seizing and remaking the current infrastructures and puts the question in many fields: who makes the machines, through what relations, 
who accesses the knowledge making them, with which flows of information and energy they work with and so on.

This opens us to a rather different question: not only "who" created the trajectory or which ideas is it based on but rather the speculative challenge of what one could do if one seizes it, as soon as it appears as non-essentialized and imbricated with many historical developments. Granted, my reading is an oblique one based in a slippage of his argument seen from the perspective of political economy and in that it might not deal with the full scope of his argument. However, this deviation is healthy and the remaining tensions rather than dissipated must be seen as proposing new beginnings, other possible construction sites.

The trajectories of energy and information show us the way to weave back labor into the fabric of the Anthropocene. Capitalist production is the ever-changing technically mediated metabolism. Technology is matter cooked up with labor mobilizing both harmful realities and containing salvageable potentials to be seized and rethought. Energy and information weaved through labor and synthesized in machines tell us a techno-social history of the management and development of production as metabolism, its materialization and our experience of our historical present.

Production itself spills over, politics and economy are bound even if one might sometimes limit and undermine the other: their relation births diagrams and flows both ways. Labor as metabolism appears as the activity of weaving information and energy that changes what the human and nature mean. The form it is abstracted within Capital as in the first chapter is the passage towards abstract labor that appears as aimed towards the production of value. When looked from this perspective, it is shown that value production is itself predicated in the liberation of carbon, the creation of metabolic rifts, forms of alien control aiming at modulation, surveillance and commodification. Marxist critique is nothing if it is not a critique of labor as it takes form within the structure of abstract domination and exploitation of capitalism.

In the next chapter we are guided by the concept of alienation as a path to expand further towards the convergence between environmental and labor struggles tethering the need for rethinking our current mode of production to the question of the Human and its destabilizations. The concept of alienation will help us look at a dichotomy: how capital alienates us from nature and technology and what would it mean to craft a politics for alienation, thinking through what the collective 
management of alienation could mean. For that, we go back to Marx's (2009) attempt to read the human in its genericity, thrown against some of the destabilizations brought by the post-human and its weaving into the Anthropocene. 


\section{Chapter 3 - Alienation, Inhuman Revisions and Tektology}

In Chapter 1 we focused on the question of production in the Anthropocene, assessing the entry of the Anthropocene through an evaluation of the "Planet Politics Manifesto" and related debates. While well intentioned, both the manifesto and to some lesser extent their critics end up too close to posing the problem always disconnected from production and related to the higher level of the ethico-political. That higher level, however, is understood in an idealistic fashion precisely due to the negligence of production in the making of the Anthropocene.

Detached from the question of production, the Anthropocene becomes fertile for ethical speculation but sterile for envisioning political alliances with other struggles and demands and their convergence in the need for the abolition of our current forms of production. Two challenges brought forth by the Anthropocene were also formulated, namely, the need to think the global and the planetary, both in their overlapping and the difference, without subsuming one into the other. For that, we recovered the category of production as metabolism, emphasized the historically determined nature of value and capitalist production.

Chapter 2 makes two main points: first, it makes an appraisal and slight deviation from Grove's (2019) "Savage Geopolitics" in that it tries to work against slippages into a vision of technology as an expression of a certain "view of matter" and move beyond it, highlighting vectors of exploitation and the formation of diagrams of power. We also marginally dealt with Grove's debates of other forms-oflife trampled by modernization centralizing the question of the machine as an actualization of concrete and virtual potentials and metabolism, at once a crystallization of social relations and an instrument radically changing the society in which it appears.

Then, we touch on the way in which labor is a hybrid activity by looking at the concept of the "Collective Laborer" (Gesamarbeiter) and how it prefigures the cyborg. Marx's theory of machines approaches how they crystallize divisions of labor, allowing for surplus-modulation by measuring and optimizing the split parts of the productive process. It also exposed the machine as a material relays that allow one to manage energy and information as separated flows. Following this synthetic scheme along the industrial revolution and crucial changes in production through specific machines, we touched three points. 
First, the thermodynamic machine, capital's reliance on fossil fuels, how they originate from strategies to keep power over labor and the irreducible biophysical shadow, planetary and local metabolic rifts brought forth by valorization; Second, electricity, the fast transmission of information and energy through space and the intensification of the management of form-giving gestures in routines of labor spell also a different way of exercising political power through information machines and also of production, as information becomes the intelligence of energy, the intelligence of capital; Last, the pulverization of the information machine scaled through planetary computation as it reconstructs crucial aspects of what labor and power are.

The materiality of such a trajectory binds production as metabolism and politics. From that perspective, the Anthropocene and production appear together, labor struggles and environmental struggles overlap and show the importance of an ecological critique of political economy. This not only invigorates political economy but also grounds much of the talk of changes at an ethical level for the Anthropocene by showing that the challenges lying ahead are not only to wonder what is the appropriate "relationality" or practices of living to take but fundamentally how to begin thinking new modes of production out of this one, how to seize and redesign on the go, how can a new way of laboring appear.

This current chapter comprises three main movements: it introduces questions of alienation and abstraction by looking at the impossibility of the unalienated life as it appears in current debates, pushing for considering "communism as the collective management of alienation" as an enabling hypothesis for recasting the concept of alienation in a different light. We sketch the historical background of Marx's theorization of alienation, demarcating some continuities and ruptures while also directly confronting the assumption of alienation as a retrieval of essence, especially as it is interpreted in the Economic-Philosophical Manuscripts (EPM).

I advance an opposition between theories of a "strong nature" and "weak nature" opting for a conception of a weak nature which is, bluntly put, the view that nature in its own unfolding creates quite unnatural things.

By looking at labor as metabolism we revisit the connection between alienation and the human as generic being, finding in Marx resources to reclaim the concept of genericity not as a positive capacity natural to the human with which to 
rekindle but as an ambivalent one, through which the human naturalizes/denaturalizes itself. This both counters the vision of the human as merely echoing the supposedly creative capacity of nature and introduces the possibility of making history through the subversion of the current forces of production. Connecting the possibility of rupturing with the social production as the material ground for a revisability and construction of what the human and nature mean, we find a quite inhuman procedure.

By revisability I mean that this inhuman capacity for naturalization/denaturalization is the capacity to review and restructure the social space in which one is grounded and restructure it, constantly redefining through praxis both what nature and the human ought to mean, opening a space for revolutionary practice and the radical restructuring of our social organization of production. It is through this possibility of radically working towards a revolutionary change of our social organization, presenting some lines of criticism of Rosi Braidotti's Post-Human, particularly formulated by Ray Brassier (2018:2021) both indirectly and more recently addressing her specifically, mindful of how they echo through the approaches I have presented in IR, arguing that this revisability is precisely what is effaced, a move only possible due to the ontologizing of ethics and a reductive picture of the interplay within humans and nature we have articulated as the concept of metabolism.

Lastly, I make a further exposition of the concept of Tektology stressing both how it singularly grasps this revisability of the human and serves as a speculative tool for two moves: first, having a vision of labor as metabolism that can both allow for historical coevalness between different forms of labor and for imagining another relation between labor and knowledge as they restructure what both the human and nature can mean.

\section{Could Communism be the Collective Management of Alienation?}

Grove $(2019)^{48}$ sketches a heuristic division of Marxist approaches to the environmental crisis: the first ones follow what he calls a "logic of contradiction".

\footnotetext{
${ }^{48}$ I should clarify that my mention of Grove's (2019) distinction here does not mean I endorse in any way the representations he makes of each of the sides. I believe he is at his most precise when he comments on specific works. His overall picture of "Marxism" is, at least for me, too broad to take seriously. It does not seem to represent the totality of what this unification could mean. Granted I am in some ways myself butchering Grove's text to serve my own purposes, I shall try to at least make it justice by cutting it at the right joints.
} 
Vulgarly, the tensions inherent to capital brings about the demise of Capital. Therefore, one resurrects the drama of the demise of capital via the ecological crisis and tries to claim that the heightening of material contradictions could finally mark the last breath of capital. For him, this marks an "amplification of Marxist eschatology" which he identifies with Moore (2015), for example, as he seeks to make the linkage between capitalism's toll on the planet and its impossibility of continuity as a vector of capital's end.

Whether Moore (2015) has any automatic revolution in mind can be questioned, but one can see this as a consequence of what I called incorporating value into nature too deeply: the environmental crisis becomes a mere expression of the crisis of capitalism, a loss of substract that comes to providentially render it impossible. Such an approach is not equal but certainly maps into my criticism of Moore's dismissal of metabolism: by conflating nature and history without thinking the gap between those two open systems with radically different scales.

On the other side, lie those whom Grove (2019) calls the Marxists tired of waiting for contradiction who seek to advance a "vanguard of transformation". He is referring to the environment formed around the "Accelerationist manifesto" and the book "Inventing the Future"49, both by Nick Srnicek and Alex Williams (2013:2015), which formulate a plea for the potential of automation of bringing about a post-work society.

In their case, they are not limited to but definitely influenced by a certain reading of Marx and how he tarries with the question of technology, of course, but there is also there a critique of how the left as a field has become often stuck in a rhetoric that fears the scaling of politics, that resigns to local implications of power and localist tactics and that ignore the potential certain technological advancements bring about in order to think about alternative futures.

Grove (2019) points that such a diagnosis, no matter how positive, carries at once a supposed openness towards the future and render everything local as infertile. To that, let us remember that what they call "folk politics" is not a typology but a tendency, it designates no one in particular but becomes an umbrella term for

\footnotetext{
49 An interesting piece of commentary on the document is "\#Celerity: A critique of the Manifesto for an Accelerationist Politics" by Mckenzie Wark, available here: https://speculativeheresy.files.wordpress.com/2013/05/wark-mckenzie-celerity.pdf). Benjamin Noys (2015) also gives an interesting overview and commentary on Accelerationism and related ideas https://tripleampersand.org/accelerated-substance-abuse/
} 
criticizing recent movements of contestation ranging from the Zapatistas ${ }^{50}$ to Occupy Wall Street.

According to them, despite the polemical edge of the argument, folk politics is not unimportant: the problem for the authors is the resignation to it as the ultimate horizon of contestation. I would say that there is little in the concept of folk politics that directly seeks to diagnose a specific problem that is the problem of the left worldwide. Rather, the concept is an aggregator of a condensed variety of problems found across different recent political contestations. Therefore, this definition represents no one completely, but rather tries to condense spread symptoms under one disease (Srnicek \& Williams, 2015).

They frame a common structure to folk politics ${ }^{51}$ based on: an emphasis on temporary suspensions of power that turn politics into therapeutic space by trying to retrieve immediacy and embodiment; emphasis on responsiveness and short-term tactics; repeated patterns of returning to good lost past rather than inventing new futures; engaging in the romanticization of rioting and insurrection rather its axiomatization that turns it into a project of power; and last, repulse towards the mediated and attempts to seek refuge in the non-technical, the affective, the bodily (Srnicek \& Williams, 2015).

Grove is reluctant to fully accept this typology, and comprehensibly so: he identifies within those currents represented by Srnicek \& Williams (2015) a tendency to downplay the role those marginalized forms-of-life can actually play and the lack of recognition for their ongoing construction of counter-practices. Therefore, for him, "Accelerationism" 52 offers another form of homogenization that merely repeats the Eurocenic frame. Hence why, despite being a welcome attempt to rebuild futurity

\footnotetext{
${ }^{50}$ For an analysis of the Zapatista Struggle in particular that in a lot of ways counter this categorization and complexifies this knot between the local and the global, see the Midnight Notes Collective's "Auroras of the Zapatistas", available for free at http://www.midnightnotes.org/auroras.html

51 There is an implicit thread of dialogue with communization theory (Invisible Committee and Tiqqun, for example) in the edge of the Accelerationist movements in general.

${ }^{52} \mathrm{He}$ does also state that it is committed to the overcoming of Malthusian limits, setting communism as this overcoming as such. However, I believe any attempt to associate Marx with Malthus by presenting him either as a Malthusian who thought there are fixed limits to economic growth or as someone who thought there are no limits so humans can just do whatever they want miss the point. While Malthus was someone Marx was extensively debating against and that indeed made the question of scarcity a problematic one for him, his position comes to trouble Marx for the fact that Malthus assumptions were based merely in a ratio between arithmetic productive growth and exponential populational growth limited to data in the colonial U.S. that then was derived as historical finalistic universal law. Marx was deeply against that as it did not take into account the way human activity could influence nature no matter how limited that was, as already shown by studies in soil sciences by people such as Justus Von Liebig who were widely important for Marx's theory of metabolism. For more on that see Foster's (2000) “Marx's Ecology".
} 
and venture towards the actualization of virtual potentials, it is deemed as stuck in what is understood to be a lack of experience and knowledge about those possibilities.

I believe the best way to parse out these positions is through productive friction: while at one hand the universal, the homogenizing totality of exchange is what represents the logic of the system per se, it is only partially experienced and tractable. It lies in what in Ch.1 I called the dichotomy between "Truth without reality and reality without truth". It is through this very mismatch experienced as a constrain to how we inhabit our present and are cast inside and outside of history at the same time, that we encounter what Jameson (1994) has called necessity, history as that which hurts, as the objective experience of limits. This encounter is from where one is compelled to break with repetition. Breakings with repetition mean rebelling, struggling and cultivating futurities, sets of knowledge and transitional spatial irruptions that are criticized by folk politics by failing to become enduring movements.

What the critique of folk politics points at is that, while those movements are indeed related to struggles that find global and planetary expression, they are not always articulated in such a linkage. However, that does not mean that we should just think globally and wait for a global narrative that is finally radical enough either, as it may not emerge but even if it does, it is worth nothing if it is not anchored in locally bound political practice. Both of those projects encounter each other in a tension that Wark (2012:2015) formulated quite well: the imagined opposition here is between either addressing the global head on or affirming the multiplicity of the local against the global. Through the perspective of friction above, the question becomes what kind of material and discursive apparatuses can mediate between one and the other. I believe that the perspective of the social organization of production and the rifts it ensues, both metabolic and epistemic as they feed and are fed by diagrams of power (as highlighted in Ch. 2) provides an interesting perspective for those linkages.

Hence, what interests me in particular in how Grove (2019) talks about this second "accelerationist" strain of Marxism is not as the crafter of a new master discourse but how it is committed structuring a new social organization of production in the ruins of the current one. For that, Grove (2019) sees two paths: either overcoming alienation or overcoming work altogether. Both of those either "unleash the potential of labor" or the positive creative potential of enslaved humans 
for other goals. This is what I believe is crucial to explore, but cautiously: we have to avoid both thinking that there is any positive substance from which the worker is already-alienated from that must be retrieved and the obverse argument that there is an inherent potential already there in laborers as a privileged historical subjectivity that must merely be affirmed. In the first, revolution rekindles with the long lost essence, in the second, revolution is already there just waiting to happen. Both hopes offer us solace from History's indifference (Postone, 2013; Tupinambá, 2017; Grove, 2019).

My argument in this chapter is to carve a path that refuses both of those framed options, shedding light at the space for a third position which is what I called the position of the inhuman, one that supposes no inherent fixed positive potential either to labor or to the human or to nature assuming it shares with it a sui generis creative potential. In this perspective, there is no positive generic distributed potential specific to the human that is not the capacity to be inhuman, to both repeat and change the coordinates of the social organization of production as a nexus generating historical determinations. One is only able to speak of a human genericity in the first place through this nexus that historically sets human genericity through the social organization of production, in particular in the form it takes through Capital and its spread through the world.

In the specific context of the Anthropocene, to purely claim the inherent potential of labor as the act of bringing such an essence into the world and recognizing oneself in it is to engage in a project in which one does not live to the potential of the Anthropocene to dislodge and recognize the messy imbrications of humans, tech and nature. This posture leads us straight back to socialist humanism: rather than exiting the $21^{\text {st }}$ century ${ }^{53}$, we find ourselves trapped in the failures of the $20^{\text {th }}$ (Wendling, 2009; Saito, 2017; Grove, 2019).

Up until now, a common feature we noticed is that Capital is a creature of abstraction: inquiring into alienation is, bluntly, inquiring into the way the products of our own activity are encountered as if foreign. How our realities are conditioned by alien forces outside of our own conscious making, how those are turned against us as when nature becomes something to exclusively be posed against. Our definition in Ch.1 of abstract labor as a singular way of framing the organization of collective

${ }^{53}$ This is an appropriation of a detournement done by Mckenzie Wark of Guy Debord's plea to exit the $20^{\text {th }}$ century. See this in "The Beach Beneath the Street" (2012) and the intro to "General Intellects" (2017) 
labor through its commonality in a specific regime based on private labor, for example, attests to a historical model of abstraction fostered by capitalist social relations. Technology also, as we have seen with surplus labor modulation, mediates specific forms of abstraction qua modes of quantification and response: the modulation of split processes of value production and their reconstitution as abstract totalities through the collective worker provide us another example. Amidst abstractions rendering us apparently powerless, the possibility of escaping from the abstract tout-court seems both unlikely and undesirable.

A provocation seeming to shift the angle through which we look at some of those problems becomes irresistible: what if communism is the collective management of alienation? ${ }^{54}$ We do indeed make history but neither with conditions chosen by us, nor divorced from the irreducible materiality of the planetary. Such a hypothesis might be worth considering for politics in the Anthropocene ${ }^{55}$. The point is how to diagram and commit to abstractions of our own making that are mindful to the imbrication between politics and economy. That might seem like committing to foreign powers all over again. However, the wager of politics must not be understood as the endless pursuit of freedom qua absence of constraints as this is precisely the form of freedom available in political discourses amidst our era of deregulation, erosion of forms of state care and exaltation of the entrepreneurial subject (Brown, 2018).

Claiming freedom as mere absence of constrains or as mere positive potential finally unleashed, merely mirrors our current iteration of capitalism's concept of market-realized freedom qua a hypothetical lack of formal constraints that, of course, can only really be a repetition of the concept of freedom our current intertwinement of state and the economy offers us. Rather, one should inquire into freedom as the capacity to create and commit to procedures and abstractions, to legislate upon the nature of how we alienate ourselves. This is a step not only for a future society but

54 A Conference, titled "Parliament of people: Communism will be the collective management of alienation" was organized around this theme, among the presents were Ray Brassier, Samo Tomsic, Nadia Bou Ali, Mattin Artiach, Paul B. Preciado and Dimitra Kotouza. It can be found here: https://www.youtube.com/watch?v $=$ wrSkus8wbsY\&t=146s. This formulation, according to organizers, is taken from a talk from Samo Tomsic in 2017's Historical Materialism conference. It appears also to Tomsic's (2019) book "The Labour of enjoyment: Towards a Critique of Libidinal Economy" in Chapter 2. While he works around a close analysis of the cross-fertilization between Marx and Lacan and its possibilities, I will focus, respecting the scope of this thesis, on the consequence of this claim for my argument and for Marx. Nevertheless, I consider both formulations compatible even though I have no time to elaborate on the exact status of this compatibility.

55 See David Chandler (2018) "Ontopolitics in the Anthropocene: An Introduction to Mapping, Sensing and Hacking" and Benjamin Bratton's (2015) "The Stack: On Sovereignty and Software” for discussions on governance. 
that comprises very mundane political organization happening in the gaps within the texture of our current sociality, gaps that include different forms of inclusion and exclusion in the capitalist system. Such a procedure is not mere fabulation of futures but a crucial grounding for political organizing if it is to rely on something beyond mere irruption and reactivity that quickly gets reintegrated into systemic logic (Tupinambá, 2017).

An example of trying to think alienation and abstraction as political potential rather than a mere constraint to be done with is found in the Xenofeminist Manifesto (XF) written by the collective Laboria Cuboniks (LC) (2018), and which attempts to think about a politics for alienation as precisely such a political effort. The point for them is to craft what they call, performing a sort of detournement ${ }^{56}$ of feminist thought, "intersectional universalism". From the universalism of the commodity form and its hidden personae of the white, rational, male, the integrated violence inherent in our mechanisms of abstraction require a counter universalism that is concrete and built in an ongoing process. With no essence to return to, no warm embrace to be expected from indifferent mother nature, seizing the infrastructure enslaving us and diagramming it towards another form of metabolism is paramount.

One must note that the method of Marxism is precisely the method of abstraction, the attempt to reproduce that which is concrete in thought, the understanding of the concrete as such as deeply influenced by abstractions constantly actualized through social practice (Brassier, 2018). Hence the role of socialized production in generating determinations at both the level of society and of the subject. Abstraction emerges not only as method but as the axis and activity of Capital and of sociality. On abstraction and the capacity to abide to our own protocols:

\footnotetext{
"Abstraction must be considered an organic and logical collective power of the mind that precedes language ${ }^{57}$, mathematics, and science in general: it is the power to perceive in detail
}

\footnotetext{
${ }^{56}$ Detournement is a category advanced by Guy Debord and the Situationists and which Mckenzie Wark (2012) situates as a key methodological practice for the situationists, especially in her book "The Beach Beneath the Street". It is better defined as a disregard for intellectual property and lineage, the hijacking of a term and the attachment of it to contexts in which it seemed foreign, a method for conceptual invention and heretical practice.

${ }^{57}$ I should clarify that what Pasquinelli is pushing is a model of an organic development of the brain and of cognition in which language emerges both as a social and biological consequence and that this model does not mean that there is any inherent creative power within the human as pre-linguistic being but that language as such is built through this interaction between the social and the biological. I cannot, however, enter into the status of this "prelinguistic" character embedded into his story. This prelinguistic nature is informed by an adaptive view of intelligence in the human that develop. See Pasquinelli (2016) e-flux entry "Abnormal Encephalization in the Age of Machine Learning" available
} 
and recognize an emotion, to project the self beyond its cultural limits, to change habits to recover from a trauma, or to invent a new norm to adapt to the environment. It is also the power, of course, to manipulate tools, machines, and information. Abstraction is deeply rooted in life and time. Deleuze and Guattari reminded us that the primeval artistic gesture of the human was an abstract line: primitive art begins with the abstract (Pasquinelli $2018 \mathrm{p}$. 58)

What one opposes to abstraction is not the unmediated, the body or the natural with which we may finally reunite with. In fact, our bodies themselves are what bind us to the positive feedback loops of capitalism as our attention span gets fractured through multiple interfaces (Sharpe, 2019). Rather, abstraction is, in short, the speculative power of the human to historically revise the status of its own determinations. Such a power, as we will see further down, when tackling alienation and externalization, is not necessarily positive per se but is in itself rather ambivalent.

It features in Marx's collective worker that the trajectory of labor is the process through which the human is starting to dissolve, the body is cut in pieces and reassembled obeying to social abstractions that are foreign to him, solidified by his own interactions. To reclaim abstraction is not getting rid of the body and realize the old Western dream of an escape from flesh ${ }^{58}$ but being able to seize and restructure the powers penetrating it. Merely claiming more body, more affect, more immediacy, less mediation and a more human world will not do.

It is seizing the capacity to abstract as that which redefines and reframes the human as such that we can radically challenge the metabolism underpinning our material existences, our embodiments and restructure our placement in the world. Pasquinelli (2018 p. 3) again lays clear the kinship between sociality and abstraction: "The paradigms of both biopower and cognitive capitalism should be described as the exploitation and alienation of the power of abstraction".

As Laboria Cuboniks (2018 p. 43) puts it: "We want neither clean hands nor beautiful souls, neither virtue nor terror. We want superior forms of corruption.". Such a demand lays bare the convergence between rethinking the vectors of

here https://www.e-flux.com/journal/75/67133/abnormal-encephalization-in-the-age-of-machinelearning $/$

58 Sadie Plant formulates the limits of such a rhetoric already on the eve of cyberculture concerning the equation of cyberspace, cybernetics, abstraction and information with a metaphor or a virtualization that should be countered by remembering the material, the body, its immediate fruition. One must take cyberspace not as metaphor but literally. Cyberspace is not an escape to outside of the body but rather its fragmentation-augmentation, not exiting the meat towards cyberspace and the realization of the soul outside the treachery of meat but the way in which cyberspace (one could say here the abstractions of capital) enters the meat and foments concrete bodily processes that can liberate or enslave us. This is formulated clearly in this paper presentation: https:/ /www.youtube.com/watch?v=doL9mRMEUGw\&t=1284s 
embodiment, production as metabolism and politics in their intertwinement. This is the speculative place in which we can think about an ethico-political commitment that is not based on realizing abstract ideals as our critique in Ch. 1 pointed at, but that begins from the material to sketch its own heresies, tilting our horizon of expectations from what is towards what it could be (Reed, 2018). If the stakes of communism as collective form of alienation are to be formulated, we might need to go back to Marx in a bit and follow a thread that leads us to understanding what alienation is and what those categories can tell us about our current predicament.

\section{Alienation, The Human and Metabolism}

One of the most notable texts corroborating the interpretation of the question of alienation in Marx in the way Grove (2019) does, meaning, as the retrieval of a forfeited human essence which capitalist socialization takes away from us is the "Economic-Philosophical Manuscripts" of it. I propose to go against this common impression regarding alienation, against the reduction of Marx's whole endeavor to a simplified version of it, showing how his thought develops in this question of nature and what directions this development sketches.

Complexifying Grove's (2019) division, I will look at questions of nature and alienation in Marx, recasting them against the common conception of Marx as merely a thinker of de-alienation as the rekindling with nature in communism to be done through the abolition of private property. This will be countered by recent returns to Hegel that cast him as a thinker of "weak nature" and readings that cast the Young Marx against his later works. Through this conjunction, we find a conception of nature that sees it as incapable of preventing estrangement, as creating quite

\footnotetext{
59 They are also referred to as Paris Manuscripts or simply 1844 Manuscripts. The value attributed to those when one is talking about Marx's oeuvre is also a highly divergent and are in fact a matter of decision into how one reads Marx. One could vulgarly say that readings of Marx influenced mainly by Althusser's epistemic break have a tendency to dismiss the writings of that time as they lie before the scientific nature of Marx's while readings that focus on a certain continuity and unified character of the problems traversing Marx's work actually find that themes from those manuscripts are revised and appear in Capital. I would argue that those two views are increasingly seen not as an either/or choice but negotiated as a continuum. The best example of the epistemic break is of course its theorizer Althusser, but readings stressing continuity within Marx and going against Althusser can be found in many shapes. One example I like is Kohei Saito’s (2017) “Karl Marx’s Ecossocialism: The Unfinished Critique of Political Economy. However, that Capital is nevertheless a work that represent a changing movement in those early assumptions is, one could say, easily accepted.
} 
unnatural things and the hope of non-alienated life as such as being quite an impossible endeavor. After that, I will show how those are consistent with concept of metabolism in Marx's own mature position. This makes both a critique of return to non-alienated pasts and fundamentally changes how one reads the concept of the human in Marx as not a function of a static species defined by fiat, relying on what Marx later called a "dumb generality" that sets a certain supposed generic shared substance but as a constant ever-changing formula of what both nature and the human mean.

Written by Marx in 1844, those manuscripts were a base text of socialist humanism $^{60}$. The interpretations regarding both the content and the placement it has in Marxist thought and method are abundant ${ }^{61}$, hence, this section and chapter are not really worried with making a case for the best interpretation or to diagnose the one that is most loyal to the Marxist endeavor. My interest lies on the productive potential of the concepts and their unfolding within Marx, as alienation weaves together the beginning of Marx's inquiry into the relation of labor and nature that would be formulated in a myriad of ways, be it through the concept of metabolism or the question of machinery and the knowledge producing it. I am, therefore, situating the question of alienation in connection to questions we have been touching on, meaning, production as metabolism, the way technology redefines the meaning of the human and of nature, mindful of possibilities and limitations of the concept of alienation to be attached to the questions of nature and technology (Saito, 2017).

While the question of how much Marx's insights in the EPM are connected or not to what he develops in Capital is one that has many answers, it will be dodged here. I will contend, inspired by both Saito (2017) and Wendling's (2009) different readings, that, while there are ruptures that cannot be ignored, looking at the earlier writings from the vantage point of the later works offer a very productive endeavor for a variety of reasons. Knowing the theoretical advancements in Capital, we must contend that, one of the main mistakes of the EPM lies in the fixation of private property as the main cause of the harms brought by commodity society. Marx is

${ }^{60}$ Those manuscripts are of huge influence for Lukács work and his work on the category of Alienation. See Lukács (2013) "History and Class Consciousness: studies in Marxist Dialectics" and for a brief set of archival and translation curiosities regarding the manuscripts see Jesus Ranieri's introduction in "Manuscritos economico-filosóficos". For a deeper overview of the manuscripts and their relevance in the intellectual history of Marxism see Hodges (1965) "Marx's contribution to humanism". See also Paul Mattick's (1978) "Humanism and Socialism" here $<$ https://www.marxists.org/archive/mattick-paul/1965/humanism.htm>

${ }^{61}$ A good overview of this diversity can be found in Bottomore's (1991) "Dictionary of Marxist Thought". See "Alienation". 
guilty of misrecognizing within the form of property relations the major expression of the capitalist system and taking property rather than value as the main vector of criticism, of at times assuming the human and his production as merely a coextension of nature, to be finally recognized under the overcoming of Capital (Tupinambá, 2017). With this underdevelopment stated, we jump to the concept of alienation.

To claim the impossibility of "unalienating" the human in Marx's work is to change the stakes of what communism could mean. While there are endless other ways to look at this question with different focuses ${ }^{62}$, I will be concerned with framing what alienation tells us about our political commitments both in the impossibility of a return to nature and in the status of the human in Marx's theorization and its possibilities. If Marx is to be more than a mere icon of a radical past, what Grove (2019) called a longing for "when intellectuals were truly dangerous" and also more than a museum piece to be conserved, this becomes crucial (Wendling, 2009; Saito, 2017; Marx, [1844] 2009).

The merit of Marx is his construction of a materialism of abstraction: commodity production and the circuits of value, labor and money on which it is predicated form myriad real abstractions that get actualized through often nonconscious practice and predicated on an irreducible materiality in order to come to exist (Brassier, 2018 p. 111-113; Saito, 2017).

Thus, we must be mindful of how Marx's EPM's are an attempt to critically unite contributions from the Classical Economists, French Socialists, Hegel, Young Hegelians and Feuerbach's critique of religion in order to criticize the historical period in which he was living, on the onslaught of the industrial revolution and the effervescence of worker struggles (Wendling, 2009). What unifies Marx's ([1844] 2009) approach to those figures, is that he approaches them through the social effectivization of their ideas, the way thought and philosophy are made literal and actualized in history and in production. This invites an exercise of looking at Marx's materialism and folding the later developments of his thought into some of the trajectories that are already set before.

\footnotetext{
62 Another very interesting thread that begins with alienation is the connection between Marx and Lacan sketched by the Llubjlana school and their original reading of the relationship between Hegel, Marx and Lacan. Fundamental texts in this lineage would be: Slavoj Zizek's (1989) "The sublime object of Ideology" and its interpretation of commodity fetishism through Sohn-Rethel and Lacan are classical. A further formulation comes in Samo Tomsic's "Marx and Lacan: The Capitalist Unconscious" (2015)
} 
This gesture takes us to two terms that appear in Marx connected to his inheritance to Hegel and to the concept of alienation ${ }^{63}$. The concepts are: externalization (entäusserung) and estrangement/alienation (entfremdung). The play and the difference between externalization and estrangement/alienation are specifically crucial for both Hegel ${ }^{64}$ and Marx and take us to the question of nature. In the specific case of Hegel, externalization, simply put, refers to the way Spirit (to be understood here as human collective self-consciousness) wrests itself from nature and creates institutions, customs and norms that then also are determinant to him, forming a "second nature" (Brassier, 2019). We must be careful, however, first because those two are not separated as autonomous spheres, in fact, the making a second nature can only emerge as a network of relations of recognition together with a network of socially mediated labor practices (Renault, 2016)

First and second nature are concepts that always appear paired in a contrast that defines the second against the first and form a long and intricate genealogy ${ }^{65}$. Broadly stated, in Hegel it spells the difference between nature as the realm of objectified processes made understandable through reasoning procedures versus processes occurring in normatively structured rationality or in what we could call culture. Unpacked, those terms in fact form a grid comprising first/second nature and subjective/objective iterations: A subjective first nature comprises the individual's biological processes, his bodily existence; a subjective second nature comprises the individual beings as actors in a certain sociality through protocols, norms, language and concepts; objective second nature comprises institutions, social conventions; and, lastly, the objective first nature is composed of inorganical matter ${ }^{66}$

\footnotetext{
${ }^{63}$ For interesting examples of very different interpretations of alienation throughout the History of Marxism see Bottomore's (1991) "A dictionary for Marxist thought". A classical interpretation against the concepts of alienation and reification are to be found in Althusser and Balibar's (2009) "Reading Capital”.

64 I have no intention of offering an interpretation of Hegel's extensive body of work and my concerns are solely guided by my purpose of developing a specific explication of Marx. My focus is not assessing Hegel's own merits per se but quite literally how parts of Marx's inheritance to him get mobilized or elided.

${ }^{65}$ Italo Testa (2009) offers a condensed account of this from journey from Classical Philosophy until Hegel.

${ }^{66}$ While I am centering on the question of the Human, the delimitation of the inorganic is a crucial point: There is in Hegel's philosophy an understanding of the organism which actually follows a line from the inorganic towards the organic. Plants appear as the middle ground as they are coordinated and their purposefulness is driven by their environment, namely the position of light, moisture etc. Animals appear as complete organisms and therefore subjects due to their capacity of self-perception and perception of finitude which is delayed through reproduction. Animals, for that matter, reveal already traces of the human capacity to exceed nature which gets concretized in Humans. See Illeterati's (2014) "The concept of organism in Hegel's philosophy of nature"
} 
(Testa, 2009). Of course, those separations are far from neatly independent but through them we can understand better what we are getting at.

The concepts of externalization and alienation are related to the discussion of first/second nature because they convey the movement through which something becomes other to itself. Therefore, the movement through which the human emerges out of nature and enters a process of sociality that is not entirely guided by nature, even if still embedded in it. The difference between both concepts is that while in externalization, this otherness harbors a trace of myself in which I can recognize that creation as determined and, to some extent, coextensive with me, estrangement stands for the non-recognition of myself into said object, the process through which this common ground disappears, it still refers to me, even if I cannot recognize my own determinations within it (Marx [1844] 2009 p. 80; Tupinambá, 2017 p. 12; Saito, 2017).

A great way to elucidate this difference between externalization and estrangement/alienation is to look at the difference between the mirror image and the doppelgänger. While the mirror shows us our own image in which we recognize ourselves, the doppelgänger acquires his own volition and personal will and faces us as a completely estranged figure, even if still referring to our own identity (Tupinambá, 2017 p. 12).

Marx specifically praises Hegel's concept of exteriorization and its development in the Phenomenology of Spirit to the way in which he takes the selfproduction of Men as a process in which his generic forces, namely this capacity of producing things that are foreign to himself are mobilized. Particularly, Marx is very interested in the fact that the self-production of the Human is taken as a continuous endeavor in History. As Marx ([1844] 2009 p. 123) puts:

Hegel takes, on the one hand the self-production of man as a process, the objectivation as de-objectivation, as exteriorization and sublation of that exteriorization; that it comprehends the essence of labor and conceives the objective, truthful man, because the it comes as an effect of its own labor. The active, effective behavior of men to himself in the condition of a generic being, the activation of his generic being as a generic being, that is, in the condition of a human being, is only possible because he exposes all of his generic forces -which is possible only through collective action of man, only as a result of history- behaving towards it as if facing objects, what is possible only in principle through the form of estrangement.

Feuerbach's deployment of those concepts is of special influence for Marx. It is through him that Marx tethers a true materialism and a real science as having to 
take the relationship among man, the social relation, as its principle. Second, Feuerbach hints at an anti-philosophical gesture in which philosophy appears as religion brought to thought and conducted through it, consisting in another form of estrangement. Third, Feuerbach's critique of Hegel and his understanding of History and historical movements only as "abstract, logic, speculative expressions" is taken even further by Marx. His point is to emphasize the literal, material movement in the concrete making of social structures. It is through Feuerbach that religion becomes a paradigmatic example of estrangement: as Man objectivates his being into God as made in his image, he makes himself an object of that object he created that gains the status of a subject. Something created by Man faces him as an alien power and turned Man into an object himself. It does not take great trouble to find out that actually this metaphor is greatly informative and harbors a trace of how Marx will deal with Capital later $^{67}$ (Feuerbach [1841] 2008, p. 193; Marx, [1844] 2009 p. 117-118; Wendling, 2009).

Testa (2009:2020) emphasizes how the processual character between externalization and estrangement. He argues that every self-conscious denaturalization brings forth another naturalization, hence, every attempt to dealienate (or de-estrange) oneself, brings other forms of alienation (or estrangement). In this light, alienation is composed of the moment in which human collective selfconsciousness engages itself in the continuous struggle to overcome necessity (pace Jameson, synthetically, an encounter with limits), which appears as an incomplete struggle that always refers to and the generation of other forms of socially mediated struggles for necessity. Ray Brassier (201768:2019), looking at externalization/estrangement points that in human collective self-consciousness those movements are always constitutive. What this means is that the standpoint that evaluates them is itself always changing because it is embedded in history, therefore, we can only access those movements immanently, from our own historical perspective, by retrospectively looking at enabling factors in the current estrangement in which we find ourselves.

\footnotetext{
${ }^{67}$ On a literal thought experiment that traces this relation between Capital and God, well beyond Feuerbach, see Ian Wright's (2020) "Capital as Real God" https://ianwrightsite.wordpress.com/2020/09/03/marx-on-capital-as-a-real-god-2/

68 This was first formulated on the Parliament of People. His talk is available here: https://www.youtube.com/watch?v $=$ wrSkus8wbsY\&t=146s. It was later published with some editions. See Ray Brassier (2019) "Strange Sameness" in Angelaki.
} 
Therefore, the processuality between externalization/estrangement, must not be understood as a two-fold consecutive process: it is not that a process of externalization will always bring forth another process of alienation but rather that in the attempt to de-estrange or de-alienate ourselves, we do so both retrospectively and bring forth forms of alienation we cannot really program. As synthetized by Brassier (2019 p. 104) externalization can at its best only be "de-estrangement as estrangement" precisely because there is no positive content inherent to externalizing as such, only a revisability of our own circumstances. Likewise, alienation and dealienation are combined as one movement uniting those functions and that, by itself, radically changes the meaning of both nature and the human shifting the grounds under which we access our own current alienated condition (Brassier, 2017:2019).

In this play between de-estrangement as estrangement, in Hegel we have a "weak nature": first and second nature are weak because they cannot really prevent self-estrangement, of externalizing things that exceed their purposes and face us just as exemplified with the doppelganger. Our externalizations change their ground (nature and ourselves) with them and, by this shift, mark the point of view that externalizes them as already-imperfect, exposing us to the danger that our creations might come to dominate us. Hence, the Human and nature are always a changing relation and neither have a completely fixed meaning, their grounds are always shifting (Tupinambá, 2017 p. 13). This instability is precisely historical immanence, exemplified by the changes in the socialized organized of production that both alienate us differently but also open the possibility of de-estrangement through alternative forms of estrangement.

This logic seems very foreign to what Grove (2019) was mentioning in which communism must tend towards the abolition of alienation which would either be the realization of a static human potential through labor or its unleashing of positivity after the abolition of labor. Such a reading of alienation, however, is possible only if one sticks to the $\mathrm{EPM}^{69}$, but not seriously defensible either in this conception of "weak nature" or by looking at the developments of Marx's own conception of

\footnotetext{
69 Tupinambá (2017) and Brassier (2017:2019:2021 forthcoming) have slightly different modulations about this reading: while Tupinambá shows it as an evolving one but gives more room for the possibility of reading in the EPM without the rest of Marx's work in mind, Brassier is less sympathetic to reading a "strong" nature even in Marx's early work, which he sees as a misinterpretation from the start. My position errs closer to Tupinambá's on that matter, mainly because both Wendling (2009) and Saito (2017) are quick to show the movement of those positions through a lot of archival work that weights in favor of the fact Marx has a gradual change in his perspectives on the question of alienation.
} 
nature and metabolism across his work. Despite lackluster systematization, Marx's scattered, but nevertheless sustained engagement with the concept of nature is quite compatible to the frame of weak nature. This not only it allows us to elucidate Marx but also offers us paths to reassess the concept of the human and some of the political stakes of the Anthropocene.

However, the plasticity between first/second nature and of deestrangement/estrangement we highlighted above is indeed downplayed in the EPM if read as a standalone source. Marx's ([1844] 2009 p. 105) residual humanist tendencies leave us right at the diagnosis that communism must mean the "positive sublation of private property, human self-estrangement" hence the "effective appropriation" of human essence by the abolition of the laws that take it away from him in social reality. The formula of communism in this sense becomes humanism=naturalism, hence, a matter of returning to owning one's creations. In this version, we have a framing of the question in which labor is essentially pure externalization, a quality inherited from nature, which is torn apart from man due to the social structure of private property. However, if the processes of estrangement/externalization are seen together as we laid above, it seems hard to withhold this formula simply because it is impossible to reclaim a genuine, uncorrupted externalization as such (Saito, 2017; Brassier, 2019).

Formulating alienation in terms of humanism=naturalism, corresponds to a "strong" conception of nature: nature externalizes itself in man who is natural and just as nature does, creates things that are coextensive with himself as well. But, through the institution of private property and the emergent social relations he is separated from this potential. The division between first and second nature, if we take this formula, cannot really be accounted for historically and must be presupposed, the social is inexplicable and separates Humans from Nature as if emerging out of nowhere. Also, in this reading, if nature is the realm of non-alienated exteriorization, all that which is alienated must be essentially external to nature which actually creates an image of second nature as an almost immaterial layer emerging out of nowhere. It is in this argumentative chain that the way out is setting ourselves to retrieve this positive and generic power of creation back, rekindling with this generic capacity that is attributed as an essential feature of our species-being we inherit from nature (Tupinambá, 2017 p. 13) ${ }^{70}$.

\footnotetext{
70 This is not to say that such a formula relying on this strong naturalization of genericity has not been
} 
Even if the strong nature hypothesis could potentially account for changes occurring in the status between man and nature, it effaces the ongoing-ness of this reconstruction, how the terms per se and the point of view that incurs on this change is already changed in this same procedure (Brassier, 2019). We find this refusal of a strong nature evident in the posterior criticism Marx makes on "Theses on Feuerbach":

To abstract from the historical process and to fix the religious sentiment as something by itself is to presuppose an abstract - isolated - human individual. Essence, therefore, can be comprehended only as "genus", as an internal, dumb generality which naturally unites the many individuals (Marx, [1888] 200271).

One could also notice this trajectory already in the radical historicization of the concept of nature appearing in The German Ideology as Marx claims both the impossibility of thinking like Feuerbach of a nature that exists as prior to the emergence of human sociality and reaffirms the existence of "a historical nature and a natural history" and their dynamics (Foster, 1999:2000; Marx \& Engels, 2007 p. 32; Saito, 2017)

Therefore, in the thesis of "weak nature", there is not a generality that is merely a function of nature by default. The generic is not the positive creative potential we inherit from being natural beings, but a form of historically and socially built way of existence based on the contentless universality of value that emerges precisely through commodity production and exchange as an insubstantial unessential universality. It is inside this generality that our own generality as species is built with a unique character.

We lie deprived not of the creative potential nature imprints into us because it has it within itself as its main feature, with which we must rekindle. Rather, the generic is the ambivalent capacity to "produce something out of the experience of being estranged from each other and from ourselves", in a way, of being able to determine and revise the determinations which we abide to. Such a capacity, in capitalism, is only offered through its crippled form of wage-labor (Tupinambá, 2017). It is precisely the spirit of Marx's wager against the political economists the denaturalization of concepts which in Classical Political Economy were seen as

important for concrete struggles conducted everywhere. Struggles against slavery in the colonies, for example, often were fond of those kinds of formulations as the property over one's own labor (and even the property over one's labor power to be sold as wished) could be mobilized as a positive political goal, especially when connected with the struggles in the metropole. For that, see the chapter on slavery in Amy Wendling's (2009) "Karl Marx on Technology and Alienation"

${ }^{71}$ Freely available here <https://www.marxists.org/archive/marx/works/1845/theses/theses.htm> 
results from idyllic narratives about the emergence of the society in which he lived, to show that what appears as natural can only appear as such by erasing its foundational and ongoing violence (Marx, 2004).

If this is the case, our own species-being as humans does not mark an essence which lie in our reality as natural beings, nor in our ideal role as externalizers that qualifies us as possible perfect creature. What marks the human is precisely the fracture between his determinations and the social activity that makes those possible, externalization can only be destrangement as estrangement, precisely because we are neither fully natural nor fully artificial but rather remaking what both of those mean:

\footnotetext{
'Human' does not name a specifiable way of being - the self, the sovereign individual, or even 'that being which is in each case mine'. It indexes the blind spot between historically specific determinations of the human (as political animal, rational animal, economic animal, but also as soul, subject, existence, etc.) and social production as the generic activity through which such determinations are generated. (Brassier, 2021 p. 14)
}

Caught between those historical determinations of the human and the fact that they stem from social production as such is where the prospect of de-alienation comes, from retrospective reconstruction done precisely within a historical present and embedded in its own abstractions. As Brassier (2020 p. 104) puts it, is through this relation that we are caught in History and able to be historical agents, retrospectively assessing what it means to "Free ourselves from compulsion", the repetition of our current norms and protocols and what "compels us to be free" as radically restructuring our own second nature, particularly in the case of Marx, restructuring the social organization of production.

This fleeting dynamic between first and second nature, and the role Marx ascribes to the social organization of production in it is an important knot to understand the meaning and ongoing change of the human. It shows how those processes are intertwined. It also calls forth to the interplay between History and Necessity we made in Ch.1, History appears as that which hurts, whose aggrievances compel us to retrospectively reassess our circumstances (Jameson, 1992).

We also have seen specifically the form of capitalist exchange as it is inflected and made through matter with impacts that are also metabolic: the rebuilding of our ground in the dynamic we have seen about human and nature are not only dynamics of thought, Marx's radicality lies precisely in making them literal. As evident, Marx's (2009:2017a) innovation on both Hegel and Feuerbach is rooting those movements not merely in consciousness but in the emergence of a novel arrangement based on 
value as an organizer of production and exchange (Brassier, 2019; Wendling, 2009 p. 48). A natural next step is to integrate this dynamic with how Marx himself conceived nature and metabolism, and metabolic intercourse as an unsurpassable part of this.

Marx specifies a historical iteration of this process that gives Capital a certain specificity, assessing his present through reflexive comparison with the past, precisely through looking at the expropriation of the commons. The concept of estrangement appears already in the notes on "Land Rent" referring to estranged land (entfremdete). Marx poses himself however against the glorification of feudal property by the romantics that merely wanted a return to the previous circumstance and directly ties estrangement and dispossession (Marx, [1844] 2009 p. 74; Saito, 2017).

By refusing to idealize feudal structures, he sees the serf as "an accident of land" that despite being estranged from it, still somehow maintains a residual intimacy with it even if subjected to an estranged power bestowed from above him by the aristocrat. The point is that while still alienated from land in some way it is still fixed to it, having land as its inorganic $b_{0 d y}{ }^{72}$, a perspective only available by retrospectively seeing the serf from the perspective of his already past dispossession. Serfs get free from the lord's personal domination, only to find themselves separated from what is retrospectively assessed as a form of continuity with nature. Such "continuity" is broken through expropriation, now they find themselves tethered to labor power as it becomes the matter to be sold for their subsistence (Marx, [1844] 2009 p. 74; Saito, 2017 p. 41).

It is specifically thinking about the colonial periphery of capitalism that Marx's theory of estrangement from land is developed in Capital into his critique of primitive accumulation in Capital's Chapter 32, showing enclosure in an even more generic form, trumping other forms of social organization (Saito, 2017). Here, Marx formalizes his critique to the idyllic pictures of the process of enclosure of the commons which both opens territory as a resource and people as mere labor-power and highlight the complicity between the state and capital in coloniality expressed

72 One could actually look at modernity as a process of body disgruntling, of extreme body modification and increasing anxiety about the mismatch between the supposed "natural" body and the "unnatural" social. Romantism is portrayed by Marx as the longing for an artificial past projected in nature, a reactionary turn against the disturbing environment of the cities. Another example of science that, just as Marxism emerges out of this disturbing feature of modernity, is psychoanalysis and its problematization of the knot between nature and culture, the interplay between transgression and normativity expressed in sexuality, a domain sometimes thought as merely instinctual. For more on that see Samo Tomsic's (2020) “The labour of enjoyment", more specifically the Chapter 2 that frames this around the concept of the death drive. 
through expropriation and accumulation (Blaney \& Inayatullah, 2010; Marx, 2017a; Coulthard, 2014).

The distinctive feature of capital as a mode of organizing production pitting humans against nature is not pictured here as a result of a set of doctrines or ideals but actualized and brought precisely through social organization of production as such. To clarify: the process of expropriation and globalization that renders possible to think of a generality as a universal whole is the material process through which humans are reduced to privately deployed labor power which sustains itself by being sold.

While this is decisively expanded in the eve of the industrial revolution, as we have seen, this is set out during the XVI century through coloniality, the spread of global markets and their connection to the slave-trade, the waging of war, the strengthening of the state apparatus and in many other iterations making the global. Of course, those determinations themselves are embedded in other hierarchies intertwined with race, gender, caste and others that place the individual into particular placements of how this passage is itself experienced socially (Moore, 2015; Saito, 2017; Grove, 2019).

One must also see a relation to the second chapter's walkthrough the concepts of the General Intellect, the Collective Worker and how one sees a new regime of both power, management and expropriation through information. Just we retrospectively see such a process as a separation from nature, those paradigmatic machines crystallize the historical changes of the division of labor, mediating metabolism as such.

Wendling (2009) emphasizes Marx's attitude towards technology must be praised for its ambivalence and refusal of both technophilia and technophobia as it grounds the possibility of a world in which people work less, a possibility paved by the virtual potentials within technology Marx himself experienced. However, she points that "Alienation can end only with the continuing use of technology, but in a system of valuation in which the tyranny of exchange-value has been eliminated and use-value is once again in view" (Wendling, 2009 p.213)

While opening the path for what I have been arguing and centralizing the need for abolishing the current structures of production related to the value-form, and also seeing great possibilities to be taken from current technological developments, there is a crucial point of divergence I have with Wendling's view. If 
we follow the logic of estrangement/externalization I have put, there is no way to back her reliance on the ending of alienation as such (Wendling, 2009 p. 213).

While understanding our present as historically limited by Capitalism, Wendling's position is anchored in the possibility that alienation is finally replaced by its good old double which finally delivers "non monstruous objectification" (Idem, p. 21). Even if she recognizes that technology is a crucial mediator of humans and their metabolism in nature, and that it is indeed a sociomorphic one that condenses divisions of labor and relations of power, she still lapses into a vision of communism as telos that brings forth a final resolution. Such a resolution means it sees externalization as entirely external to any alienation and not in the processual character emphasized by Brassier and Testa.

Wendling's move, therefore, is insufficient as it merely dislodges positivity from the human apparently, as it still poses it as a capacity to rekindle with, but one that is inaugurated when capitalism is abolished. Wendling (2009 p. 21) claims that Marx transfers the dilemma in the overcoming of estrangement and alienation in Hegel to the material realm. If we take the interpretations above, however, we see that Wendling forecloses precisely de-estrangement as estrangement and is somewhat trapped in a framework of strong nature. While she is right in her grounding of technology as a tool through which the human unmakes and remakes itself and nature and that such tools embody diagrams related to the social division of labor and also material flows of energy and information, she is still stuck to a certain infallibility of technology as soon as the social organization which it echoes is changed and does away with alienation, which is nothing than a remnant of this positive potential, only that it is deferred to the communist future to come.

Now that technology is recast, we might look to the concept of metabolism (Stoffwechse) as the category through which we understood the formal reproduction of Capital through its inflection upon matter (Stoff). Hence, an ecological critique of political economy is a critique of the mode of estrangement advanced by capital as an organizer of nature and of technology through social production. Thinking in those terms is one of the ways to get out of the ethico-political that appears merely as a high legislative principle in the guise of a bottom-up change of consciousness brought by awareness: the affirmation of a speculative potential to the Anthropocene must be grounded in understanding the need for both abolition of our current social 
organization of production and the making of another one (as I have already argued) (Saito 2017).

Referring back to the value-form qua mode of organization, we already noticed in the exposition on abstract labor that labor under capitalism is abstracted in a historically specific way ${ }^{73}$. This is based on the transhistorical necessity of organizing labor qua human expenditure of nerves and muscles that, in the capitalist society, is based on private labors that must have their results made compatible in the market through the generalization effected by money. Therefore, what metabolism exposes is this ongoing embeddedness of the social organization of production as the substract for erecting a "second nature".

This attests to how the reproduction of economic-social forms such as the commodity, money and value (Formwechse) in the domain of second nature are always irreducibly material forms of metabolism (Stoffwechse) and actualized through very concrete organizations of labor (Saito, 2017 p. 71). The concept of metabolism and its messy usages as a metaphor for labor involving machines, nerves, muscles, materials and so on are how Marx can bridge a consistent conception of nature that can account both for an analysis of the inflection of economic forms into the world and their materialization.

Labor appears not as positive capacity but as this ambivalence lying right at the porous border between first and second nature and remaking it. Such a remaking, however, appears as indifferent to us: our experiences of self-estrangement as the capacity to invert relations between creator and creation is precisely what capital monopolizes (Tupinambá, 2017). In production they manifest within the current frame of capitalist sociality: the promise of wage-labor, the ecological regime of capital, the machine that faces the laborer as an object outside due to the fact that the knowledge taken to build it is unknown, the collective worker that disgruntles the labor process and the laborer's body and skill in pieces into the factory's ecology, the structural underemployment that propels one straight into platformed capital, the commodification of leisure, the environmentally predatory approach to commodities that when quickly depleted leave populations wrecked.

\footnotetext{
73 One could counter this argument that claiming that this genericity appearing of labor as natural activity is only a result of Capital's homogenization effectuated in the market. However, to that strictly social reading I think there is also a strong point on seeing this as constitutive and appropriated in a particular manner through a naturalist framework which sees the evolution of humans tethered to divisions of labor and other forms of socialization. Those would be quite compatible with both Saito's (2017) and Blaney and Inayatullah's (2010) approaches in my opinion, even if I cannot quite make that point throughout the thesis.
} 
Therefore, the mobilization of trying to suture a concept of a weak nature into Marx is complemented through the category of metabolism, one that emerges as the way Marx could understand the relationship between economic forms and matter, a point crucial for his metabolism and which makes his theory worth thinking in the Anthropocene. Through this theory of weak nature, also, one can recognize historical immanence and refuse to accept an essential feature both identifying transhistorically what the human is (Brassier, 2019). There is space, as it will be clear with Bogdanov, both for a naturalist scientific stance on the human and a social account of its embeddedness.

Communism as the abolition of the value form emerges not as the abolishment of alienation, the final rendezvous with nature and our integration with it, but as moving towards the collective management of alienation, the experience of abiding by self-made protocols, a continuous effort, what Brassier (2019) synthetized as de-estrangement as estrangement. This is an attempt to repeat the gesture of breaking with previous modes of production through the active seizing/remaking of the virtual potentials lying within our own historical circumstances and its production and also through other forms of life that lie within our historical grasp that open not processes to mirror but the labor of constructing possible alternatives (Reed, 2018).

We need to proceed with the utmost care though: as we have stressed the continuous nature of the play between first and second nature renders impossible to index a point of view as if outside of history to legislate from as in the humanist=naturalism formula. If as we have seen nature is weak and the human's "generic" capacity to create is not a positive reconnection with nature, but the capacity to engage in "destrangement as estrangement" this framework of revisability through our capacity of restructuring our social organization of production is one that revises what both the human and nature can mean (Brassier, 2017:2019). Communism is the collective management of alienation as long as it stands for the capacity of revising how we organize our lives as such through the possibility of destruction and reconstruction of the different grounds in which we exist and for the capacity of setting ourselves not free from alienation but to increasingly alienate ourselves in our own terms. In short, Communism as the collective management of alienation appears as reckoning that externalization can only happen through deestrangement as estrangement. 
This negative quality of the Human is to change our own ground through experiments with that which we externalize and then encounters us as strange. Attuning it to Reed's (2018) term Xenophilia, one can see it also as a sensibility to that which performs this tilting of our horizon and points towards other articulations within it, towards a vector of revision. This revisability constitutes what Reza Negarestani calls the "Inhuman":

"Humanism cannot be regarded as a claim about the human that can simply be professed once, subsequently turned into a foundation or axiom, and the whole matter concluded. Inhumanism is a nomenclature for the infeasibility of this one-time profession. It is a figure for the impossibility of ever putting the matter to rest once and for all." (Negarestani in Mackay and Avanessian, 2017 p. 439)

From this perspective, however, to work only based on this de-stabilization by the Anthropocene, thinking that what comes after is a rekindling with any kind of potentiality, inscribed in any essential feature inherent to the human (as a perfect externalizer mirroring nature's capacity, for example) but also in seeing nature as a creative force underpinning and expressing itself commonly in all things that exist, constitute a mere reversal that still takes one to the same dead end it tries to dispel.

Hoping that our predicament by default delivers realizations of new connections, potentials for multiplicity and change of consciousness as new ideas and perspectives emerge incurs, in a lot of ways, in the risk of falling prey not only to the hope that one can "save the world" through some ingrained quality of the human but to the inverse hope that, as the world crumbles, we will finally get rid of the world's shackles and be able to experience it with more and more freedom.

Chandler $(2019)^{74}$ provocatively points at how discourses such as the Anthropocene and Globalization often give us the feeling that while everything is changing, everything is still the same on the surface. This rings very true, just as globalization's so promised destabilization of the nation state today seems like overhyped wishful thinking, the same might be happening to the Anthropocene. In the end, feeble masters made by ourselves that still rule over us are no less our masters just because we can laugh and rejoice in our spare times and safe spaces at their weakness while we still exist in a world made mostly by them.

\footnotetext{
74 Entry fully available: https://iiraorg.com/2019/08/18/rethinking-the-anthropocene-ascarnivalocene/
} 


\section{Post-Humanity and Reification}

The previous section might be charged of smuggling back this capacity of human exteriorization qua a singular feature of humans and lapsing all over again into an inattention to the historical weight of the human, to those who are not identified with it. It might seem as if I am, after all, attempting to spoil the great carnivalesque feature of our current political conjuncture and rescuing the human (Chandler, 2019).

I want to argue that some of those forms of affirmation that appear as progressive realizations of diversity and inclusion, of new possibilities of futurity, might reveal themselves more imbricated into the logic of capitalism than they seem to disclose and that they concede far too much ground to a conception of nature which relies on seeing ontology as an instance of ethics. This move relies both in an effacing of history and in a speculative naturalism that sets the basis of nature in a petrified image that always expresses an underlying common tendency in all of matter. For that, I will begin with a text from Rosi Braidotti (2019) and reframe some points in Brassier's (2019:2021) critique of her work, which I believe sets a good continuity for my usage of alienation already inspired by his work.

The choice for formulating a critique of Braidotti's argument comes from her approach, which seeks to affirm the destabilizing features of the Anthropocene. It is brought for three reasons: first, due to relevance inside and outside of IR as Braidotti's arguments perform a related gesture to the privilege given to the EthicoPolitical in IR; second, as I believe it might help me further the conception I espoused in the previous sections; third, positioning myself further against the focus on ethics in the shape I already criticized on Ch. 1 (Chandler, 2019:2020; Burke et. al 2016).

The Post-Human and its close affiliation to the post-anthropocentric comprises what Braidotti sees as a transdisciplinary field of study and of political practice. It can be seen as aggregating to variable extents a critique of the human as a "measure of all things", species hierarchy and human exceptionalism. Two vectors of critique form this field. The first vector is made of black, women, queer, gay, native, post-colonial studies that emerged both expanding what reason and knowledge could look like and displace the previously implemented. The second vectors come through the increasingly technical mediation of our times expressed by media, digital studies, art, science studies and many others. Both of those are in the business of criticizing and destabilizing "structural anthropocentrism", "built-in Eurocentrism" and 
"methodological-nationalism" and are constitutive of a new transdisciplinarity that is predicated on changing forms of producing knowledge for this ever-changing world. This vector for her is what organizes knowledge regarding the possibilities of inhabiting the Anthropocene (Braidotti, 2019 p. 44).

I cherish her attention and care towards the fertile transdisciplinarity happening around themes related to the Anthropocene and the destabilizations they bring forth, her attempt to affirm and make kinship with other forms of knowledge. The bulk of my critique is how she conceptualizes the Human and its related theoretical innovation, the Post-Human, looking at the consequences it has for imagining politics and for this play between nature and the human I have been highlighting. My point is that her conceptualization relies on problematic conflation of nature as being the actual harbor of positivity and that by consequence her politics also look quite bleak, failing to really foment direct avenues of struggle, performing an iteration of multiculturalism and multispecies that relies on the positing of a common metaphysical substance and a reification of the human as such. In this sense, it fails to envision and promote a revolutionary restructuring of our current predicament.

An objection to any attempts to ground a genericity of the human in this generic play between de-estrangement as estrangement and its quite concrete materialization through labor, even if I stressed the human as this animal out of which emerge quite unnatural things, and who has this inadequacy constantly changed, comes as a question of inclusion: who has been allowed to be recognized as Human? Such a claim is the culmination of a certain logical pathway that Braidotti (2019) illustrates right in the beginning of the text, meaning, that the Human as a category is essentially bound to the continuous reproduction of its constitutive oppression:

"[A] normative category that indexes access to privileges and entitlements. Appeals to the 'human' are always discriminatory: they create structural distinctions and inequalities among different categories of humans, let alone between humans and non-humans (Braidotti, 2019 p. 35)

I will turn to that in a few moments, before I expose Braidotti's argument. She points to both the increasing relevance of the ensemble between identity and environmental politics as condensers of struggles. She is also attentive to the new technological advances we are witnessing in the onslaught of "cognitive capitalism", which she theorizes having in mind new emergent forms of control, information and 
coding. She understands coding as capitalism's main operation, to be understood as the creation of axioms, protocols and symbols that allow activities to be integrated into what one codes as the human.

While in the intersection between those abovementioned fields people produce strains of knowledge that are deeply embedded and coded by capital both as it finances it and extracts new structures for organizing itself, there lies also often marginalized processes of becoming that cannot be captured by it and that mark a failure from its coding power. However, this lies for Braidotti in picturing "Cognitive capitalism" as the spreading of code as enframing and hindering life. Let us remember also that the material shifts in this category based on the assembling of what I called Cyberfossil Capital is the fact that code as the extraction of information through machinery and its roles as a modulator of surplus, protocol of political power and a commodified in his own right, right at the passage of coding to Marxian surplus-value of flow, aimed towards the production of value (Pasquinelli, 2013).

Braidotti (2019 p. 35; 2019b) asks us not to think of what she calls the posthuman as a saving grace, as it is neither a subversive revolutionary subject nor an apocalyptic signal, in fact, it has in a way always been there. It is described as a "conceptual persona" and as such it is not substantialized and despite being embodied it works as a figuration. This figuration is born out of our present which she identifies with "cognitive capitalism" having in mind the advancements of power and control through increasingly technified and even biogenetical means. It also works as a way of "avoid[ing] the rhetorical generalizations about pan-humanity", the "endangered human" to be tended for and an avoidance of claims erasing differences and that want to put us "all in this together". This specific critique of claims of panhumanity are also frequent as we have seen in the lineage of criticizing the Anthropos in the grammar of the Anthropocene (Burke et. al, 2016; Fishel et. al 2018; Grove, 2019; Braidotti, 2019 p. 48). In this case, the Post-Human is that which, situated in those areas and imbrications we mention, has the capacity to exceed coding and who articulates decoded flows. Therefore, the opposition to capitalist coding is decoding.

On those remaining decoded flows, she places her bet, they mark in new "epistemological openings" which she opposes to capitalism's "epistemic acceleration" in a neat bracketing between that which is inside and that which exceeds. By epistemic acceleration she understands the way capital both amplifies and open new possibilities for cognition through "epistemic acceleration", but she is 
still reluctant to make a project out of it or even to further locate it. While Pasquinelli (2018) defines epistemic acceleration quite differently, as the "reappropriation of fixed capital as technology and knowledge" which repurposes Capital's augmenting capacities towards other goals while rethinking them, a position I largely backed up in Ch. 2, Braidotti, on the other hand, would rather compose what she calls an "ethic of affirmation" that means also deaccelerating those movements, rescuing and composing virtual potentials out of those neglected groups that may compose "alternative subject formations" outside our current order, letting the question of this repurposing and seizing bracketed off. (Pasquinelli, 2018 p. 7; Braidotti, 2019).

All in all, Braidotti's tale goes like this: the effervescence of this new field of post-humanities is not entirely subsumed into capital and converges everywhere as a call for affirmation: the dissolution of the human (the determinate predicate) reveals itself as the return of the repressed multiplicity, connected to an "affirmative ethics" that reveals itself as having survived homogenization. This ensues an "ethics" of affirmation: we can finally, through this, redefine subjectivity as an "expanded self" set a "different vision of mediated matter" that lies beyond Capital's coding. Such an ethics is not enough to really transgress the current oppressive order directly but forms a "meta-pattern" that actualizes and includes "missing people" that never had a place in "official cartographies", never were part of "the Human" understood as exclusionary category (Braidotti, 2019).

Those "missing people" find each other in the basis of a monistic substance which is univocal, immanent to itself and intelligent in both human and non-human organisms in their will to prosper, to live, as conatus or the way in which matter expresses its "ontological desire for the expression of its innermost freedom". It is this substance that animates such an ethics into the world and actualizes it, bringing not a pan-humanity but a field of relationality. In this, her move is similar to the one made by Jane Bennet's widely cited book "Vibrant Matter" which Braidotti also relates to her vital materialism, one that is no strange to Grove's (2018) plea for another concept of matter:

"If I am right that an image of inert matter helps to animate our current practice of aggressively wasteful and planet-endangering consumption, then a materiality experienced as a lively force with agentic capacity could animate a more economically sustainable public" (Bennet, 2010 p. 51)

Now of course, having been grappling with Marx for quite some time, this becomes a problem of plain idealism: an idea of matter to rescue us all from the mean ideas of capital, the voluntarism of finally choosing to live otherwise, the 
compulsion advanced by the reproduction of our current order becomes a matter of awareness to opt out. Subjectivity becomes again a matter of consciousness, the subject as labor-power disappears. There is little in this framing that really considers the singularity within Marx's materialism, one that sees ideas as resulting from social practice from which people participate unaware. With this suspicion open, let us keep going.

Her point is that those destabilizations open a field for a politics that claim "no uncontaminated outside", recognizing the "absolute immanence of power". Braidotti localizes her move as being influenced by Latour ${ }^{75}$ as she comments about his flat ontology as the attempt to see "collaborative networks" between human and nonhuman elements as each appear as symmetrical nodes in a network, sharing an equal standing, recognizing that such an approach falls into some problems. Braidotti purports to fix those by "recasting ethical and political subjectivity for our times" through the claim the common substance underlying everything itself follows an ethical pathway (Braidotti, 2019).

There are many points of this trajectory that appear open for some criticism or at least some questioning. Let us start by going back to what I pointed above with the humanism=nature formula. We see that Braidotti (2019) is indeed interested in the changes occurring within what the human means, in fact, those changes are what warrant her argument in the first place and are coextensive with the unfolding of cognitive capitalism.

She begins fixing the meaning of the human as always oppressive and essentially an exercise in discrimination but she also requires a specific concept of nature: nature ought to be the play of matter expressing its conatus $^{76}$, which she identifies as underlying unifying substance and intelligence inscribed into everything, be it organic or be it inorganic.

Now, even if she recognizes the continuity between nature and culture, their connection is formalized through this ground. Brassier (2021) leaves no doubt: her project requires a metaphysical concept of nature, a panpsychist fix in which all matter is conscious that only works if one grants thought to matter, if one

\footnotetext{
75 For a critique of Flat ontology in Latour's work in particular, see Brassier's (2009) entry in the volume about "Speculative Realism" organized by Levi Bryant and Nick Srnicek.

${ }^{76}$ Conatus is synthetically formulated by Spinoza in the Ethics Part 3 Proposition 6 "Everything, in so far as it is in itself, endeavors to persist in its own being". Of particular interest in Braidotti is that she takes this concept from how Deleuze (1988) reads Spinoza, see "Spinoza and Us" in Spinoza: Practical Philosophy.
} 
anthropomorphizes it. This is the inversion of a project trying to assert continuity between the human and nature, the other side would be scientific naturalism, which asks how sapience emerges and how cognitive human structures emerge from nature and which is based, particularly, in a positivist picture. Brassier claims both are reductions, but specifically regarding Braidotti's fix, he claims that anthropomorphizing matter is symptomatic of:

[a] subordination of politics to ethics, and of history to ontology. The result is at once the ontologizing of ethics and the 'ethicizing' of ontology, ratified in Deleuze's reading of Spinoza. It is this double movement that explains why posthumanism can affirm alterity and denounce subjugation while rejecting any human-centred rationale for the rightness of alterity or the wrongness of its subjugation (Brassier, 2021 p. 7)

The specific way in which she subsumes capitalism to $\operatorname{coding}^{77}$ is not incidental but deeply related to this rhetorical move: the opposition to the category of the human comes from seeing it as coded as such, even if its code is historically mutable. The move implicated is to side with that which is decoded, free flowing nature, and affirm continuity with it guaranteed through a common substance between human and nature, a substance that itself follows a certain ethic. Not only concrete historical processes of expropriation are effaced but also there is absolutely no commitment to the abolition of the current forms of sociality such as value, labor, the family and so on. Brassier (2021) rightly points that her emphasis on decoding forms a "metaphysical anti-capitalism" that finds its ground only in creative potential, emerging from the bottom up and destabilizing power will be enough for the human, understood here as nothing less than the historical ensemble we live in, to be abolished.

Brassier (2021) claims that the argument advanced by Braidotti is cut from the same cloth as capitalism. This can be seen in similar shapes in critiques of flatontologies and shown by her affiliation with Latour and the effacing of problems of epistemology and subjectivity. It is interesting that she does not go in his same total flattening and still retains a particularity of the concrete post-human subject for advancing an ethical project, even if this subject becomes merely a spokesperson ${ }^{78}$ for the substance's naturalized ethical unfolding (Braidotti, 2006:2019).

\footnotetext{
77 Pasquinelli (2008:2013) has a different reading of this same point in Deleuze, which I find far more productive as it sutures Marx back into Deleuze's thought in a quite creative manner. For more, see "Animal Spirits: a bestiary of the commons" or his article "Capitalismo Maquínico e mais-valia de rede".

${ }^{78}$ See also Latour's (2004) vision of an "Object-Oriented Democracy" in his "From Realpolitik to Dingpolitik: An Introduction for Making Things Public" available here: http://www.brunolatour.fr/node/208
} 
Siding Braidotti and Brassier: the Human is an ideal image for Braidotti which come to being and to social validation through coding; hence why it is inherently reactionary in its determinations by the state, family and the economy and also why she sides with the decoded. For Brassier (2019) with his emphasis on historical immanence, estrangement stands precisely for the way in which the determinations of the human are historical and situated within a certain mode of production that itself generates new determinations. Human history unfolds both through those determinations and creating those determinations through the activity of socialized production. The human stands precisely as the space between both of these things, between subversion and continuity.

The "inhuman" is the recognition of the out-of-jointness of those two things, this intertwinement of compulsion and the possibility of freedom that appears fleetingly but (and this is crucial) does not rely on the realization of a substance that is ever present in the workings of nature. Rather, it needs to be made through attacking precisely that generator of determinations that is found in the social organization of production (Negarestani, 2017; Braidotti, 2019; Brassier, 2021) ${ }^{79}$.

Hence, history takes the backseat in the sense that the opposition between the coded and the decoded is not accounted for but supposed, inflected as a transhistorical valence: as Brassier (2021) puts, there is a renaturalization of social antagonism through the positing of coded and decoded. This goes against Marx's denaturalization of it through his focus on historical immanence and immanent critique of capitalism as a mode of wealth production we advanced earlier in this chapter through the concept of alienation.

Brassier (2021) maps this particular operation within Braidotti (2019) relating it to a framework of reification in which the posited living force within matter instead of money becomes the general equivalent. As discussed, capitalism is based on this aggregation of private labors represented by money in the market which becomes the lubricant for socially binding unrelated activities and equivalating them which as we have seen is deeply related to dispossession as by losing his continuity with nature and social relations that sediment it, one finds himself short of things to sell that are not labor-power (Marx, 2009; Marx, 2017 p. 149; Brassier, 2021).

\footnotetext{
79 This binary between repetition and freedom resonates a lot with Badiou (2009) in his "Theory of the Subject", particularly on his essay "A materialist reversal of materialism". His critique of Deleuze also would be very applicable to Rosi Braidotti.
} 
This process occurs not through centralized command but through a network of relations which reproduce this very movement constantly: “they don't know but they still do it ${ }^{\prime \prime 0}$ hence why the problem is not of a false consciousness but of the historical immanence of consciousness fostered by relations of production as such $^{81}$, produced and reproduced through exchange (Marx, 2017a p. 149; Saito, 2017; Otani, 2018; Sohn-Rethel, 2020). I am not claiming Braidotti (2019) is in favor of all of those things but rather that her form of emancipation cannot break with history, but only suppose and posit the inherent strength forces that both remain and share a common substance that might overthrow it when affirmed.

Indeed, however, production takes the backseat in Braidotti. This is not strange to what we have seen to some extent in Ch. 1, because it has to be subsumed to the creativity of a "strong" nature as originary stance which remains positive, merely parasited by production, this causes a neglect of the relevance of production as a predicate that structures consciousness and social practice. It also, as Brassier (2021) puts, performs the logic of naturalization through a reifying gesture. If in the commodity, the generality of human labors qua physical expenditure is a transhistorical activity that becomes historically determined as abstract labor through the mediation of private labors by money for value generation ${ }^{82}$, in Braidotti this gesture is repeated, but through the universalization of sentience through conatus, which is attributed as the common ground between matter, life, humans and the whole world.

Curiously, in both Lukács and Adorno, reification's effect on the human is portrayed as a sort of congealment, as if he becomes an 'it', an inanimate bundle of matter, whose causal pathways are inaccessible and who abides by a law that is not only foreign but unchangeable (Testa, 2009). Not only the particularity of the human (and of history, sapience, labor) as particularly embedded in History are effaced but this congealment is encouraged and posed as emancipatory. Of course, I am not making a case for the autonomy neither of the human nor of nature as such, but for

\footnotetext{
${ }^{80}$ An original and now classic reading of this is offered in Slavoj Zizek's (1991) "The sublime object of Ideology"

81 Balibar in a recent interview with Kuzel (2020) "Ideology and Science" formulates a difference between Deleuze's Vitalistic Spinoza related to Ethics and affects and the Epistemic Spinoza in Althusser, the one stressing both the imaginary character of subjectivity as it pertains to a certain social field and shapes a certain conception of History.

82 We can say indeed that this arrangement itself is a classic case of seeing the past through the present: maybe those organizations appear analogous to this same physical ground precisely through the gesture that renders them equivalent providing a form for accounting for coevalness. See Inayatullah and Blaney (2010).
} 
gap which renders difficult their total unification, even if their borders and definitions are porous, a relationship I attempted to perform already through the concept of metabolism.

For all this very inclusive potential, we encounter quite modest politics. Braidotti leaves no place for doubt in an interview with Iu Andrés:

I believe that revolution today is a fascist concept. I believe that the people calling for revolution are from the extreme right: they are Steve Bannon, they are conservatives who believe in a neo-revolution to recover the values and notions of God, nation and family. I believe that at present a more preferable option is active activism, a collective commitment to creating affirmative values, rather than joining what seems to me to be a fascist restoration of the notion of revolution that merely aims to open the doors to violence and abuse and to turn the clock back again to pre-1968. (Braidotti, 2019b)

The aversion to revolutionary movements and their equivalence with fascism as the epitome of values and norm-setting is mediated precisely through the phobia of the interplay I explicated in the section above, of the generic in its negative sense, as the capacity of making protocols from which one is alienated of but nevertheless attempting to craft the shape of the abstractions that penetrate oneself. In the same interview, when asked if she is an optimist, she of course prefers the concept of affirmation, as for not downplaying the deep difficult of our current situation. "What is necessary is a radical transformation, following the bases of feminism, anti-racism and anti-fascism" (Braidotti, 2019; 2019b). Providence returns, only this time dressed in exciting, colorful, multicultural garments.

A proto-critique of this approach in IR is found in David Chandler's (2019) refusal of the concept of hope, which should be taken with a grain of salt. Specifically, he addresses the concept of hope appearing associated to the affirmation of inherent trends in the Anthropocene that are now unleashed by the displacement of the image of Man and all the determinant features seen by it. While I am not convinced that the elimination of hope per se as an expectation or political affect is actually that much of a gamechanger, I agree with him that conceptions of hope often find in affirmation what liberate us from the malaises of a crumbling modernity by reinstating providence as such: salvation not through Man but through the positing creative energy in that which is not it, which represents the creative potential that lies untainted by our usual habits of thought.

I want to lay very clear that I am not descending the usual path of criticizing the "identitarian struggles" or demonizing them as mere distractions that if only were channeled elsewhere would finally grant us communism. Not only those struggles of women, queer and indigenous people are not "merely identitarian" but their radicality 
is revealed precisely because the realization of their goals lie far beyond mere recognition and individual empowerment and cannot possibly be fully accommodated within capitalism.

As Endnotes (2021) recently claimed, class as a category is increasingly mediated by identity and deeply intertwined with it both demographically as people in the lower classes are particularly marked by race, for example, and also in terms of the organization and central concerns of social movements. In a scenario in which the forms of capitalist sociality are crumbling down as we have seen with both unemployment and underemployment, identity is both a logic of mobilization and an organizational obstacle as many of those grievances are common and in need of articulating aggrieved middle classes, technical laborers, surplus populations, movements for social justice and other "revolutionaries without a revolution" that irrupt in unrest but do not articulate perennial basis and programs, the form of which we have seen with the format of "folk politics".

A lot of the grammars of working-class resistance have become quite different through changes in the forces of production that gave the final blow to the image of the Fordist worker, through a mediatic space that in its overspread materiality facilitates the commodification of identity as such, increasingly tried to be made amenable to capitalist forms of recognition. Of course, the forms of recognition capital can offer are "Freedom, Equality, Property and Bentham" and that not only fail to materially address the difficulties of those groups but also fatally conceals the role the social organization of production have in their suffering, an operation not so different from the attempt to pit environmental struggles as foreign to worker's struggles and that remains through this kind of framework espoused by Braidotti (Marx, 2013; Coulthard, 2014).

Concluding, the post-human appears as a movement which despite being concretely related to very fruitful movements (the transdisciplinarity of knowledges, new themes within the humanities, the acknowledgement of the importance understanding our relation to nature, the resurgence of struggles, the recovery of different forms-of-life and so on) is still trapped in a frame that lies both homologous and (at least) unconsciously complicit to capitalist institutions and logic both as it ends up ontologizing antagonism through the dichotomy of coded and decoded forfeiting historical immanence and by committing itself to certain determinations of the human rather than their revisable character. 
Ironically enough, the focus on the ethico-political, in its neglect of the sphere of production, appears as rather lackluster, because it does not provide us a coherent frame for understanding social movements and struggles being formed related to production and reproduction nor understanding of some of the technical underpinnings of our current situation, not to mention the dead-ends it may fall when conceptualizing nature in the way exposed as it keeps the possibility of a constant revision of nature and construction of a naturalist frame submitted to the whims of the underpinning substance lies within it (Brassier, 2021).

Our provocation of communism as the collective management of alienation starts making more and more sense as we analyze both the centrality of production and the gap between our intertwinement in and capacity to break with History as we recast the human as the vector of revisability of alienation as such. Recovering a bit of the pace, we have seen the Anthropocene invites us to speculate on the future meanings of both labor, technology and the human. Analogous to the gap between our compulsion to be free and the possibility of freedom from compulsion, we are invited in the Anthropocene to make mediations: between different fields, scales, areas of knowledge, forms-of-life, divisions of labor and entities. This invitation reveals itself not only as an imaginative challenge but the very condition for intervening. For that, I set myself before the end, to recover a particular failed revolutionary project, Bogdanov's Tektology, as it tries to weave together not only an enlightening perspective concerning each of these areas but also to make this act of mediating as such a science in its own right, a form of comradely construction of both the human and the world in all of their intertwinements.

\section{Tektology and Metabolism for the Anthropocene}

Just as the labor of the inhuman binds the need for remaking ourselves and nature, I will in this chapter elaborate on the concept of Tektology, the science of organization envisioned by Bogdanov as the science of coordinating a future communist society, appearing in a way that spells communism as the collective management of alienation. I will begin by making a quick presentation of its context and connecting tektology to the scope of the chapter. My argument is that Tektology offers crucial insight for understanding possible futures in the Anthropocene and as it considers the category of metabolism, offers us with a form of binding different forms of knowledge and struggle in a very experimental manner, as it forms a 
method for the kind of revisability lying at the core of the concept of the inhuman and its relation to externalization as de-estrangement as estrangement or dealienation through seizing the mechanisms of alienation.

For that, I will present how Bogdanov expanded the question of nature and present Tektology by emphasizing how it cuts at the joints of three main points for rethinking labor in the Anthropocene that we have touched upon, namely, the question of coevalness of different historical ways of living and laboring and the division of labor as it separates information and energy and reproduces a separation between the labor and knowledge of the machines, structures and organizational arrangements in which he operates. We discover in Tektology a navigational tool for the Anthropocene as it spells a certain methodological sensibility to labor and to those crucial questions. I will not focus on making a systematic presentation of the concepts inherent to tektology but focusing on what it can do as a tool for thinking communism as the collective management of alienation.

Tektology's creator Bogdanov is among those figures whose work appears as the blueprint of an exciting life trajectory: his experience in Proletkult attempting to craft a novel proletarian education and culture bridging the gap between science labor and art; in medicine, the founding of the major institute for blood transfusion that experimented with its potential as a tool for invigorating the physical disposition of the comrades; in revolutionary practice as a Bolshevik both allied and adversary to Lenin; in Marxist scholarship as he became an author of one of the most popular introductions to political economy, one that was found in the 1920's translated by the Communist Party of Britain. (White, 2018). Mckenzie Wark (2016a) encapsulates Bogdanov's proposition as a view of our species as a builder of worlds, even if sometimes this building is quite perverse and destructive. One could see Tektology as an alternative method for doing so.

More in detail, Bogdanov's (1984 p. 10:209) Tektology is an attempt of crafting a "general organizational science". Organization in this sense can be understood as a perspective, a way of looking at phenomena (both involving human intervention or not, just as our relationship between metabolism and the planetary in Ch. 1) and how its structure is disorganized and reorganized again, attentive to the material flows that happen from those changes, having in mind not only those but also the porosity of the borders of this system, the environment which they may change. Tektology is an attempt to formalize something of his own experiences 
between many spaces articulating theory and praxis. For that, he envisioned that Tektology would become something not so different from mathematics, "achiev[ing] the same degree of formal purity" through a symbolism of its own, a precise language for formulating problems and answers (Bogdanov, 1983 p. 56; White, 2018).

It claims to be a general science can be understood only by knowing it is a monism of organization, that is, a systematizing effort predicated less in claiming a unified logic to the unfolding of matter in the universe (as we have seen above) but because it seeks to build a whole revisable picture out of the pieced-up snapshots that scientifical inquiry could build, each in its own disciplinary confines. It is also crucial that science for Bogdanov is not high-science but a rather low-proletarian scientific endeavor. Science, experience and socially organized labor appear, in all its different forms, as deeply embedded into exercises of reasoning and making things with and against the world. Reason here is not opposed to perception but made and located through it. Knowledge is framed fundamentally as an endeavor of experimentation, both in its acquisition, testing and revisability (Bogdanov, 1983; Wark, 2016a). It is not a scientific socialism, but a socialism of science (Wark, 2016a)

A linguistic example of Tektology is to be found in metaphor. Metaphors, vulgarly put, are based on tracing experimental relations between two supposedly related things and through practice being able to verify if such a resemblance is in fact an enabling or a disabling one. For example, in a beehive there are not queens in our sense of the word. However, those metaphors may enable some sorts of experiences and investigations into those animals' sociality that might be helpful for some time. However, it is only by experimenting with metaphor that one can really decide to continue using it or changing it for another, better representation. (Wark, 2016a)

His concern is not legislating what is the form of the science or even of inquiry that has to be conducted but rather asking how can we abstract from determinations and create connections through structural similarity of different forms of labor. In Bogdanov, multiplicity is pragmatically formulated, allied in the act of sketching and experimenting between knowledge and labor as metabolism (Wark, 2016a; Bogdanov, 2020 p. 14). The speculative edge of tektology lies in the fact that it looks at the way Capital manages and propagates forms and seeks to retrieve that potentiality as a continuous exercise. 
In this sense, Tektology offers us one possible sensibility for what Patricia Reed (2018) calls diagramming, a fabulation of the potential that abstracted structures can have for formulating new norms, horizons and practices as such. In that sense it goes beyond the mere taxonomic cataloguing of knowledge as dead structure, moving towards its mutual invigoration. Bogdanov's work seems like it is neither from his time nor from ours, a product of an alternative reality. It is noteworthy that it showed an interest in multiple fields of knowledge and how other civilizations across time and space organized their labor, trying to find similarities or points of contact. Coincidentally, a similar leap is noted in the end of Marx's life as well as Blaney and Inayatullah (2010) lay evident by the sudden interest in traditional societies and the change in Marx's stance regarding colonialism, from a position of cherishing British intervention in India to an enduring interest in so-called primitive societies.

It is in this sense that I claim that Tektology may be helpful as a practice for thinking about knowledges as Grove (2019) connects them to forms-of-life. Grove (2019) seeks to prevent "extra-moderns" from appearing both as saving graces and of reviving myths of virtuous savages. While we have very different pictures of what the future could possibly look like and what systematizing theories can offer, I believe Tektology serves to operationalize a traffic between different forms of knowledge and of social organization that operate neither presupposing the homogenization of structure as such nor in the congealment of forms-of-life as stagnated artifacts.

Saito (2017) extensively clarifies how abstract labor entails both a category of critique and one of overall analysis, in that it reveals to us how an abstract form of wealth inflects itself into matter modifying a general, transhistorical feature of humans that in socially relating are always weaved into multiple metabolisms with nature. It also accounts for the specificity of our arrangement based on value as a form of wealth and production arranged through private labors organized and realized through money-mediated exchange.

Blaney and Inayatullah (2010) inquire further into this dual character of abstract labor but looking at Marx's hesitation regarding the category in Capital and the Grundrisse. For them, between this gap splitting abstract labor in its most minimal definition as metabolism, before its historical specificity in Capital, reveals a crucial gap for reading different labor organizations and different cultural 
conceptions of wealth, life and so on. Historical difference as mandatorily developmental difference starts to implode when looked at from this perspective as we do not lie in a stage beyond but share time with other people. One must reiterate, in this crucial juncture, that working through this minimal definition neither spells a glorification of the form labor has in capitalism, nor attributes to it any kind of inherent creative potential but merely recognizes its play in naturalization/denaturalization and the possibility of thinking about it otherwise.

Bogdanov (1983) himself, in this issue, is in an interesting spot: by looking at this very minimal definition of labor as metabolism and how it takes different forms, he finds ways of expanding beyond what Inayatullah and Blaney (2010) are doing to Historiography: while they offer a comparison between cultures in the broadest sense, Bogdanov recursively binds this minimal definition as a mediator, a common ground. In fact, Tektology is about precisely performing this same kind of generalization by noting what common forms and structures emerging out of knowledge, labor and science in their broadest sense can form different forms of labor collaboration with neither a promise for closure nor a presupposition of immediate resemblance.

It opens space for a future that can support the coevalness of different forms of economic organization, bound not by an abstract ideal but that sketches interactions out of the materiality and frictions that define, labor, culture, science and knowledge. However, it reminds that such a future is impossible if not articulated around connection between struggles for the destruction of capitalist social forms, against the growing impossibility of social reproduction and one that spells a way of organizing nature.

This answers a critique from Grove (2019) setting in a large field of Marxist theory and praxis the possibility for not only for seeking to escape but of fundamentally altering and destroying it, taking charge of the powers rendering it possible. The horizon of such a question is not ideal but thinking with one's feet, as one navigates and binds struggles. What we are left with is an initial modest procedure for what Grove (2019) diagnosis as the lack of experimentation between different forms-of-life in "engineered communists".

Such a reading hints at a possible way of structuring experimentation that need not to end in "new enclosures", precisely, they must be built on the destruction of capitalist social forms, by the refusal of the logic that continuously pushes 
enclosing as such. Pieces for building such a future lie everywhere as long as we find ways of practically collaborating our shared existence in time not necessarily by mimicry but by forms of integration and indifference too that still need to be concretely built through politics.

Bogdanov works with such a simplified conception of labor precisely as he tries to understand the changing forms on top of this simple metabolic activity as a procedure of dealing with different scales: one can both stop at the level of saying abstract labor within Capital takes the shape Saito (2017) systematizes or go even further for a specific sector, a specific activity, a specific molecular flow such activity puts forward and see many overlapping determinations humming beneath this one, structures that can be more or less spread.

This spirit of a certain "vulgarity" comes through in his singular reading of the category of experience: experience for Bogdanov is deeply related to the movement of life as such, less as a principle of truth and more as a principle of navigation whose conditions are always revised (Bogdanov, 2016; 2020). Even if a disputed topic as the nature of experience cannot be expanded on given the scope of the text and my own expertise, it is no surprise that experience is per se a crucial question for Bogdanov as well. A lot of his work follows Ernst Mach and how he was already trying to understand the emergence of our perception out of biological evolution through a naturalist framework (Gorelik, 1984; Bogdanov, 2020; Wark, 2016a).

What Bogdanov (2016; 2020 p. 65) does, as a Marxist, is to bind this process of biological emergence of cognition to social theory, evaluating how each kind of organization of production makes people reason about the world in a particular way, forming a specific experience of nature. It is through this minimal definition of labor that he makes the laboring subject his conceptual personae. This human that labors, however, has very porous borders to his environment, tools and sociability: one could both say that he is a cyborg in the Haraway sense and that the environment as such is never a stable surface but an active participant in all of the processes (Gorelik, 1984; Wark, 2016c). Funnily enough, just as Marx sought to understand the ape through the anatomy of the human, it is through the anatomy of the cyborg, understood as the inhuman splintering of the supposed stable image of the human body that we discover the revisability of human and nature as such (Pasquinelli, 2018). 
Bogdanov (1983 p. 4-7) does not see organization as an exclusively human quality, in fact, he recognizes nature as the first organizer, marveled by the complexity of the structures it builds. However, he finds that as it articulates itself into what we have called "second nature", a specific central role appears for organization in human societies, one deeply related to the transhistorical way labor in its most synthetic definition is always a metabolism with nature.

He is not focused on asserting the authority of the human as a dogma: the division between natural and artificial for him is meaningless as both offer ways of organization, therefore there are neither natural rights in the human as species nor a glorification of human's capacity for creation. What he is interested is in the constant scientific revisability of this relationship (Bogdanov, 1983 pgs. 74). A main source of his puzzlement is, in fact, a typical scientific naturalist question which separates him from Braidotti's solution: how come the human as a "population" has progressively, through different forms of labor, crafted what we have called a second nature and changed both its humanity and what nature means and the conditions of that experience (Wark, 2016a; Bogdanov, 2020).

The particularity of the Human as an organizer, for Bogdanov (1983), is warranted by three instruments he acquires through evolution, understood here in a critical Darwinian" ${ }^{83}$ sense and how it comes to organize what we call a "second nature". It is related to how Engels (1968) speculated the appearance of tool-wielding and socially organized labor in primates as tied to a mixture of biological and social factors.

Therefore, the species emerges in a mutual imbrication that articulate and form what we call a second nature: language, "organization" as technique developments for dividing tasks and instrument-making, and the generation of socially mediated norms ${ }^{84}$ (Bogdanov, 1983). This allows, in humans, not only an exponential better management of knowledge but its transfer: cognition is viral, spread through sociality, it takes a singular shape in humans because of developments in how to teach "discrete chunks of behavior" over those interactions.

\footnotetext{
${ }^{83}$ Note that, the reception of Darwin in Russia is itself a very interesting issue. Darwin famously modeled a lot of his insights on evolution on economic categories such as overpopulation and scarcity. The rebuttal of those in Russia were both a cultural matter and an empirical one as living in an extensive territory in comparison to Britain, little about this logic seemed to hold. See Todes (1989) "Darwin without Malthus: The Struggle for Existence in Russian Evolutionary Thought".

${ }^{84}$ There is of course not time for me to argue for each of those and the debate around them. As it is simply enormous. See Wolfendale's (2019) “The reformatting of homo sapiens" for a modest entry into it.
} 
They, in fact, facilitate the emergence of all of those "instruments" with which a second nature is made of and from which it can be restructured (Wolfendale, $2019 \mathrm{p}$. 12).

As Wolfendale puts:

[The] emergence of techno-linguistic rationality reformats the biology of the human species, in order that it can better reformat the neurology of human individuals. Nevertheless, there is no reason to think that the institution of rationality is irrevocably tied to these specific morphological and computational forms. The inhuman system that ensouls our bodies transforming us into subjects responsible for our thoughts, agents responsible for our actions, and selves responsible for our own cultivation - can ensoul entirely alien somatic forms. Nietzsche's re-evaluation of values and Foucault's experimentation with selfhood may demand a substantially similar information processing protocol, but they may equally take place on a substantially different information processing platform. (Wolfendale, 2019)

It is interesting to note the convergence with two things: both what Pasquinelli (2018) calls the power of abstraction and that we mentioned above and also the kind of revisability of meanings in the formula of weak nature and the "inhuman" that we have been developing. Far from spelling a resolution, a static utopia, it is precisely this revisability of the human through "destrangement as estrangement" and how can one constantly build society, labor and politics that is at the center of Tektology.

In his novel "Red Star", portraying a communist society living in Mars that abducts a Bolshevik for a scientific and societal exchange, one sees nothing frictionless about organization of labor. In factories, workers find themselves entranced by machines that become vectors of enjoyment, but suffer from accidents quite often due to their entrancement in it. The Martians are in deep trouble and their planet is amidst an ecological crisis, one which reunites scientists and workers to decide what to do and the moral dilemma of colonizing the Earth or not, to which our protagonist responds by violent rebellion (Bogdanov, 2019).

Wark sums it up perfectly:

"Tektology diagrams organizational forms and situations, but there are only particular organizations. There's no prior unity or ultimate synthesis, no permanent harmony that they subtend or intend. Not even the revolution can forge a unity of the disparate natural and social forms as if by fiat. Red Mars has an imperfect way of organizing labor and nature, which can't prevent the exhaustion of fossil fuels (...), a political revolution is not the solution to anything. It merely enables the problem of organization to be posed" (Wark, 2016a p. 50).

Posing the problem of labor within the whole speculative frenzy brought forth by the Anthropocene was my main axis of critique throughout the dissertation, in some of the iterations in which it appears. Production, technology and the specificity of the human as overthrower and maker of politics are either assumed to 
be bad topics, or presupposed to go away without organizational friction, supposed to disappear when faced by a new "ethics".

Those presuppositions are backed up by the despair of our current condition and/or by the supposed inherent potential within nature and minoritarian tendencies which abolishes capitalism by fiat, finding an unusual companionship with the supposition of an automatism inherent to capitalism's downfall. Meanwhile, speculative impulses fall flat: when labor is not a problem of the future even in a very grounded level, critique political economy as well takes the backseat in the understanding of our present and in how we conceive our future.

The division of labor itself becomes a crucial point: as discussed in Ch. 2, the crystallization of knowledge in machinery, together with the commodification of information signalize another instance of appropriation of the commons in which Capital is predicated. Pasquinelli $(2017 ; 2018)$ calls this gap, playing with the concept of metabolic rift, an "epistemic rift": as labor is reframed and forks information and energy, the organization of production as such complexifies itself in tools and interfaces which are more and more inaccessible to us. This epistemic rift also does something to how we see nature as it becomes more and more a mere environment reduced to the functions of being either a source of what we need or a disposal spot for what has already been exhausted.

Our two rifts remain deeply intertwined and in Cyberfossil Capital: knotting the biosphere with capital's abstraction, the rift between Science, its crystallization into technology and labor. How do we both resist to this formation and imagine another world pass through the question of seizing the potentialities of science and technology, expanding the limits of both and challenging their bracketing is the main question for Bogdanov (1983; 2020), both reducing the time we take working and finding other forms of doing so. The infrastructures we have today face us as this particular assemblage of information and energy, one we cannot oppose effectively by bracketing their problems as unrelated (Pasquinelli, 2017).

If speculation comes through bridging a gap between what is happening and what could be, one may begin by looking for trouble, movements that begin hinting at seizing powers of abstraction as such. One example is the overspread global struggle of platform workers that arise both in countries in the global south and also in countries of the overdeveloped world and whose tactics differ from ground-floor organizing and striking as recently in the "App Strike" in Brazil which united under 
the flag of Antifascism, or union-mediated legal contestation such as the passing of the Prop22 laws in California which swinged in favor of Uber and Lyft on treating gig-workers as independent contractors ${ }^{85}$. Those are not merely labor struggles but struggles that respond also to other determinations. In Brazil for example, gigworkers in food delivery and their struggles are coextensive with the distribution of such underemployment among black young men (Abilio, 2019).

This maps the struggle for the commons unfolding in multiple overlapping fields, labor, environmental and the environment become all grounds for contestation, begging the question of the forms that bind them together, what structures are similar or continuous between those irruptions of struggle against capital. Sassen (2014) makes a very generative connection between the growth of complexity and the brutality of expulsions, showing how finance, labor and environmental struggles are related to atrocity in contemporary capitalism and how complexity largely facilitates it. However, she is reluctant to flip the tables: even if she does not bind the existence of complexity to necessarily generating oppression, she is still reluctant to deal with it. It is about time we invert the question and ask what can this infrastructure of complexity do for us and how can we challenge and seize it. Tektology in that sense offers a specific sensibility for reframing it, a crucial quality for looking at the living processes around the same question.

This process manifests in various fronts, not one of them presenting a definite solution but each partially concerned with very specific themes from art to city life to other forms of connection: Zach Blas's Contra-Internet aesthetics, Possibilities of Anti-Web communication protocols, Blockchain and P2P networking, Data and platform cooperatives seeking to change city-level governance and guarantee data privacy, struggles for Universal Basic Income and Hacker activism compose parts of this patchwork (Srnicek \& Williams, 2014; Sharpe, 2019; Fuchs, 2019; Calzada, 2021; Huws, 2021). In a context of worldwide stunted employment generation, our future spells lives more and more swamped by deprivation, anxiety, exhaustion, strained and grinded to a halt (Fisher, 2009; Berlant, 2011).

${ }^{85}$ https://edition.cnn.com/2020/11/04/tech/california-proposition-22/index.html https://www.uol.com.br/ecoa/ultimas-noticias/2020/06/29/brequedosapps-promove-mobilizacaoe-pede-apoio-a-greve-dos-entregadores.htm 
The commonality of those struggles as we have seen, in short, lies in the need for the abolition of our current social organization of production and the social forms it carries for surviving, the understanding of the metabolic and epistemic rifts it creates and by locating the responsibility and revisability of those in our field of practical political contestation.

I want to end by recalling an aspect of film-essay by Harun Farocki entitled "Comparison by a Third". Farocki invites our gaze to look at two scenes of labor making the same commodity in entirely different scenarios. In one side, a largely automated European brick-factory has a single worker monitoring tireless machines. On the other side, we see traditional processes of brick production, a succession of people in their tasks: from making clay to the final dried brick, the processes happen in radically different rhythms and spaces. Their siding is sustained by a minimal continuity as both are recognized as labor and made by spending someone's brains and muscles. However, the viewer finds himself in the position of the third, looking at the homogenization of those very different labors in act, facilitated by the technical, visual apparatuses showing them. One assumes the perspective of an eye/machine and embodies abstraction informed by the main social form in which we encounter it, namely, the commensurability effected by money. In doing so, an ambiguous feeling: neither nostalgia for the traditional nor too much excitement for the technological. As Seymour (2010) puts, the false choice between either sociality + poverty through extenuating work versus isolation + efficiency is dispelled.

As the viewer is invited to have his vision temporarily augmented, and his vision only, as the work is void of commentary, something goes on: with this very Tektological comparison that parallels the embodiment of two structures through their commonality, the possibility of a revolutionary overcoming that disrupts the given coordinates on how the viewer reads them is visible. The made opposition as such appears as an activity of comparison that asks for the fabulation of new forms, the charting of new connections and a wholesale restructuring of our mode of production, the emergence of a third that rethinks metabolism as such. One opens the possibility beyond the preconceived opposition, the possibility for thinking and doing other forms for socializing knowledge, distributing and changing the production of wealth, other forms of socialization and other metrics for our living as such. From such commitment, speculation invites to the scene the non-ideal but worthy collective labor of charting new possibilities. 


\section{Concluding notes}

In this chapter, my main general point was to position the hypothesis of communism as the collective management of alienation in order to deny two main lines of thought: both that we need to be freed from capital and rekindle with our natural creative potential and its obverse, that this potential is already there within nature as such and its affirmation merely coincides with the overthrow of capitalism. Rather than choosing one of those options, I sought those who carve another path between this opposition to think with.

I started by denying the possibility of the unalienated life and by looking at some recent deployments of the concepts of alienation and abstraction as they are tethered to the reappropriation not of freedom understood as the absence of constraints but to a slight reframing in which freedom appears as the capacity to create and abide to protocols of our own making.

This demanded a return to the concepts of externalization and estrangement/alienation with and beyond Marx. I approach it with two objectives: first, to take further the possibility of communism being the collective management of alienation and second to relate the concept of alienation to the concept of metabolism. I built an opposition between strong and weak nature siding with a weak one, localizing the problems with a strong conception of nature both through Marx's own early works and how he veers in the opposite direction later. A conception of weak nature allows us to understand alienation differently: not only nature creates things out of its own control but we also cannot really de-alienate ourselves as our creations as such face us as always strange.

Therefore, externalization is not merely the imagination of a necessarily positive potential hindered by a structure be it property or value. Rather, it can only be de-estrangement as estrangement, the revisability of the terms in which we can break with, on one hand, our own determinations and, on the other, radically change the mechanism of socialized production that produces determinations as such, shifting the ground in which we stand and restructuring the coordinates of our own thought and embodiment.

This allows us to localize the human through the figure of the inhuman, locating the radical revisability in how what nature and the human mean are constantly built as a function of the social organization of production. Such changes 
are not only metaphorical or merely abstract but literal, irreducibly made through processes of metabolism, in which the human interacts with nature and changes it and himself in the process. Through this insight, we bind the conception of a weak nature to how Marx himself dealt with nature later in his thought through the conception of metabolism in his later work inspired and beyond the sciences of his time.

Then, I staged a critique of Braidotti's Post-Humanism by arguing that despite its supposedly radical shell, it's avoidance of historicization of the conditions in which it makes its ontological claims become deeply problematic. I posed myself against its subsumption of nature to a single ethically charged substance granting common ground to all there is and looking at its purported radicality as being hindered by precisely those theoretical commitments, problematizing some of the rhetoric of affirmation not only in Braidotti's work but also connected to my critique of how affirmation is mobilized in IR.

Finally, Tektology, a supposed meta-science of an utopic society, appears as an inhumanizing practice that begins to formulate some of the practical commitments in understanding de-alienation as collective management of alienation as it locates the revisability of both the human and nature and of the human as "natural" being himself as happening practically through labor and metabolism.

It is an attempt to bind together labor and science not only as abstract concepts but across scales through structural formalization, hinting at what could be new forms of abstraction. Those emerge both connected to what Pasquinelli (2018) called abstraction and as a constant practice of construction that constantly reshape what the human and what nature can mean, not through legislating a common principle but through cross-fertilization. In its recognition of labor as metabolism and knowledge as bound to labor and collaboration that we find Tektology addressing both the metabolic and the epistemic rift, both problematizing and repurposing the forked global machine that constitutes what we discussed in Ch. 2 as Cyberfossil Capital.

As such, it also politically hints at a step in the direction of what I called the friction between a "folk politics" and a global politics, mediating alliances through organizational forms and the struggle against them. It is only through this friction that we begin mending this that we could tentatively call another rift, which tries to think of a local distilled outside of the global and of a completely abstracted global 
not messed and fractured by locality. Lastly, Tektology, metabolism, labor, technology all pose crucial questions regarding how we rethink the social organization of labor. Pursuing such a question generates productive friction and hopefully allow us to think a bit like the Bogdanov painted above: if our "species" is a builder of worlds and one that inhumanizes itself in the process of doing so, it becomes imperative to ask how to bring this world to dust and build another one, a task that can only be done through the collaboration of many different labors, sets of knowledge and to be actualized in practice. 


\section{Conclusion}

This conclusion weaves together some of the threads that have been mobilized in this thesis. For the sake of clarity, I will proceed chapter by chapter focusing on the main argumentative line, namely, how each chapter is involved in the task of constructing an analysis and critique of approaches to the Anthropocene within IR. This critique is performed by centering the question of the social organization of production through Marxist theory, arguing that it offers crucial tools for that endeavor. Right after each chapter is systematized, I will point to other research questions and pathways that emerged while doing this dissertation.

Chapter 1 introduces the Anthropocene, showing briefly how it appears as a category of scientific inquiry and, how its reception performs a destabilization in the humanities that shakes some of the core foundations of IR. The Anthropocene is seen as a material assemblage that marks both a technological and epistemic achievement and that also is embedded within a violent history of globalization. In its unfolding, the Anthropocene appears as a vector of historical revision as it both destabilizes categories which make our political imaginary (the human, hope, death, risk, crisis and so on) while also bringing a whole speculative frenzy regarding what the future could look like. One point, however, a crucial one, appears to be forgotten, namely, how the social organization of production by value both underpins this relationship between the historical and the planetary and how it should also be a target of that speculative edge.

This neglect is seen as having serious consequences: production is cast as a mere expression of the ideas animating politics. While production is indeed political, the possibility of a radical change of production becomes grounded in the possibility of making a society with another set of ideals. In this enframing, politics and production are ultimately posed as problems of consciousness. An archetypical format of this claim is that "We cannot continue to go on like that, therefore, we must invent other ways of existing". Socially organized production is framed ultimately as an expression of a bundle of ideas around which social relations are articulated. In such a format, thank god, the Anthropocene comes to disturb the core tenets of our belief system. Politics becomes the need to affirm this destabilization and reap its fruits.

I argued that such a picture ignores the immanent way in which the social organization of production conditions thought and praxis as a central determination. 
For that, I have argued for a return to Marx's as a thinker of the social organization of production as a generator of determinations for the subject and as a trenchant critic of the move that casts politics as a matter of raising consciousness regarding abstract ideals. In particular, I chose to focus on Marx's critique of value as historically determined form of wealth production. In that sense, I sticked with Marx's concept of metabolism as a navigational tool to mediate the stakes of this collision between the planetary and the historical. Sticking with it allows for keeping an ontological monism and a methodological dualism that neither deny the status of humans as a part of nature nor projects into nature a logic that is too foreign to it.

If in Chapter 1 labor appears as socially mediated process of metabolism, it is in Chapter 2 that we cast some light in the fact that the labor process is always mediated by machines that stand between the human and nature, machines themselves that are made through both natural materials and human labor. This marks labor as a process in which all parts reveal themselves to be quite imbricated with each other.

Chapter 2 tackles how the relationship between the Anthropocene and technology is narrated. It starts from a particular problem, namely, the claim to a unified trajectory of western technology, guided by western ideas and material hegemony that have brought us the Anthropocene. The problem with such a narrative, particularly when one is thinking about political economy is that, even though it responds to a vector of accumulation it might slip into a dangerous conflation in which technology is seen as merely expressing ideas about matter, a theoretical move not so distant from the one criticized on Chapter 1.

This positing of technology as merely a consequence of certain ideas about matter has some consequences. It makes technology appears binarily as an either/or relation, connected or not connected to western ideas, ignoring how there is a fair amount of stealing and cross-fertilization coexisting between different epistemologies and the extermination carried out by Capital and the nation-state. It also erases the trail of the labor making those technologies and the effects they have on labor as such.

Complementing these limitations, I sought to follow Marx and emphasize the machine in its ambivalence: it neither saves us from work by fiat nor merely presents oppression in changing shapes. It appears as a crystallization of the social division of labor and as a metric apparatus through which one abstracts and manages labor. 
However, technology offers the possibility of diminishing the need for labor, a tool that when seized and remade inscribes the possibility of abolishing abstract labor as it appears in capitalism.

Through Marx and Simondon we saw that the machine appears in this metabolic process of production as a relay between energy and information, and that the management of those two, through machines, is intrinsically connected with changes in the social division of labor through the work/energy relationship, as well as having a kinship with certain diagrams of power. Through such a picture, both environmental and labor struggles converge as struggles for a change in the structure of production. The problem of remaking our mode of production is posed not only in terms of affirming whatever is not identified with "western technology" but complexifies it, posing the problem of both repurposing forces of production and redesigning them on the go.

This look towards the machine also reinscribes the relationship in our contemporary terms of an "old" industrial economy and the "new" digital economy, emphasizing the materiality of both and their compliance. Doing so helps us to avoid a conflation of the digital with the immaterial and to account for the tendencies emerging right out of the stagnation in the industrial sector and the proliferation of the informational one. Those generate certain tendencies towards underemployment and gaps in the format of social reproduction and the promise of wage labor in which Capital is predicated.

Chapter 3, in that sense, continues Chapter 2's attempt to think about a radical reorganization of production and technology as a crucial vector from where new futurities might bloom. In Chapter 3, we pointed to some of the productive political tensions between local/global, abstract/concrete and have discussed particularly the tendency of running from the global towards the local, from the mediated towards the unmediated but, without siding with neither of them, we have thought about what do their friction produce. Opting for friction goes against identifying abstractions or mediation as always creatures of Capital entrapping one into domination. Rather, abstraction was cast as the speculative power of the human to go beyond itself, of selecting and legislating on the powers and procedures that penetrate us.

We note that it is not about ending abstraction per se but negotiating alternative ways of control over it, procedures of abstraction that lie beyond the logic 
of capital. Of course, such a move has wide implications that could not even begin be covered. For one, it pushes towards the collective labor of rethinking the particular iteration between Capital, Nation and State and alternative forms of governance, community and socially organized production and how those three can be related.

Nevertheless, I focused on the question of the social organization of production through the category of alienation and the (im)possibility of its end. My point was to assess it by neither positing a positive specifically human essence to rekindle with which grants finally the possibility of externalization as a potentiality, nor ontologizing creativity in nature and merely seeking its affirmation as an alignment with this inherent quality. Note also that, this second move is deeply related to the critique I was carrying out in Chapter 1, as it is the ground through which the Anthropocene is often posed as a problem of raising consciousness and affirming a new ethic. Against setting the end of alienation I have tried to venture beyond the binary separation between estrangement and externalization as separated moments and of emancipation framed as the end of estrangement.

Doing so, we dispel the possibility both of a human essence and of an inherently positive content in nature. Emancipation can only be de-estrangement as estrangement, and can only be assessed as such retrospectively. This means there is no way of rekindling with creative capacities and having final mastery regarding everything we create. Rather, what we have is the revisability of the social circumstances in which we exist as such, one that both delivers us the continuous promise of overcoming necessity and compels us with the promise of further freedom that can only be attained through different forms of estrangement and their revisability. In short, the collective reinvention of production is the possibility of breaking with History, it is there that we locate the stakes for rethinking production in the Anthropocene.

If we take production as a crucial stance generating determinations regarding how we appear as subjects and, often unconsciously, become operators and creators of technology and nature through labor as metabolic social practice, we encounter a rather unsettling picture regarding what the Human could be. If the Human is neither the ideal rekindling grounded in the "dumb generality" of species nor the bad image hindering the power of an innermost substance that expresses freedom, what can it be? What is the genericity that allows one to speak of it? 
The generic about the human is its rather inhuman and ambivalent capacity of externalizing things from which it then becomes estranged and that, in the process of doing so, it changes all the terms of the relation in which they are made, remaking the human and nature in this process. In this light, the hope for merely affirming the Anthropocene appears quite problematic not only in its presupposition of ethics within ontology that does little to break with history but also as it may end up identifying in resistances and tendencies within our current frame as the weight of being transgressive by default.

Tektology makes an appearance right at the end in two of its qualities: first, as a conceptual tool that hints at what a collective management of alienation could be, taking the form of a pratical and experimental monism of organization, forming a framework for this inhuman revisability as such. Second, Tektology reveals the possibility of framing of the relationship between knowledges and organizations of production, as an attempt to play with the tensions between global/local abstract/concrete and offering opportunities for a productive friction.

Tektology also hints at a question that could not be fully formulated, namely, the relationship between science and Marxism, in particular to how Marxism deals with the natural sciences. While metabolism offers both a useful category for the question of labor and nature and even the material imprint of the abstract into matter as was formulated, it also implicitly questions the place of Marxist theory as such: is it to be a democratic centralism as a privileged last instance? Is it to be a vector a collaboration? Those are all questions that could not be mobilized.

I believe Bogdanov tries to offer a naturalist solution through and beyond his influence by Mach, trying to ground a naturalist and materialist theory of the subject that is possibly updated by new discoveries in the sciences and mindful of the relation between the social and the biological. Adrian Johnston has also been exploring those questions in his work. I believe that there is still a lot of work to be done in order to unpack this possibility further, particularly in some of the debates around this as they are taken by the likes of Ray Brassier in Nihil Unbound and even the kinship of many of those questions with Wilfrid Sellars.

Having laid out this chapter-by-chapter summary, now I echo Stafford Beer's (1995) motto in "Brain of the Firm": "If it works it's out of date". Such an attitude, when applied to revising the meaning of one's just-finished text, invites pinpointing the lines of thought that by various constrains ended up not quite working. Through 
those, we might attempt to sketch research pathways that could be taken forward in the future.

First, a question that has been tackled but did not get explored in depth is how Blaney and Inayatullah's (2010) endeavor in localizing the political economy as a cultural artifact as well as a material one is complemented by recent scholarship that centralize the question of metabolism in Marx's work. While the theoretical move effected by Blaney and Inayatullah (2010) succeeds to conjoin culture and political economy, it not only hints at a similar definition of labor as metabolism mindful of how the abstract organizes the concrete, there is an implication of that reading to how we read technology. Ever since Simondon, one of the utmost goals of a philosophy of technic is precisely to show that technic is not opposed to culture but in fact an intimate part of it.

What is disclosed in this conjunction is the possibility of a materialist Marxist historiography of technique as a cultural artifact, which opens an even deeper path for understanding different social organizations of production, divisions of labor and concepts of wealth which can help in building very interesting political alternatives that recognize the capacity of the subaltern to subvert the system as such. Such a project could find have great conversations with the project of cosmotechnics as being carried out by people such as Yuk Hui, and it might articulate crucial stakes for how we think about the Anthropocene as well.

Second, there is a quite unsettling general question that appeared both in the texts on the problem of the Anthropocene and in my own time inhabiting the area of IR broadly spoken. The problem was the status of the triad Capital-Nation-State in critical scholarship. Of course, there should be a mea culpa by me, as I have mostly focused on Capital and marginally on how it shares diagrams of power with the state. However, I believe that methodologically being able to look at this triad, the possibility of rendering it tractable and the procedure to deal with it is itself a question to be pursued further.

In IR, the concept that usually render this triad approachable is the concept of modernity, which aggregates the three into a category to be criticized. The critique of the connection between those three things is a crucial direction for IR and is in fact where it can produce theory that understands what the global actually is. Nevertheless, I believe that there is also a general problem, which is that the concept of "modernity" often appears as an ur-concept that wraps this triad together and 
performs a far too hasty conjunction that borders the attribution of identity to some of their logics. One might ask whether is it possible that this integration is not so seamless as it appears, and maybe we should produce systematic thought not on the ur-category but rather on the triad aware of its connections and fractures.

Lastly, a related, another enduring and underexplored question is articulated around the concept of infrastructure. I believe that the international, understood as the political space brought coextensively with the expansion of what Chakrabarty (2018) calls the global is often faced as a political problem, in that it structures the relationship and the image of nation-states as fractured political units and set a certain political grammar. Such a kind of criticism is exemplified in the sophisticated scholarship taken in multidimensional ways by people such as Robert Walker, Michael J. Shapiro and in International Political Sociology broadly spoken.

However, while one is often aware of the materiality and historicity of the global, there is a vulgar materiality to it that does not quite get its due, even less so focusing on how it is intertwined with the dilemmas of political economy. One could ask how the international is made and articulated through the technical mediation of many particular artifacts such as: ships, telegraphs, telephone networks, satellites, pipelines, wires, databases and the labor that build and operate them. Those might cast the problem of the international as also a struggle over labor as technically mediated metabolism and see how it gets enacted and actualized.

As the construction of a globalized infrastructure is an affair in which a significant part of the relationship between nation-states and capital are carried and also where flows of commodities, people, information and money are happening, such an endeavor can help both illuminate the historical compliance between capital and the nation-state and also cast a look at the relations and forces of production that underpin the material construction of the international as a material and unequal space of circulation. As of now, I believe the tools for beginning to answer those questions are to be found both in Benjamin Bratton's work on planetary computation and sovereignty in the age of planetary computation and in Kojin Karatani's work on world history through modes of exchange and the CapitalNation-State triad. All in all, such a line of inquiry seems to provide an interesting apparatus to understand the intertwinement of the nation-state with Capital and hint at a speculative momentum that might illuminate a small part of an urgent task, charting the possibilities of building other futures in the ruins of this one. 


\section{Bibliography}

ABILIO, Ludmila C. Uberização: Do empreendedorismo para o autogerenciamento subordinado Uberization: From entrepreneurship to subordinated self-management. Psicoperspectivas Vol. 11 N. 3, 2019

ALTHUSSER, Louis. For Marx. Radical Thinkers. London; New York: Verso. 2005

ALTVATER, Elmar. The social formation of capitalism, fossil energy, and oilimperialism. Centre for Civil Society Colloquium on the Economy, Society and Nature: 1-21. 2005

ALQUATI, Romano. Organic Composition of Capital and Labor-Power at Olivetti .Available at $<$ https://www.printfriendly.com/p/g/LfW55X $>$ [1961] 2013

ALQUATI, Romano. 1975 "Sulla Fiat e altri scritti" Milan, Giangiacomo Feltrinelli Editore. 1975

ARRIGHI, G.; SILVER, B. J.; BREWER, B. D. Industrial convergence, globalization, and the persistence of the North-South divide. Studies in Comparative International Development, v. 38, n. 1, p. 3-31, mar. 2003.

BARDER, A. D. Empire Within: international hierarchy and its imperial laboratories of governance. New York, NY: Routledge, Taylor \& Francis Group, 2017.

BEER, S. Brain of the firm: the managerial cybernetics of organization. $2 \mathrm{~d}$ ed ed. Chichester [Eng.] ; New York: J. Wiley, 1981.

BEER, S. Stafford Beer - Brain of the Firm-Wiley (1995).pdf. London: John Wiley \& Sons, [s.d.].

BENANAV, A. Automation and the Future of Work-1. New Left Review, v. 119, p. 34, 2019a.

BENANAV, A. Automation and the Future of Work-2. New Left Review, v. 120, p. 30, 2019b.

BERLANT, L. G. Cruel optimism. Durham: Duke University Press, 2011.

BHAMBRA, G. K. Colonial global economy: towards a theoretical reorientation of political economy. Review of International Political Economy, v. 0, n. 0, p. $1-16,20$ out. 2020.

BLANEY, D. L. Savage Economics: Wealth, Poverty and the Temporal Walls of Capitalism. 1. ed. [s.1.] Routledge, 2010.

BLAS, Z. Contra-Internet. Disponível em: $<$ https://www.e-

flux.com/journal/74/59816/contra-internet/>. Acesso em: 11 mar. 2021. 
BOGDANOV, A. Essays on Tektology: The General Science of Organization. Tradução: George Gorelik. Second Edition ed. [s.1.] Intersystems Publications, 1984.

BOGDANOV, A. The philosophy of living experience: popular outlines. Leiden ; Boston: Brill, $2016 \mathrm{a}$.

BOGDANOV, A.; ROWLEY, D. G. Empiriomonism: essays in philosophy. books 1-3. Leiden; Boston: Brill, 2020.

BOUSQUET, A.; CURTIS, S. Beyond models and metaphors: complexity theory, systems thinking and international relations. Cambridge Review of

International Affairs, v. 24, n. 1, p. 43-62, mar. 2011.

BRAIDOTTI, R. Posthuman, All Too Human: Towards a New Process Ontology. Theory, Culture \& Society, v. 23, n. 7-8, p. 197-208, dez. 2006.

BRAIDOTTI, R. A Theoretical Framework for the Critical Posthumanities. Theory, Culture \& Society, v. Vol. 36, n. 6, p. 31-61, 2019.

BRAIDOTTI, R.. "What Is Necessary Is a Radical Transformation, Following the Bases of Feminism, Anti-Racism and Anti-Fascism. CCCB $L A B$ (blog).

Interviewd conceded to Iu Andrés. 2019. Available at $<$ http://lab.cccb.org/en/rosibraidotti-what-is-necessary-is-a-radical-transformation-following-the-bases-offeminism-anti-racism-and-anti-fascism/?

BRASSIER, Ray. Concrete-in-Thought, Concrete-in-Act: Marx, Materialism and the Exchange Abstraction Crisis and Critique Vol. 5 Issue 1. 2018

BRASSIER, R. Strange Sameness. In: TRAFFORD, J.; WOLFENDALE, P. (Eds.). . Alien Vectors. 1. ed. [s.1.] Routledge, 2020. p. 88-94.

BRASSIER, Ray. "The Human". Unpublished paper. 2021. Available at https://www.foreignobjekt.com/post/ray-brassier-posthuman-pragmatismselecting-power-the-human-from-subversion-to-compulsion

BRATTON, B. Some Trace Effects of the Post-Anthropocene: On Accelerationist Geopolitical Aesthetics. e-flux, v. 46, 2013.

BROWN, W. Neoliberalism's Frankenstein: Authoritarian Freedom in TwentyFirst Century "Democracies". Critical Times, v. 1, n. 1, p. 20, 2018.

BURKE, A. et al. Planet Politics: A Manifesto from the End of IR. Millennium: Journal of International Studies, v. 44, n. 3, p. 499-523, jun. 2016

CAFFENTZIS, G. Escape from the Law of value? Disponível em: $<$ http://libcom.org/library/escape-aufheben-5>. Acesso em: 25 fev. 2021.

CAFFENTZIS, G. A discourse on prophetic method. The Commoner, v. 13, p. 20, 2009. 
CAFFENTZIS, G. In letters of blood and fire: work, machines, and the crisis of capitalism. Oakland, Calif: PM Press, 2013.

CALZADA, I. Data and Platform Co-ops in Smart City Citizenship: interview with Igor Calzada, 2021. Disponível em:

$<$ https://digilabour.com.br/2021/01/06/data-and-platform-co-ops-in-smart-citycitizenship-interview-with-igor-calzada/>. Acesso em: 11 mar. 2021

CASTELLS, M. The New Public Sphere: Global Civil Society, Communication Networks, and Global Governance. p. 16, 2008.

CHAKRABARTY, D. Provincializing Europe: postcolonial thought and historical difference. Princeton, N.J: Princeton University Press, 2000.

CHAKRABARTY, D. The Planet: An Emergent Humanist Category. Critical Inquiry, v. 46, n. 1, p. 1-31, set. 2019.

CHANDLER, D. The death of hope? Affirmation in the Anthropocene.

Globalizations, v. 16, n. 5, p. 695-706, 2019.

CHANDLER, D.; CUDWORTH, E.; HOBDEN, S. Anthropocene, Capitalocene and Liberal Cosmopolitan IR: A Response to Burke et al.'s 'Planet Politics'.

Millennium: Journal of International Studies, v. 46, n. 2, p. 190-208, jan. 2018 .

CLEGG, J.; LUCAS, R. Three Agricultural Revolutions. South Atlantic Quarterly, v. 119, n. 1, p. 95-111, 1 jan. 2020.

COULTHARD, G. S. Red skin, white masks: rejecting the colonial politics of recognition. Minneapolis: University of Minnesota Press, 2014.

CRUTZEN, P. J. The “Anthropocene”. In: EHLERS, E.; KRAFFT, T. (Eds.). . Earth System Science in the Anthropocene. Berlin, Heidelberg: Springer, 2006. p. 13-18.

DAGGETT, C. N. The birth of energy: fossil fuels, thermodynamics, and the politics of work. Durham: Duke University Press, 2019.

DAVIES, M. "You Can't Charge Innocent People for Saving Their Lives!" Work in Buffy the Vampire Slayer1: You Can't Charge Innocent People for Saving Their Lives! International Political Sociology, v. 4, n. 2, p. 178-195, 7 jun. 2010.

DELEUZE, G. Controle e Devir, 1990. Disponível em: $<$ https://historiacultural.mpbnet.com.br/pos-modernismo/Controle e Devir.pdf $>$ DELEUZE, G.; HAND, S. Foucault. Minneapolis: University of Minnesota Press, 1988. 
ENDNOTES. Onward Barbarians. p. 66, 2021. Available at https://endnotes.org.uk/other texts/en/endnotes-onward-barbarians.

ENGELS, F. A situação da classe trabalhadora na Inglaterra segundo as observações do autor e fontes autênticas. Tradução: B. A Schumann; Tradução: José Paulo Netto. São Paulo: Boitempo, 2008.

EROUKHMANOFF, C.; HARKER, M. Reflections on the posthuman in international relations: the anthropocene, security and ecology. [s.l: s.n.].

FISHEL, S. et al. Defending Planet Politics. Millennium: Journal of International Studies, v. 46, n. 2, p. 209-219, jan. 2018.

FOSTER, J. B. Marx's Theory of Metabolic Rift: Classical Foundations for Environmental Sociology. American Journal of Sociology, v. 105, n. 2, p. $366-$ 405, set. 1999.

FOSTER, J. B. Marx's ecology: materialism and nature. New York: Monthly Review Press, 2000.

FOSTER, J. B. et al. Monthly Review | Marx and Alienated SpeciesismMonthly Review, 1 dez. 2018. Disponível em:

$<$ https://monthlyreview.org/2018/12/01/marx-and-alienated-speciesism/>. Acesso em: 13 out. 2020

FOSTER, J. B. "Marx's Theory of Metabolic Rift: Classical Foundations for Environmental Sociology"". [s.d.].

FOSTER, J. B.; BURKETT, P. Marx and the earth: an anti-critique. Leiden: Brill, 2016.

FOSTER, J. B.; BURKETT, P.; GLOBAL, M. E. P. Monthly Review | Value Isn't EverythingMonthly Review, 1 nov. 2018. Disponível em:

$<$ https://monthlyreview.org/2018/11/01/value-isnt-everything/>. Acesso em: 30 set. 2020

FUCHS, C. Digital labour and Karl Marx. New York, NY: Routledge, Taylor \& Francis Group, 2014.

FUCHS, C. The Digital Labour Theory of Value and Karl Marx in the Age of Facebook, YouTube, Twitter, and Weibo. In: FISHER, E.; FUCHS, C. (Eds.). . Reconsidering Value and Labour in the Digital Age. London: Palgrave Macmillan UK, 2015. p. 26-41.

FUCHS, C. "Uma Internet alternativa deve combinar serviço público e cooperativas de plataforma", 2019. Disponível em:

$<$ https://digilabour.com.br/2019/09/13/christian-fuchs-internet-alternativatrabalho-digital/>. Acesso em: 6 fev. 2021 
GRAEBER, D. Alteridade radical é só outra forma de dizer "realidade". Resposta de David Graeber a Viveiros de Castro., 4 ago. 2016. Disponível em: $<$ https://maquinacrisica.org/2016/08/04/alteridade-radical-e-so-outra-forma-dedizer-realidade-resposta-de-david-graeber-a-viveiros-de-castro/>. Acesso em: 1 dez. 2020

GRAEBER, D. Bullshit jobs. First Simon\&Schuster hardcover edition ed. New York: Simon \& Schuster, 2018.

GROVE, J. Jairus Grove response to Jedediah Purdy. Text. Disponível em: $<$ https://bostonreview.net/forum/new-nature/jairus-grove-jairus-grove-responsejedediah-purdy>. Acesso em: 28 set. 2020.

GROVE, J. From geopolitics to geotechnics: global futures in the shadow of automation, cunning machines, and human speciation. International Relations, v. 34, n. 3, p. 432-455, set. 2020.

GROVE, J. V. Savage ecology: war and geopolitics at the end of the world. Durham: Duke University Press, 2019.

HARAWAY, D. Antropoceno, Capitaloceno, Plantationoceno, Chthuluceno: fazendo parentes. n. 5, p. 8, 2016.

HARAWAY, D. J. Simians, cyborgs, and women: the reinvention of nature. New York: Routledge, 1991.

HARAWAY, D. J. et al. Antropologia do ciborgue: as vertigens do póshumano. Belo Horizonte: Autentica, 2013.

HARVEY, D. Spaces of global capitalism. London; New York, NY: Verso, 2006.

HUWS, Ursula. Desmercantilizar as plataformas. Digilabour. 2020 Accessed in March 11th 2021. Available at $<$

https://digilabour.com.br/2020/10/04/desmercantilizar-as-plataformas-entrevistacom-ursula-huws/

KAPOOR, I. Capitalism, culture, agency: Dependency versus postcolonial theory. Third World Quarterly, v. 23, n. 4, p. 647-664, ago. 2002.

KAPOOR, I. Cold critique, faint passion, bleak future: Post-Development's surrender to global capitalism. Third World Quarterly, v. 38, n. 12, p. 2664 2683, 2 dez. 2017.

LABORIA CUBONIKS (Collective), The xenofeminist manifesto: a politics for alienation. Brooklyn: Verso, 2018.

LATOUR, Bruno and Weibel, Peter. Critical Zones: The Science and Politics of Landing on Earth. Karlsruhe: ZKM; Cambridge, MA and London: MIT Press, 2020 . 
LEVIS, C. et al. Persistent effects of pre-Columbian plant domestication on Amazonian forest composition. Science, v. 355, n. 6328, p. 925-931, 3 mar. 2017.

LÖVBRAND, E.; MOBJÖRK, M.; SÖDER, R. The Anthropocene and the geopolitical imagination: Re-writing Earth as political space. Earth System Governance, v. 4, p. 100051, jun. 2020.

MACKAY, R.; AVANESSIAN, A. (EDS.). Accelerate: the accelerationist reader. Second edition ed. Falmouth, UK: Urbanomic Media Ltd, 2014.

MALM, A. The Origins of Fossil Capital: From Water to Steam in the British Cotton Industry. Historical Materialism, p. 54, 2013.

MARX, K. The Poverty of Philosophy. Progress Publishers trans. Institute of Marxism Leninism. Available at https:/www.marxists.org/archive/marx/works/1847/poverty-philosophy/

MARX, K. Manuscritos econômico-filosóficos. Tradução: Jesus Ranieri. São Paulo: Boitempo Editorial, 2009.

MARX, K. "Fragment on Machines" in Accelerate: The Accelerationist Reader. Mackay, Robin, e Armen Avanessian, Second edition. Falmouth, UK: Urbanomic Media Ltd. 2014

MARX, K. O Capital: Crítica da Economia Política. Livro 1: O processo de produção do capital. Tradução: Rubens Enderle. 3.ed ed. São Paulo, SP: Boitempo Editorial, 2017b.

MARX, K. O Capital III: O processo global da produção capitalista. Tradução: Rubens Enderle. Rio de Janeiro: Boitempo Editorial, 2017a.

MCCARTHY, D. R. (ED.). Technology and world politics: an introduction. Abingdon, Oxon ; New York, NY: Routledge, 2018.

MCNALLY, D. Monsters of the market: zombies, vampires, and global capitalism. Chicago, Ill: Haymarket Books, 2012.

MITCHELL, A. Is IR going extinct? European Journal of International Relations, v. 23, n. 1, p. 3-25, mar. 2017.

MOORE, J. W. The End of Cheap Nature. Or How I Learned to Stop Worrying about "The" Environment and Love the Crisis of Capitalism. In: [s.1: s.n.]. p. 30.

MOORE, J. W. Capitalism in the Web of Life: Ecology and the Accumulation of Capital. London; New York: Verso Books, 2015.

NAKAMURA, L. Indigenous Circuits: Navajo Women and the Racialization of Early Electronic Manufacture. American Quarterly, v. 66, n. 4, p. 919-941, 2014. 
NEGARESTANI, Reza. "Labor of the Inhuman" in Accelerate: The Accelerationist Reader. Mackay, Robin, e Armen Avanessian, Second edition. Falmouth, UK: Urbanomic Media Ltd. 2014

OTANI, T. A Guide to Marxian Political Economy. Cham: Springer International Publishing, 2018.

PARIKKA, J. A geology of media. Minneapolis ; London: University of Minnesota Press, 2015.

PASQUINELLI, M. Animal spirits: a bestiary of the commons. Rotterdam: NAi Publ, 2008.

PASQUINELLI, M. Capitalismo maquínico e mais-valia de rede: Notas sobre a economia política da máquina de Turing. LUGAR COMUM No39, pp. 13-36, n. 39 , p. 24, 2013.

PASQUINELLI, M. The Eye of the Algorithm: Cognitive Anthropocene and the Making of the World Brain. Fall Semester, p. 6, 2014.

PASQUINELLI, M. Italian Operaismo and the Information Machine. Theory, Culture \& Society, v. 32, n. 3, p. 49-68, maio 2015.

PASQUINELLI, M. Abnormal Encephalization in the Age of Machine Learning. e-flux, v. Journal \#75, set. 2016.

PASQUINELLI, M. The Automaton of the Anthropocene: On Carbosilicon Machines and Cyberfossil Capital. South Atlantic Quarterly, v. 116, n. 2, p. 311-326, abr. 2017.

PASQUINELLI, M. The Labour of Abstraction: Seven Transitional Theses on Marxism and Accelerationism. Philosophical Literary Journal Logos, v. 28, n. 2, p. 55-64, 2018.

PASQUINELLI, M. On the origins of Marx's general intellect. Radical Philosophy, v. 2.06, p. 14, 2019.

PICKERING, Andrew. The Cybernetic Brain: Sketches of Another Future. Chicago ; London: University of Chicago Press. 2010

POSTONE, M. Tempo, trabalho e dominação social: uma reinterpretação da teoria crítica de Marx. Tradução: Amilton Reis; Tradução: Paulo Cézar Castanheira. 1a edição ed. São Paulo, SP: Boitempo Editorial, 2014.

POSTONE, M.; RUDA, F.; HAMZA, A. An interview with Moishe Postone: That Capital has its limits does not mean that it will collapse. Crisis and Critique, v. 3, n. 3, p. 18, 2016. 
REED, Patricia. Diagramming the commons KunstAllmend (Artistic Commons) Symposium at Dampfzentrale, Bern, CH. Initiated by Nicolas Y Galeazzi, 2014.

REED, Patricia. Xenophily and Computational Denaturalization. E-flux. 2018. Available athttps://www.e-flux.com/architecture/artificiallabor/140674/xenophily-and-computational-denaturalization/

RITCHIE, H.; ROSER, M. Fossil Fuels. Our World in Data, 2017. Available at https://ourworldindata.org/fossil-fuels

ROTH, R. Marx on technical change in the critical edition. The European Journal of the History of Economic Thought, v. 17, n. 5, p. 1223-1251, dez. 2010 .

SAITŌ, K. Karl Marx's ecosocialism: capitalism, nature, and the unfinished critique of political economy. New York: Monthly Review Press, 2017.

SASSEN, S. Expulsions: brutality and complexity in the global economy. Cambridge, Massachusetts: The Belknap Press of Harvard University Press, 2014.

SCHATZBERG, E. Technik Comes to America: Changing Meanings of Technology before 1930. Technology and Culture, v. 47, n. 3, p. 486-512, 2006.

SEYMOUR, B. Eliminating Labour: Aesthetic Economy in Harun Farocki. Text. Disponível em: $<$ https://www.metamute.org/editorial/articles/eliminatinglabour-aesthetic-economy-harun-farocki>. Acesso em: 11 mar. 2021.

SHANNON, Claude. The Bell System Technical Journal, Vol. 27, pp. 379-423, 623-656, July. 1948. Available in $<$ http://people.math.harvard.edu/ ctm/home/text/others/shannon/entropy/entropy. pdf $>$

SHARPE, T. A Ceded Interfile: Future-Oriented Social \& Cognitive Design\&\&\& Journal, 2019. Disponível em: $<$ https://tripleampersand.org/cededinterfile-future-oriented-socialcognitive-design/>. Acesso em: 11 mar. 2021

SIMANGAN, D. Where is the Anthropocene? IR in a new geological epoch. International Affairs, v. 96, n. 1, p. 211-224, 1 jan. 2020.

SIMONDON, G. On the mode of existence of technical objects. Minneapolis, MN: Univocal Pub, 2016.

SIMONDON, G. Do modo de existência dos objetos técnicos. Tradução: Vera Ribeiro. Rio de Janeiro: Contraponto, 2020.

SIMONDON, Gilbert, e Arne De Boever. Technical Mentality. In Gilbert Simondon, editado por Arne De Boever, Shirley S. Y. Murray, e Jon Roffe, 1-14. Edinburgh University Press. 2013 
SOHN-RETHEL, A. Intellectual and manual labour: a critique of epistemology. London: Macmillan, 1978.

SRNICEK, N.; WILLIAMS, A. \#ACCELERATE MANIFESTO for an Accelerationist PoliticsCritical Legal Thinking, 14 maio 2013. Disponível em: $<$ https://criticallegalthinking.com/2013/05/14/accelerate-manifesto-for-anaccelerationist-politics/>. Acesso em: 11 mar. 2021

SRNICEK, N.; WILLIAMS, A. Inventing the future: postcapitalism and a world without work. Brooklyn, NY: Verso Books, 2015.

SRNICEK, Nick. Representing complexity: the material construction of world politics. PhD thesis, The London School of Economics and Political Science (LSE). 2013

STEFFEN, W.; CRUTZEN, P. J.; MCNEILL, J. R. The Anthropocene: Are Humans Now Overwhelming the Great Forces of Nature? v. 36, n. 8, p. 8, 2007.

STEVENS, W. K. New Eye on Nature: The Real Constant Is Eternal Turmoil (Published 1990). The New York Times, 31 jul. 1990.

STUBBLEFIELD, C. Managing the Planet: The Anthropocene, Good Stewardship, and the Empty Promise of a Solution to Ecological Crisis. Societies, v. 8 , n. 2, p. 38 , jun. 2018 .

TESTA, I. Second Nature and Recognition: Hegel and the Social Space. CriticaI Horizom: A Journal of Philosophy and Social Theory 341-70, v. 10, n. 3, p. 341-70, 2009.

TUPINAMBÁ, G. Abstração real e autonomização do valorLavraPalavra, 21 mar. 2016. Disponível em: <https://lavrapalavra.com/2016/03/21/abstracao-real-eautonomizacao-do-valor/>. Acesso em: 11 mar. 2021

TUPINAMBÁ, G. The unemployable and the generic: rethinking the commons in the communist hypothesis. Palgrave Communications, v. 3, n. 1, p. 17073, out. 2017.

TURING, Alan. 1950 "Computing Machinery and Intelligence." Mind 49: 433460

WARK, M. Third nature. Cultural Studies, v. 8, n. 1, p. 115-132, jan. 1994.

WARK, M. A hacker manifesto. Cambridge, MA: Harvard University Press, 2004.

WARK, M. The beach beneath the street: the everyday life and glorious times of the Situationist International. London; New York: Verso, 2011.

WARK, M. Telesthesia: communication, culture, and class. Cambridge, UK ; Malden, MA: Polity, 2012. 
WARK, M. The Capitalocene. Public seminar. 2015. Disponível em:

$<$ https://publicseminar.org/2015/10/the-capitalocene/>. Acesso em: 26 set. 2020.

WARK, M. Molecular red: theory for the anthropocene. Paperback ed. London New York: Verso, 2016a.

WARK, M. Althusserians Anonymous (the relapse). Public Seminar 2016b Disponível em: $<$ https://publicseminar.org/2016/02/aa/> . Acesso em: 9 nov. 2020.

WARK, M. Chthulucene, Capitalocene, Anthropocene. Public Seminar 2016c. Disponível em: $<$ https://publicseminar.org/2016/09/chthulu/>. Acesso em: 26 set. 2020.

WARK, M. General intellects: twenty-one thinkers for the twenty-first century. London; New York: Verso Books, 2017.

WARK, M. Capital is dead. London; New York: Verso, 2019.

WENDLING, A. E. Karl Marx on technology and alienation. Basingstoke [England] ; New York: Palgrave Macmillan, 2009.

WHITE, J. D. Alexander Bogdanov's Conception of Proletarian Culture.

Revolutionary Russia, v. 26, n. 1, p. 52-70, jun. 2013.

WHITE, J. D. Red Hamlet: the life and ideas of Alexander Bogdanov. Leiden ; Boston: Brill, 2018.

WIENER, N. Cybernetics: or, Control and communication in the animal and the machine. Second edition, 2019 reissue ed. Cambridge, MA: The MIT Press, 2019. 


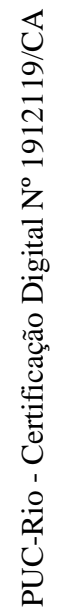

